\title{
A novel approach to model dynamic flow interactions between storm sewer system and overland surface for different land covers in urban areas
}

\author{
Tsang-Jung Chang ${ }^{1,2}$, Chia-Ho Wang ${ }^{1}$ and Albert S. Chen ${ }^{3, *}$ \\ ${ }^{1}$ Department of Bioenvironmental Systems Engineering, National Taiwan University, Taipei, \\ Taiwan \\ ${ }^{2}$ Center for Weather and Climate Disaster Research, National Taiwan University, Taipei, \\ Taiwan \\ ${ }^{3}$ Centre for Water Systems, College of Engineering, Mathematics and Physical Sciences, \\ University of Exeter, Exeter, United Kingdom
}

\section{Abstract}

In this study, we developed a novel approach to simulate dynamic flow interactions between storm sewers and overland surface for different land covers in urban areas. The proposed approach couples the one-dimensional (1D) sewer flow model (SFM) and the two-dimensional (2D) overland flow model (OFM) with different techniques depending on the land cover type of the study areas. For roads, pavements, plazas, and so forth where rainfall becomes surface runoff before entering the sewer system, the rainfall-runoff process is simulated directly in the $2 \mathrm{D}$ OFM, and the runoff is drained to the sewer network via inlets, which is regarded as the input to 1D SFM. For green areas on which rainfall falls into the permeable ground surface and the generated direct runoff traverses terrain, the deduction rate is applied to the rainfall for reflecting the soil infiltration in the 2D OFM. For flat building roofs with drainage facilities allowing rainfall to drain directly from the roof to sewer networks, the rainfallrunoff process is simulated using the hydrological module in the 1D SFM where no rainfall is applied to these areas in the 2D OFM. The 1D SFM is used for hydraulic simulations in the sewer network. Where the flow in the drainage network exceeds its capacity, a surcharge occurs and water may spill onto the ground surface if the pressure head in a manhole exceeds the ground elevation. The overflow discharge 
from the sewer system is calculated by the 1D SFM and considered a point source in the 2D OFM. The overland flow will return into the sewer network when it reaches an inlet that connects to an un-surcharged manhole. In this case, the inlet is considered as a point sink in the 2D OFM and an inflow to a manhole in the 1D SFM. The proposed approach was compared to other five urban flood modelling techniques with four rainfall events that had previously recorded inundation areas. The merits and drawbacks of each modelling technique were compared and discussed. Based on the simulated results, the proposed approach was found to simulate floodings closer to the survey records than other approaches because the physical rainfallrunoff phenomena in urban environment were better reflected.

Keywords: Coupled 1D/2D flood model; Dynamic flow interaction; Model comparison; Overland flow; Roof drainage; Storm sewer flow.

\section{Introduction}

Sewer drainage systems are essential infrastructures in modern cities to convey the runoff during storm events. Like all structural measures, the design capacity of a drainage system limits its ability to cope with runoff that exceeds the design standard. To assess the performance of drainage networks during heavy rainfall events, numerical models have become a popular solution for flood risk analysis. Among numerical models, one-dimensional (1D) sewer flow models (SFMs) are the most commonly used tool because of the relatively simple model construction, the high efficiency and the shorter runtime for simulations. Many 1D software packages are currently available to simulate the hydraulic performance of urban drainage systems. The Storm Water Management Model (SWMM) is an open-source model with complete functions (Rossman, 2010) such that it has been widely adopted in academic studies (Oraei Zare et al., 2012; Ranger et al., 2011) and by commercial 
software packages like MIKE SWMM (DHI Software, 2014) and XP-SWMM (XP Solutions, 2013). Other software packages with different hydraulic solvers, such as MIKE MOUSE (DHI Software, 2014) and InfoWorks ICM (Innovyze, 2014) are also popular in industrial practices.

The sole use of a 1D SFM can only predict, in terms of ground surface, the surcharge volume from the drainage system, which is translated into the flood depth of a sub-catchment using a depth-volume or area-volume function. This approach assumes no flow interaction between sub-catchments, which over-simplifies the surface runoff ${ }^{1}$ dynamic, especially for flat areas, such that Djordjević et al. (1999) proposed the 1D/1D dual drainage approach, which regards surface flow paths and detention ponds as a further drainage network to convey surface runoffs and to improve the modelling result. With an improved data acquisition algorithm to enhance the representation of surface drainage network, the 1D/1D dual drainage models can produce accurate results along pathways and inside ponds (Allitt et al., 2009; Leandro et al., 2009; Maksimović et al., 2009). Nevertheless, the assumption that the flow is confined by the drainage system becomes invalid when the flood depth is greater than the bank of a flow path or the crest of a pond, the runoff movement no longer follows the predetermined pathways and the overland flooding outside pathways and ponds occurs. The 1D SFMs and the 1D/1D dual drainage models will not be able to simulate the situation properly and the two-dimensional (2D) overland flow model (OFM) is required for such analysis (Chang et al., 2011; Kao and Chang, 2012).

\footnotetext{
${ }^{1}$ In this paper, the 'surface runoff' represents the water flow on the surface that can be simulated by either 1D OFMs or 2D OFMs. The 'overland flow' means the water travelling outside the pre-defined surface pathways (e.g. roads, open drainage channels), which can only be described by 2D OFMs.
} 
The growing capability of computing tools, the availability of high-resolution data and the demand for detailed information on the location of floods and their magnitude, have increased the applications of 2D OFMs in recent years (Néelz and Pender, 2013). To simulate detailed flood propagation on the ground surface, many physicalbased 2D OFMs for solving shallow water equations (SWEs) have been developed. Hunter et al. (2008), and Néelz and Pender (2013) have compared the performance of a wide range of $2 \mathrm{D}$ flood models using common test cases. These include academic research models (e.g. LISFLOOD-FP, Bates et al., 2010; UIM, Chen et al., 2012) and commercial software (e.g. MIKE FLOOD, DHI Software, 2012; ISIS 2D, Halcrow, 2012; InfoWorks ICM, Innovyze, 2012). The models adopt different governing equations (such as full SWEs or simplified approximation), computing grids (irregular meshes or regular cells) and parallelisation techniques (OpenMP, OpenMPI and GPU) to simulate flooding. The results (Néelz and Pender, 2013) showed that although most 2D flood models can produce similar results, the details for some critical conditions would vary significantly due to the assumptions or nature of different models.

The Environment Agency developed the first national surface water map for England and Wales using the JFlow-DW (Lamb et al., 2009) on a five metre resolution grid that disregarded the function of the sewer network. This type of approach is referred to as the 2D OFM only in the later sections in the study. Subsequently, the updated Flood Map for Surface Water (uFMfSW) for England and Wales (Environment Agency, 2013) on a $2 \mathrm{~m}$ resolution grid was produced using an improved model JFlow+ 2D (Crossley et al., 2010a, 2010b). The function of the sewer network was represented by subtracting a constant rate of rainfall in the uFMfSW. It is herein referred to as the $2 \mathrm{D}$ OFM with rainfall reduction approach. Chen et al. (2009) 
Please cite: Chang, T.J., Wang C.H., Chen, A.S., 2015, A novel approach to model dynamic flow interactions between storm sewer system and overland surface for different land covers in urban areas, Journal of Hydrology, doi: 10.1016/j.jhydrol.2015.03.014, in press.

represented the function of sewer drainage system with a constant infiltration rate in the 2D OFM in a case study in south east London. Unlike the reduced rainfall rate used in the uFMfSW (Environment Agency, 2013) such that the excess runoff cannot be collected by sewer system in the 2D OFM, Chen et al.'s approach (2009) allows the surface water to be drained when the capacity in the sewer network is available. Hsu et al. (2000) used the surcharge hydrographs at manholes calculated by the SWMM as inputs to a 2D OFM to simulate urban flooding. The assumption that the flow can only move from the sewer system to the ground surface, but not vice versa, failed to accurately describe the phenomenon that occurs where surface runoff reenters the drainage system. Hence, in such a combined SFM/OFM approach, the flood extent and depths tend to be over-estimated in downstream areas. The initial rainfall-runoff process was simulated by the RUNOFF module of SWMM and applied to manholes directly as the input of the EXTRAN module. Therefore, the information of flooding during this initial phase within manhole sub-catchments was presented as excess volume, as with the surcharge volume in the 1D SFM only approach. The detailed flood dynamic on the ground surface in this phase was disregarded.

To improve the overestimation drawback of the combined SFM/OFM approach, some academic researchers have attempted new coupling methodologies (Hsu et al., 2002; Seyoum et al., 2012). The 1D SFM and the 2D OFM use different computing time steps due to the nature of the problem (Chen et al., 2007), and the 2D OFMs often adopt adaptive time steps to speed up simulations (Bates et al., 2010; Hunter et al., 2005). To avoid further errors occurring in model coupling because of different time steps being used in different models, Chen et al. (2007) suggested a solution for time synchronisation between 1D SFM and 2D OFM to ensure exact values are exchanged during model communications. 
Commercial software developers also provide various 2D modelling products that are bi-directionally coupled with 1D channel or 1D sewer models. SOBEK is a fully coupled hydraulic model that is able to simulate sewer, channel and overland flows concurrently (Deltares systems, 2014). In SOBEK, three manhole types, such as closed, reservoir and loss, can be set for modelling. The closed type does not allow the water to escape from the 1D sewer system such that no flow exchange with the 2D overland surface will occur. For the reservoir type, a storage area above a manhole is defined as a pond for keeping the surcharged water to represent the flooding on the 2D overland surface, despite no 2D OFM being involved. For the loss type, the water exceeding the surface level above a manhole will be removed from 1D SFM and added to the 2D OFM. XP-SWMM 2D (Phillips et al., 2005) was developed by adding the TUFLOW 2D module (Syme, 2001) with the XP-SWMM 1D model to enhance its capability for urban flood modelling. Similar integration was also applied to couple the 1D river, the 2D overland and the 1D sewer models as the ISIS-TUFLOW-PIPE (Halcrow, 2013). The MIKE Urban (DHI Software, 2014) has seen the integration of MIKE 11, MIKE MOUSE/SWMM and MIKE FLOOD models to simulate combined river, sewer and floodplain modelling. Coupling the 2D cells within a given radius from a manhole with sewer nodes is used (DHI Software, 2014) for collecting the runoff from or distributing the surcharge to the $2 \mathrm{D}$ computing domain. Similarly, the InfoWorks 2D module also has been integrated with the InfoWorks CS and InfoWorks RS for 1D/2D modelling in both sewers and rivers. InfoWorks links the 2D mesh to sewer nodes as 2D, Gully 2D or Inlet 2D types and uses equations corresponding to those types for determining the interacting discharge between the 1D sewer and 2D overland flow (Innovyze, 2014). 
The aforementioned academic and commercial models for coupling the 1D SFM and the 2D OFM can be classified into two methodologies, i.e. the coupled SFM/OFM approach (e.g. Chen et al., 2007; Seyoum et al., 2012) and the coupled OFM/SFM approach (e.g. Hsu et al., 2002). Commercial packages like SOBEK, MIKE Urban and InfoWorks provide both coupling approaches in model settings, nevertheless, they only allow a single approach to be used in a single simulation.

The coupled SFM/OFM approach directly applies all the rainfall to the 1D SFM, which usually adopts a hydrological model to calculate the inflow discharges of manholes for hydraulic modelling. The sewer flow is simulated first and then the surcharge from manholes triggers flood simulations in the 2D OFM. This coupling method enhances the description of bi-directional flow interactions between the sewer system and the overland surface. For built-up areas in which building roofs have a rainfall collection system installed to drain rainfall on the roof directly to the storm sewer networks, the coupled SFM/OFM approach is also applicable if the excess water beyond the roof inlet capacity is confined by the retaining walls, which is not generally considered as flooding.

However, as with the combined SFM/OFM approach assuming that a subcatchment's runoff is collected via gullies and completely drained to the sewer networks via manholes, the initial surface runoff dynamic between the runoff origin and the receiving manhole is simulated by hydrological model and simplified as a representing volume of depth of a sub-catchment. Thus, the coupled SFM/OFM approach can only deal with the surcharge-induced inundation in urban areas and flood underestimation errors may occur if the rainfall intensity exceeds the capacity of the inlet in the sewer system. The more exceedance this has, the more errors will occur. 
In contrast, in open spaces in urban areas, the rainfall falls to the ground surface and becomes direct runoffs traversing a substantial distance along the terrain before reaching a drainage inlet or manhole. The simplified representation of the initial rainfall-runoff dynamic using the coupled SFM/OFM approach will not be able to describe the phenomena accurately such that the coupled OFM/SFM is required. In the coupled OFM/SFM approach, rainfall is applied to the 2D OFM and a $100 \%$ runoff coefficient is used for manmade surfaces such as roads, pavements, plazas, while a deduction factor is applied to natural open spaces such as green areas to account for the soil infiltration.

The above review demonstrates that a strong link between 1D sewers and 2D overland flow for different land covers in urban areas is fundamental; however, it has not yet been the subject of in depth study. This study aims to develop a novel approach that couples 1D SFM and 2D OFM to simulate dynamic flow interactions between storm-sewers and overland surface for different land covers and flat building roofs in urban flood modelling. The details of different modelling approaches will be described in the next section, followed by the section of model applications. The modelling results of the proposed approach and those that adopt other published urban flood modelling techniques are compared and discussed in the proceeding section. Finally, we will conclude with the main research findings and provide suggestions for helping practitioners to select an appropriate approach for urban flood simulations.

\section{Methodology}

\subsection{Hydraulic models}

We used the 1D SWMM (version 4.4h) with 2D OFM for urban flood simulations in this paper. The SWMM version $4.4 \mathrm{~h}$, instead of the latest version $5 . \mathrm{x}$, was used as it 
was written in FORTRAN code, also employed in the 2D model. The source code in SWMM was modified to include the 2D overland flow routing module. We understand that improvments have been made to the computing engine and bugs have been fixed in the SWMM 5 code. In our case, we did not experience bug related difficulties while carrying out this study but were unable to take advantage of the improved computing engine.

\subsubsection{Governing equation for 1D SFM}

The 1D SWEs are used as the governing equation for solving sewer flow. In this paper, the continuity equation for manhole is modified as Eq. (1) to include the flow interaction with the 2D OFM.

$$
\frac{\partial h}{\partial t}=\frac{\sum_{k} Q_{p_{k}}+\sum_{k} Q_{i_{k}}-Q_{s}}{A_{m}}
$$

where, $h$ is the water head at manhole; $t$ is time; $Q_{p_{k}}$ is the discharge of the $k^{\text {th }}$ pipe connecting to the manhole (positive for entering flow, negative for exiting flow); $Q_{i_{k}}$ is the discharge of the $k^{\text {th }}$ inlet from overland surface or upstream subcatchment; $Q_{s}$ is the surcharge discharge leaving the sewer system to the overland surface; $A_{m}$ is the surface of manhole.

For the flow in pipes, SWMM assumes the outflow equals to the inflow and combines the momentum equation and the continuity equation, as shown in Eq. (2), to slove the average discharge in a pipe.

$$
\frac{\partial Q_{p}}{\partial t}+g A_{p} S_{f}+2 V_{p} \frac{\partial A_{p}}{\partial t}-V_{p}^{2} \frac{\partial A_{p}}{\partial t}+g A_{p} \frac{\partial h}{\partial x}=0
$$

where, $Q_{p}$ is the discharge in the pipe; $g$ is gravitational acceleration; $A_{p}$ is the cross-sectional area of the pipe; $S_{f}$ is the friction slope from Manning's equation; $V_{p}$ 
is the velocity in the pipe. Details about equation solving in SWMM can be found in

Roserner et al. (1988).

\subsubsection{Governing equation for 2D OFM}

2D OFM assumes that that the acceleration term is small in comparison with the gravitation and friction terms, such that the inertial term of the SWEs is disregarded and the governing equations are written as:

$$
\begin{gathered}
\frac{\partial d}{\partial t}+\frac{\partial u d}{\partial x}+\frac{\partial v d}{\partial y}=q_{s}(x, y, t)-q_{i}(x, y, t) \\
-\frac{\partial h}{\partial x}=S_{f x}+\frac{\left[q_{s}(x, y, t)\right] u}{g d} \\
-\frac{\partial h}{\partial y}=S_{f y}+\frac{\left[q_{s}(x, y, t)\right] v}{g d}
\end{gathered}
$$

where, $d$ is the water depth, $u$ and $v$ are the velocity components in the $x$ and $y$ directions, respectively, $h=d+z$ is the water surface elevation, $S_{f x}=\frac{n^{2} u \sqrt{u^{2}+v^{2}}}{d^{4 / 3}}$ and $S_{f y}=\frac{n^{2} v \sqrt{u^{2}+v^{2}}}{d^{4 / 3}}$ are friction slopes along the $x$ and $y$ directions, respectively. $q_{s}(x, y, t)$ and $q_{i}(x, y, t)$ are the rate of water entering and leaving ground surface per unit area, which are expressed as

$$
\begin{gathered}
q_{s}(x, y, t)=I+\sum_{k}\left[\frac{Q_{s}\left(x_{k}, y_{k}, t\right)}{A_{s}\left(x_{k}, y_{k}\right)}\right] \delta\left(x-x_{k}, y-y_{k}\right) \\
q_{i}(x, y, t)=\sum_{k}\left[\frac{Q_{i}\left(x_{k}, y_{k}, t\right)}{A_{i}\left(x_{k}, y_{k}\right)}\right] \delta\left(x-x_{k}, y-y_{k}\right)
\end{gathered}
$$

in which, $I$ is the rainfall excess intensity, $Q_{s}\left(x_{k}, y_{k}, t\right)$ is the manhole surcharge, $Q_{i}\left(x_{k}, y_{k}, t\right)$ is the inlet discharge, where the manhole surcharges and inlet discharge 
occur in sewer systems are considered as point sources and sinks in 2D overland

flow. $A_{s}\left(x_{k}, y_{k}\right)$ represents the distributed area of manhole surcharge, $A_{i}\left(x_{k}, y_{k}\right)$ is the catchment area for inlet at the point $\left(x_{k}, y_{k}\right)$, and $\delta$ is the Dirac delta function.

In Eqs. (4) and (5), it is assumed that the influx direction of rainfall or manhole effluent is normal to the overland surface and the inlet drainage leaves with practically the overland flow velocity components $u$ and $v$ (Abbott and Minns, 1998). The unknowns $d, u$ and $v$ in Eqs. (3) to (5) are solved by an alternating direction explicit scheme. The derivation of finite difference method was depicted in an earlier paper (Hsu et al., 2000).

\subsubsection{Interaction between sewer and overland flow}

When the water level in a manhole reaches the ground elevation, the surcharge occurs such that the flow will move from the sub-surface to the surface system. The surcharge from manhole $Q_{s}\left(x_{k}, y_{k}, t\right)$ is calculated by the EXTRAN module in the SWMM and assumed to be distributed uniformly in the adjacent area $A_{s}\left(x_{k}, y_{k}\right)$ around location $\left(x_{k}, y_{k}\right)$ for use by overland flow model.

In contrast, the surface runoff may be collected by inlets and drained to the sewer network. The water in the neighbouring area $A_{i}\left(x_{k}, y_{k}\right)$ is collected by the inlet at location $\left(x_{k}, y_{k}\right)$ and drains to sewer systems through the manhole junction that the inlet connects to. Various types of inlets, such as curb-opening inlet, gutter inlet and grated inlet (Mays, 2011) can be used in urban drainage systems and the capacity $Q_{d}\left(x_{k}, y_{k}\right)$ can be determined based on their design. Where surcharge does not occur, the overland flow drains at the discharge of inlet capacity unless the flow rate is under the design capacity. The inlet discharge $Q_{i}\left(x_{k}, y_{k}, t\right)$ is expressed as follows: 


$$
Q_{i}\left(x_{k}, y_{k}, t\right)=\min \left[A_{i}\left(x_{k}, y_{k}\right) \frac{\partial d\left(x_{k}, y_{k}, t\right)}{\partial t}, Q_{d}\left(x_{k}, y_{k}\right)\right]
$$

where, $d\left(x_{k}, y_{k}, t\right)$ is the water depth at location $\left(x_{k}, y_{k}\right)$ and time $t, Q_{d}\left(x_{k}, y_{k}\right)$ is the design capacity of the inlet at location $\left(x_{k}, y_{k}\right)$, which is a given constant. In the case that the manhole which the inlet connects to is unsurcharged, the water in the neighbouring area $A_{i}\left(x_{k}, y_{k}\right)$ drains with the rate $Q_{i}\left(x_{k}, y_{k}, t\right)$ shown in Eq. (8). In contrast, if the manhole is surcharged, (implying that the water is surcharging to overland instead of entering sewer) the inlet discharge $Q_{i}\left(x_{k}, y_{k}, t\right)$ is set to zero.

\subsection{Approaches for 2D flood modelling}

\subsubsection{D OFM only}

Only the 2D OFM is used for hydraulic modelling, i.e. $Q_{s}\left(x_{k}, y_{k}, t\right)$ and $Q_{i}\left(x_{k}, y_{k}, t\right)$ are zero in Eqs. (6) and (7) in this approach. Rainfall is applied to the ground surface directly and the generated runoff only travels along the terrain.

\subsubsection{D OFM with rainfall reduction or infiltration rate}

This approach is almost identical to the 2D OFM only. The sole difference is that a reduction factor for discounting the rainfall is used to mimic the function of the sewer network. The reduction factor is determined based on the design capacity of the drainage system, the blockage condition and the impervious area ratio. The factor is case study dependent and it may be determined based on the design standard of a city's sewer system. For example, the uFMfSW adopted 0.7 as the runoff coefficient and an additional $12 \mathrm{~mm} / \mathrm{h}$ reduction to account for the infiltration and the function of urban drainage systems (Environment Agency, 2013). Burton et al. (2010) considered the British Standard BS EN 752 (British Standards Institution, 1998) and 
Please cite: Chang, T.J., Wang C.H., Chen, A.S., 2015, A novel approach to model dynamic flow interactions between storm sewer system and overland surface for different land covers in urban areas, Journal of Hydrology, doi: 10.1016/j.jhydrol.2015.03.014, in press.

used one in twenty year design rainfall for setting up an infiltration rate to reflect the function of drainage in 2D OFM.

\subsection{Approaches for 2D flood modelling with 1D SFM}

\subsubsection{Combined SFM/OFM}

The combined SFM/OFM approach assumes that all the runoff of a sub-catchment is collected via gullies and drained to the sewer networks via manholes. The initial surface runoff dynamics between the runoff origin and the receiving manhole are calculated by using the SWMM RUNOFF module and are used as inflow discharges of manholes in EXTRAN module. After the SWMM simulations, the surcharges from manholes are considered as point sources $Q_{s}\left(x_{k}, y_{k}, t\right)$ in the 2D OFM simulations. No return flow from surface to sub-surface is allowed to occur in the approach, i.e. $Q_{i}\left(x_{k}, y_{k}, t\right)=0$. SFM and OFM are executed sequentially and only one directional flow interaction can be simulated, so the approach is regarded as combined SFM/OFM.

\subsubsection{Coupled SFM/OFM}

The coupled SFM/OFM approach allows the flow between the sewer system and overland surface to interact bi-directionally. The rainfall is applied to the SWMM RUNOFF module to calculate the inflow discharges of manholes for the EXTRAN module, which means that the initial surface runoff dynamics between the runoff origin and the receiving manhole are disregarded. After the SWMM simulations, the surcharges from manholes are considered as point sources $Q_{s}\left(x_{k}, y_{k}, t\right)$ in the 2D OFM simulations. The surface runoff will return to the sewer system when it reaches an inlet that is connected to an unsurcharged manhole. If a manhole is not surcharged but runoff on the ground surface is present, the drainage discharge will 
be calculated using Eq. (6) and added to the inflow of the connected manhole. The $Q_{i}\left(x_{k}, y_{k}, t\right)$ of all inlets that a manhole is connected to are summarised as the inflow discharge of the SWMM, whereas $q_{i}(x, y, t)$ is considered as point sinks in the 2D OFM. The rainfall is input to the SFM first and the OFM is triggered by the sewer surcharge such that the approach is classified as coupled SFM/OFM.

\subsubsection{Coupled OFM/SFM}

Instead of using the SWMM RUNOFF module to calculate the surface runoff drained to manholes, the rainfall is applied to the ground surface directly for the 2D OFM. The surface runoff only flows into the sewer system after having being collected by inlets, where $Q_{i}\left(x_{k}, y_{k}, t\right)$ is not zero. Where the flow exceeds the sewer capacity, it may return from sub-surface to the ground surface via a surcharged manhole as a point source $Q_{s}\left(x_{k}, y_{k}, t\right)$ in the 2D OFM. The rainfall is input to the OFM first and the SFM is triggered by the drainage flows such that the approach is considered as coupled OFM/SFM.

\subsubsection{Mixed SFM/OFM and OFM/SFM coupling}

In urban areas, the transport process between the storm sewer flow and the surface runoff differs for various land covers. As shown in Figure 1a, the runoff generated by rainfall in open spaces propagates on the ground surface until it infiltrates into soil (developed and undeveloped green area lands), or drains to the storm sewer via inlets or gullies (roads, pavements, plazas), or detents in water fields (creeks, ponds). The coupled OFM/SFM approach described in section 2.3.3 is adopted for modelling the flow dynamic in the open spaces. The open spaces may have different densities of inlets to collect the surface runoff. The setting of inlets depends on the design standard of urban drainage for different land uses. 
For roads, pavements, and plazas, the surface is considered as $100 \%$ impervious, such that the rainfall was directly applied to the 2D OFM. In the case of water fields such as creeks and ponds, the water will accumulate and then overflow. If the water level becomes higher than the surrounding terrain elevation, the 2D OFM only approach described in section 2.2.1 is used. For green area, where some rainfall may infiltrate the soil and the remainder becomes direct runoff travelling along the terrain, the rainfall applied onto these surface types would be reduced by a constant value to represent the soil infiltration rate, (depending on the soil type). As the direct runoff traverses the terrain, it may have dynamic flow interactions between sewer system and overland surface via inlets for developed green lands; however, no inlet was set for undeveloped green lands and therefore no flow interaction between the surface and the sewer systems will occur. Consequently, coupled OFM/SFM approach and 2D OFM with rainfall reduction approach rate are applied to developed and undeveloped lands, respectively.

For built-up areas shown in Figure 1b, the computing procedure employed is dependent on the rainfall intensity and roof type. For buildings with rainfall collection systems on their roofs, each roof can be considered as a sub-catchment with a series of collecting gullies, inlets and vertical pipes installed to drain the water on the roof directly to the storm sewer networks. If the generated runoff on the roof does not exceed the design capacity of the collecting inlet, the rainfall is applied to the SWMM RUNOFF module to calculate the discharge of the manhole connected to the roof inlet. The rainfall in the area is set as zero in the 2D OFM. The computing procedure is the same as the coupled SFM/OFM approach, as described in section 2.3.2. If the generated runoff on the roof exceeds the design capacity of the collecting inlets, the excess runoff may remain on the roof or spill to the neighbouring ground surface, 
Please cite: Chang, T.J., Wang C.H., Chen, A.S., 2015, A novel approach to model dynamic flow interactions between storm sewer system and overland surface for different land covers in urban areas, Journal of Hydrology, doi: 10.1016/j.jhydrol.2015.03.014, in press.

depending on the type of roof. For flat roofed buildings with retaining walls to confine the excess runoff, the roof acts as a storage pond, in which excess water remains within in, to be released into the sewer afterward. Each building is regarded as a sub-catchment with a catchment area equivalent to that of the roof in question. A node with a small cross-sectional area for each building is set in SWMM with crown elevation set at roof height. A pipe is set to connect each inlet node with its collecting manhole. The size of the pipe is set to restrict the discharge that can reflect the inlet capacity such as the excess water which will be ponded on the roof sub-catchment before entering the sewer system. The design capacity per square metre for roof drainage is the same value for all buildings, which is determined by the intensity of design rainfall, but the total inlet capacity of every building varies because the roof areas of buildings are different.

For other roof conditions, including (1) roofs without a rainfall collection system; (2) roofs with rainfall collection systems but no retaining walls and (3) roofs with rainfall collection systems and retaining walls but the ponding water level on the roof is more elevated than the crest of the retaining walls, the excess runoff will discharge to the neighbour ground directly. Consequently, the coupled OFM/SFM approach will be required to describe the dynamic. If roof heights are included in the DEM, the rainfall can be applied to the building cells in the 2D OFM. Nevertheless, such DEM application implies that the buildings are flood-proof which may not be accurate in all instances. In contrast, if the bare terrain DEM is used, a pre-processing algorithm will be required to apply the rainfall on the roof to its neighbouring cells, receiving the excess runoff in the 2D OFM. This is because the DEM represents the elevation inside a building, where the rainfall cannot enter directly and the excess runoff from the roof may flow to a direction different from the ground slope. 
Please cite: Chang, T.J., Wang C.H., Chen, A.S., 2015, A novel approach to model dynamic flow interactions between storm sewer system and overland surface for different land covers in urban areas, Journal of Hydrology, doi: 10.1016/j.jhydrol.2015.03.014, in press.

\section{Case study description}

\subsection{Study area}

In this paper, we adopted the Sanxia district, located in the south-western part of New Taipei City, Taiwan, as the study area. The region, as shown in

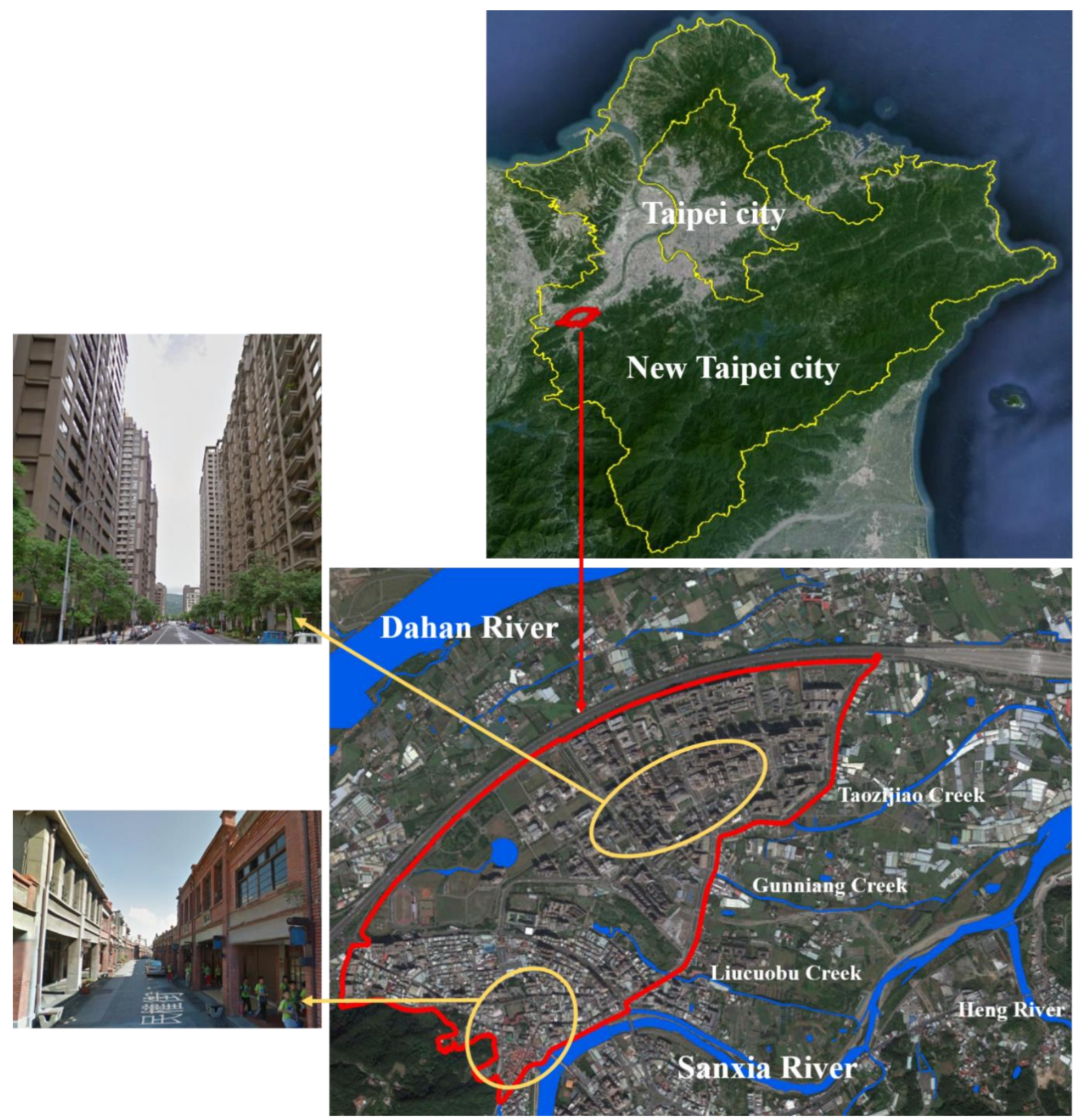

Figure 2, has an area $2.77 \mathrm{~km}^{2}$ and is surrounded by hills to the west, the flood levees along the Sanxia River to the south, a local expressway to the east, and 
Please cite: Chang, T.J., Wang C.H., Chen, A.S., 2015, A novel approach to model dynamic flow interactions between storm sewer system and overland surface for different land covers in urban areas, Journal of Hydrology, doi: 10.1016/j.jhydrol.2015.03.014, in press.

Highway No. 3 is to the north.

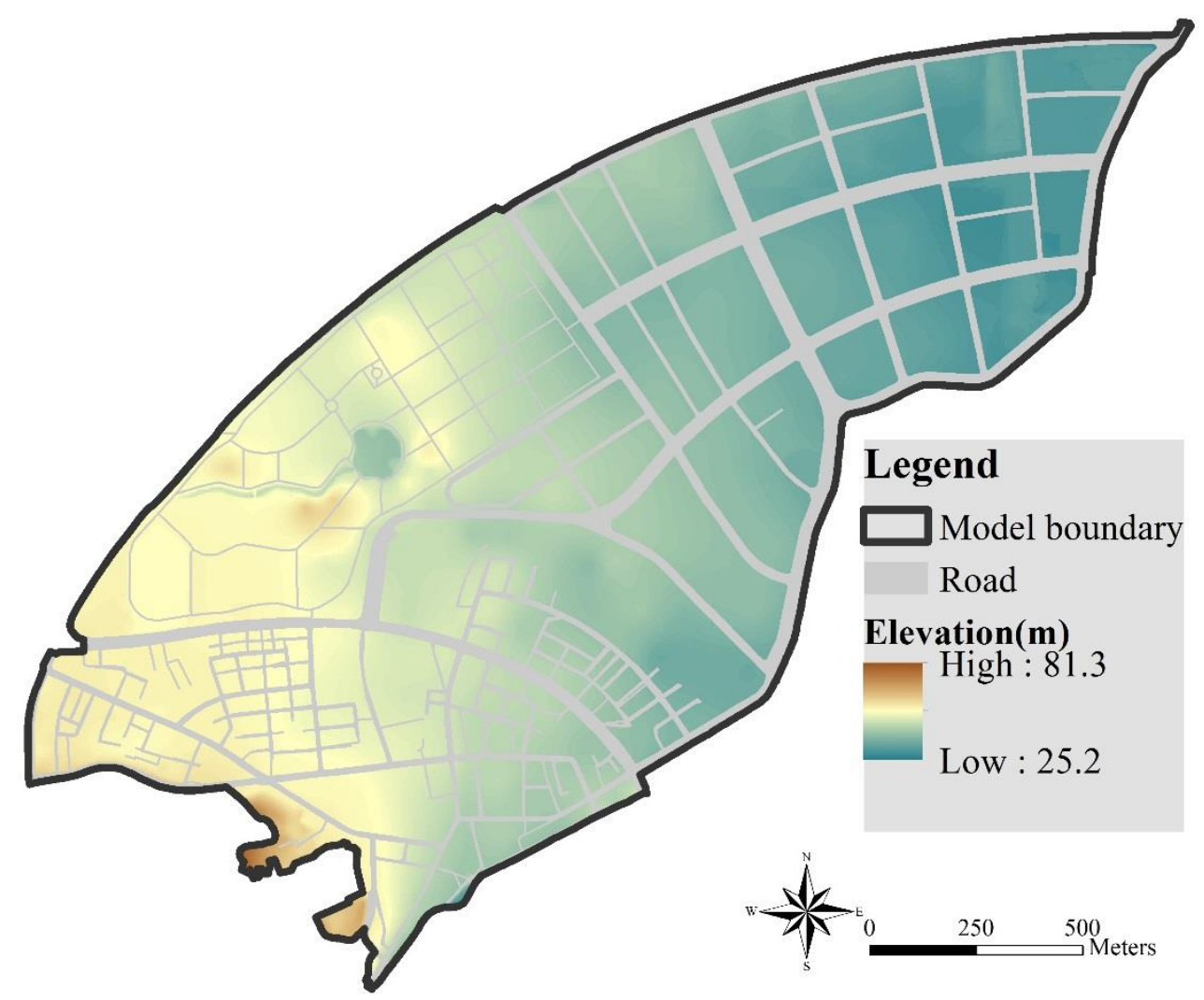

Figure 3 shows the surface elevation of the study area. The highest and lowest elevations of the area are $81.3 \mathrm{~m}$ and $25.2 \mathrm{~m}$ above the mean ocean datum, respectively, and its elevation decreases north-eastward. 
Please cite: Chang, T.J., Wang C.H., Chen, A.S., 2015, A novel approach to model dynamic flow interactions between storm sewer system and overland surface for different land covers in urban areas, Journal of Hydrology, doi: 10.1016/j.jhydrol.2015.03.014, in press.

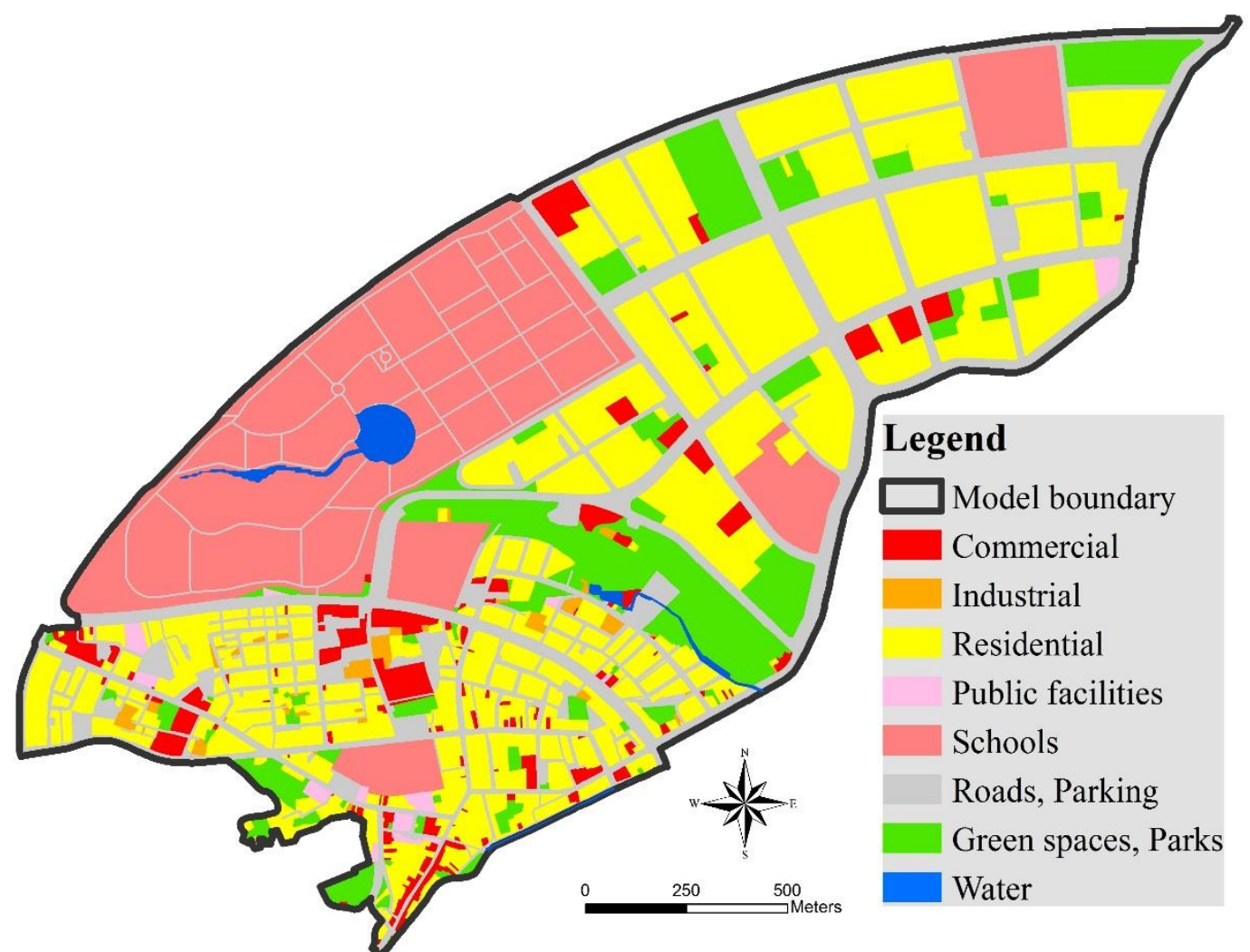

(a)

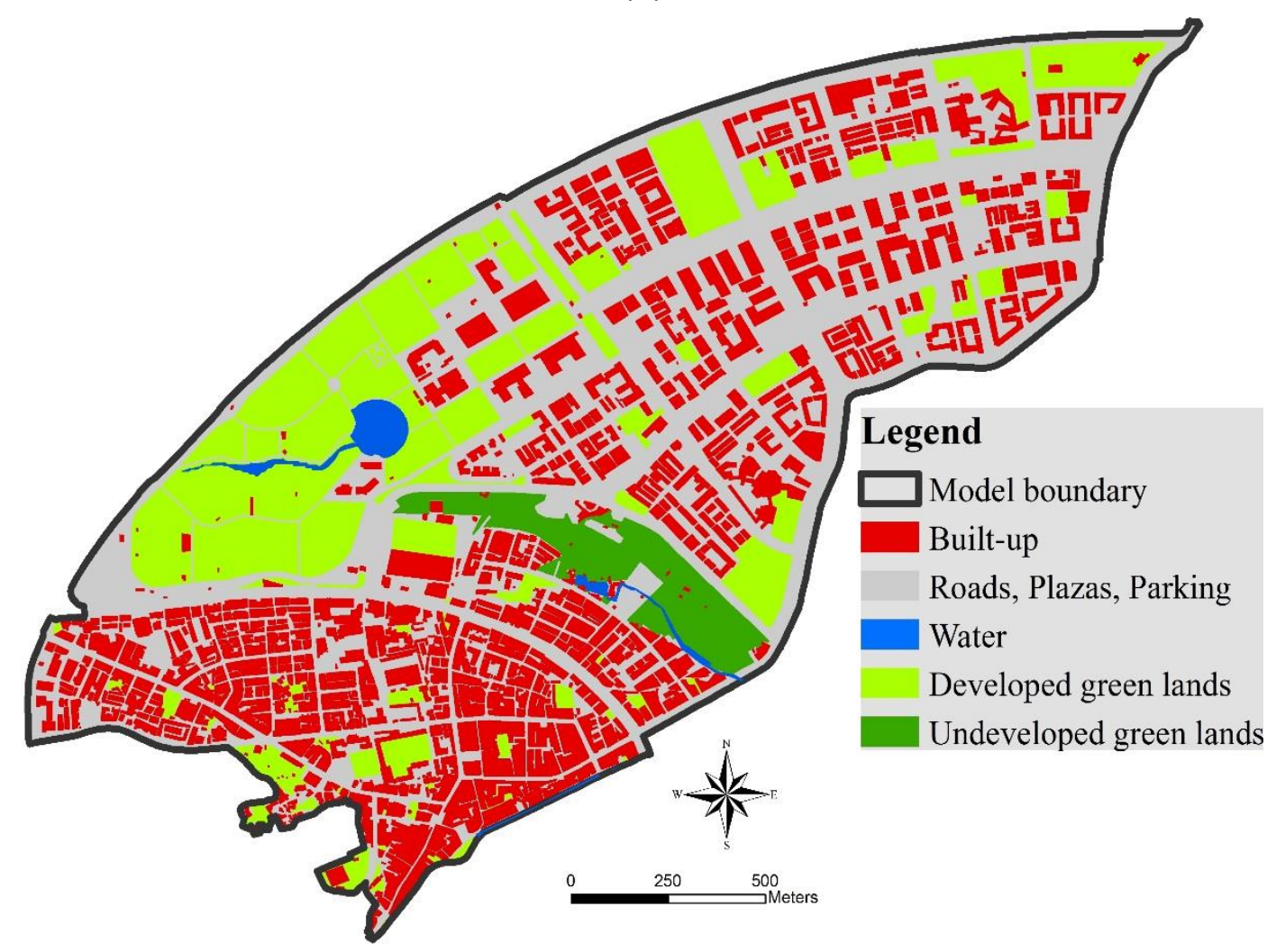

(b)

Figure $4 \mathrm{a}$ and $4 \mathrm{~b}$ display the land uses and land covers of the study area, respectively. There are eight land-use types in Figure $4 \mathrm{a}$, and this district is mostly a 
residential region with a university campus. In Figure $4 \mathrm{~b}$, the area can be classified into five different land cover types, including built-up areas, roads and plazas, water fields, developed green lands and undeveloped green lands. The land cover information is used to set up the parameters and its modelling method in the mixed SFM/OFM and OFM/SFM coupling approach. The main soil type in the study area is clay with poor drainage condition such that $3 \mathrm{~mm}$ is used for natural land cover to reflect the soil infiltration (Landon, 1984).

The region is an isolated urban drainage area due to its geographic conditions. The storm sewer system in this district, as shown in

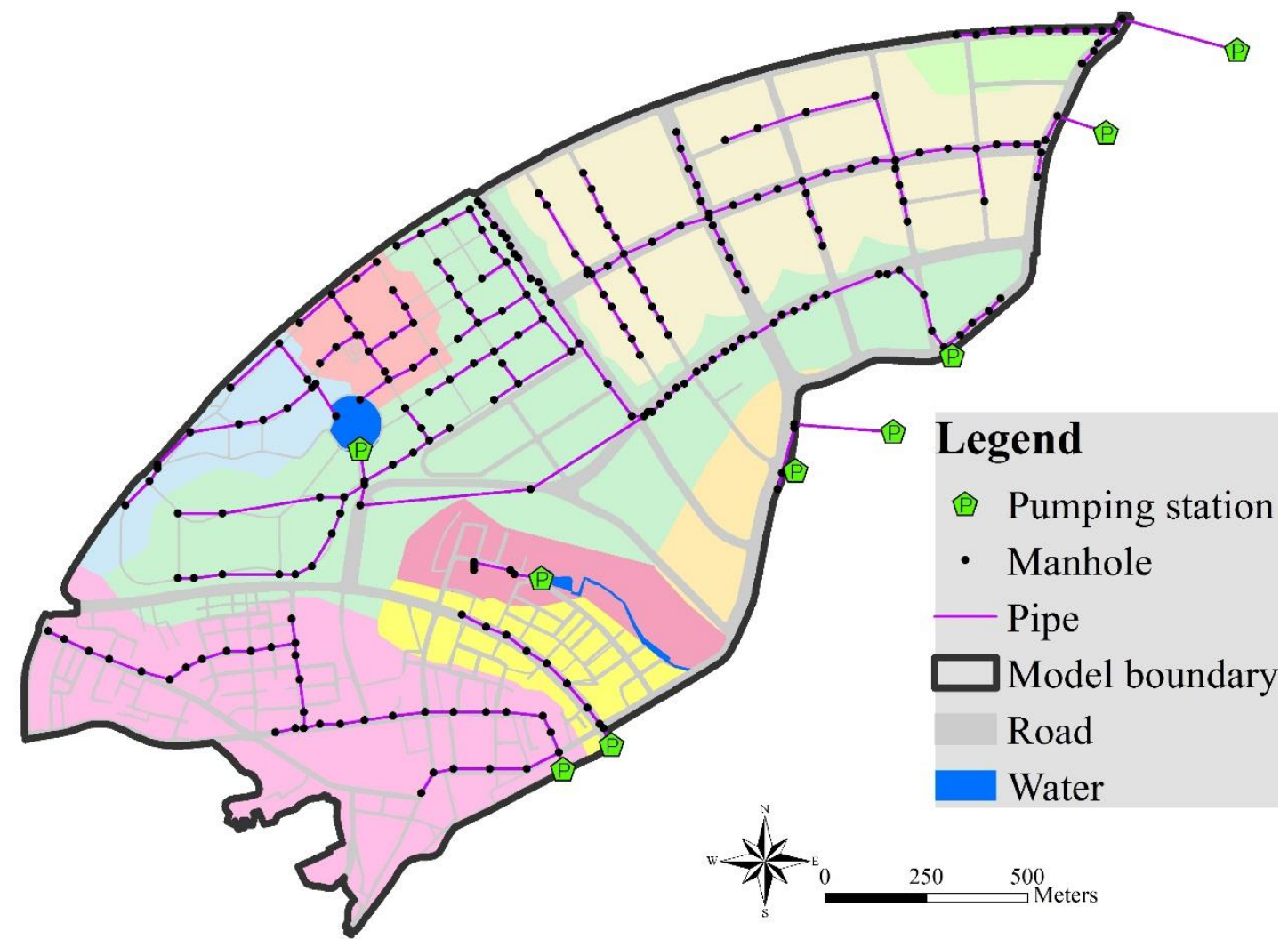

Figure 5, includes nine networks that collect the runoff and drain to the detention pond inside the university campus or to the Sanxia River. The design rainfall intensity of the storm sewer system is $40 \mathrm{~mm} / \mathrm{h}$, equivalent to a five-year return period event. A flap valve is installed at the downstream end of each network to 
prevent the backwater coming from the river when the water level in the river channel is higher than the one at the sewer outlet. A pumping station has also been built at the downstream of each network to pump the water out of the region as the downstream water level is too high to drain the runoff by gravity.

\subsection{Flood events}

Two short and two long-duration rainfall events were selected to compare detailed flood propagation processes for different modelling approaches. In these four flood events, the flooded areas were all recorded and delineated by the New Taipei City Government immediately after their occurrences.

\subsubsection{Short duration rainfall events}

In June 2012, a series of storms hit the northern Taiwan and resulted in two flooding events in the study area within one week, $12^{\text {th }}$ and $15^{\text {th }}$ June. 
Please cite: Chang, T.J., Wang C.H., Chen, A.S., 2015, A novel approach to model dynamic flow interactions between storm sewer system and overland surface for different land covers in urban areas, Journal of Hydrology, doi: 10.1016/j.jhydrol.2015.03.014, in press.

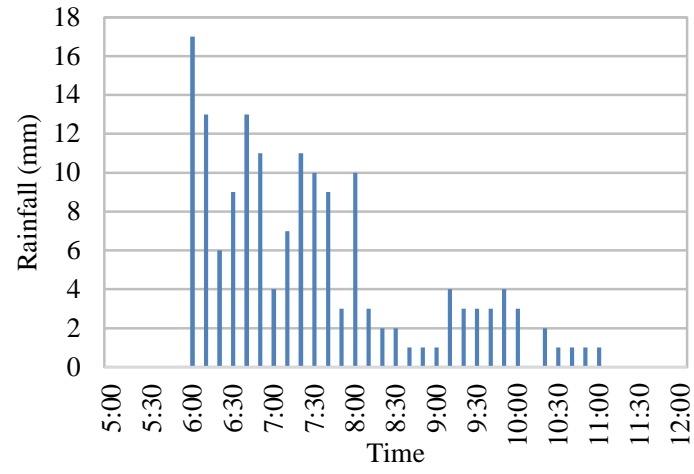

(a)

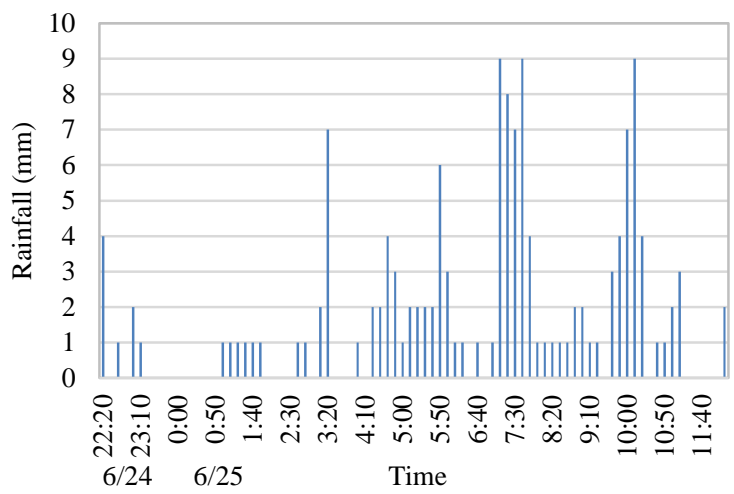

(c)

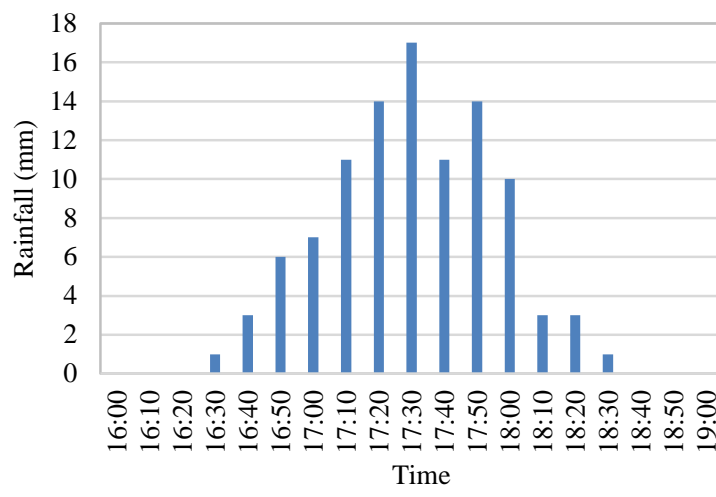

(b)

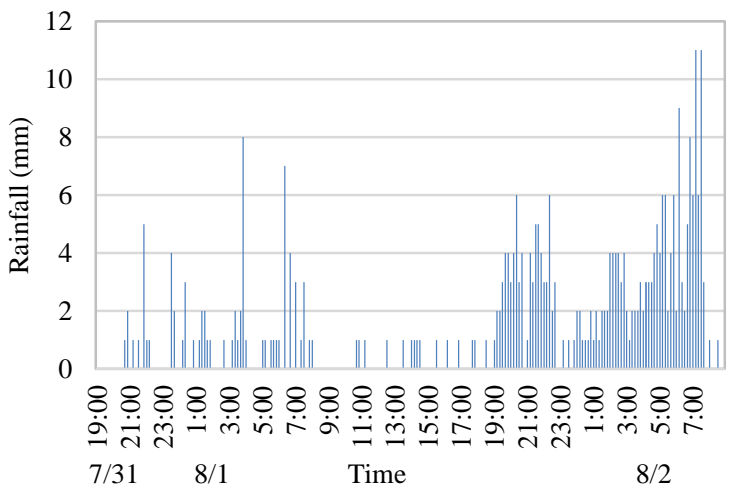

(d)

Figure 6 a shows the rainfall hyetograph of the $12^{\text {th }}$ June event. The total rainfall was $159 \mathrm{~mm}$ within five hours with the peak rainfall $17 \mathrm{~mm}$ occurred between 5:50 and 6:00, and the peak hourly accumulation $69 \mathrm{~mm}$ between 5:50 and 6:50. 
Please cite: Chang, T.J., Wang C.H., Chen, A.S., 2015, A novel approach to model dynamic flow interactions between storm sewer system and overland surface for different land covers in urban areas, Journal of Hydrology, doi: 10.1016/j.jhydrol.2015.03.014, in press.

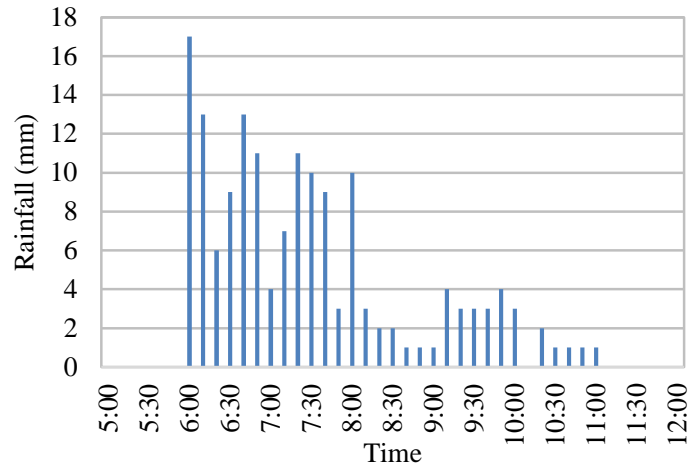

(a)

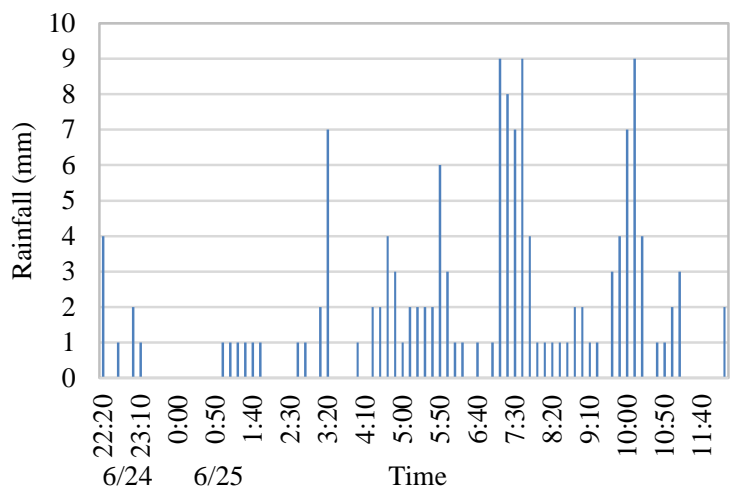

(c)

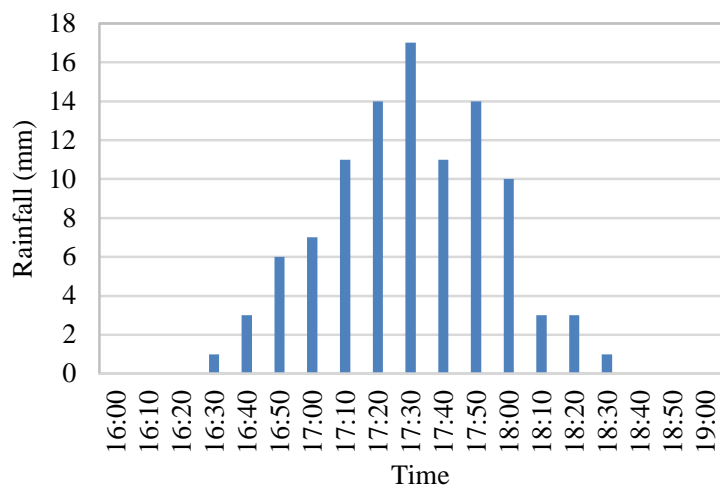

(b)

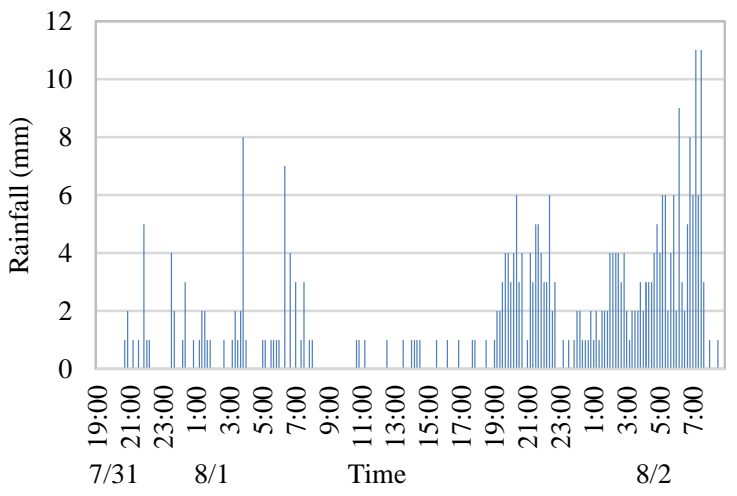

(d)

Figure $6 \mathrm{~b}$ shows the rainfall hyetograph of the $15^{\text {th }}$ June event. The rainfall duration was shorter but with a higher intensity. A total of $101 \mathrm{~mm}$ was recorded within two hours with a peak rainfall between 17:20 and 17:30. The peak hourly intensity was $77 \mathrm{~mm}$ at the hour between 17:00 and 18:00. 


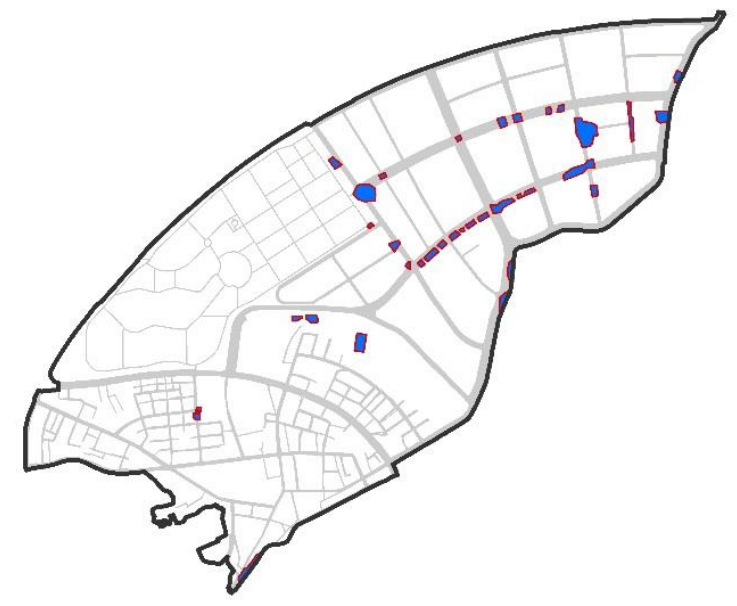

(a)

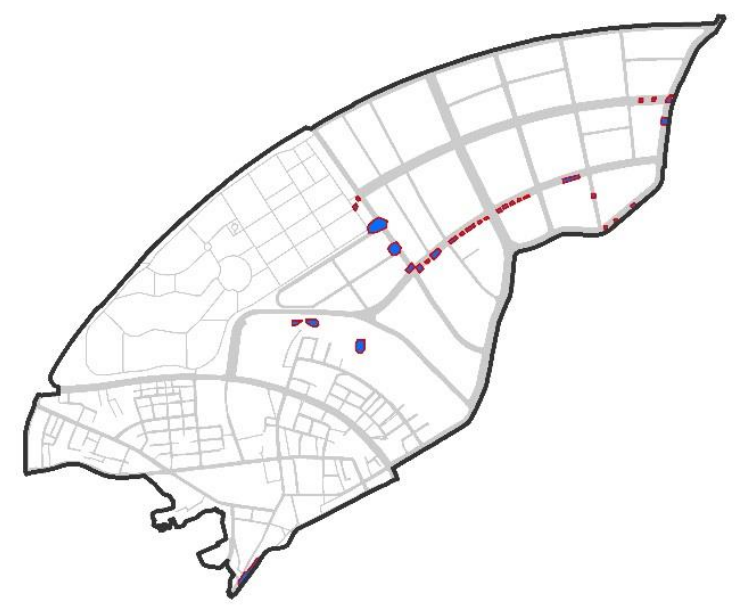

(c)

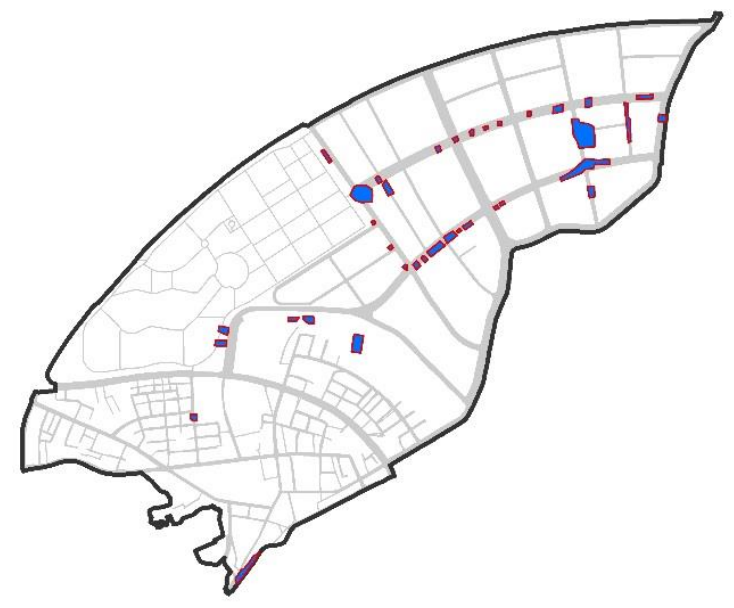

(b)

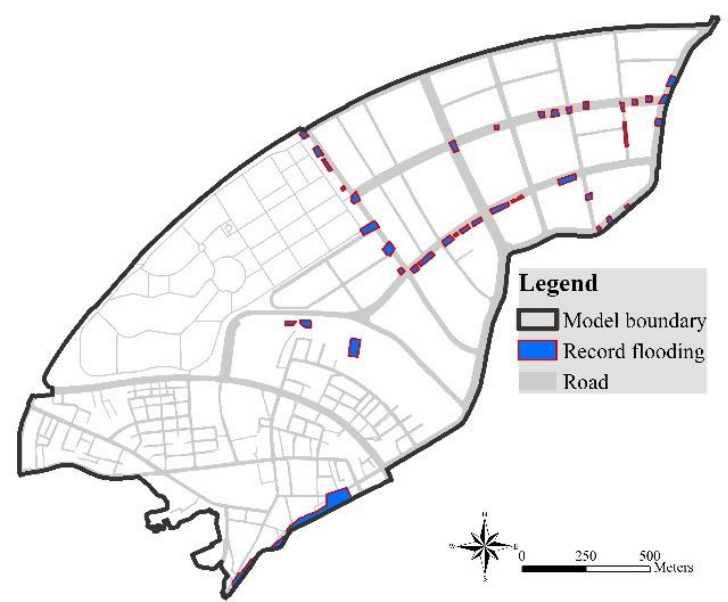

(d)

Figure $7 \mathrm{a}$ and $7 \mathrm{~b}$ provide the recorded inundation areas of both events, respectively. For the $12^{\text {th }}$ June event, the inundation area was about 4.6 hectares, and the depths were between 20 and $80 \mathrm{~cm}$. The flooding started at 6:30 and ended at 9:00. For the $15^{\text {th }}$ June event, the inundation area was about 4.3 hectares, and the depths ranged from 30 to $100 \mathrm{~cm}$. The maximum inundation depth was about $100 \mathrm{~cm}$ which occurred at the gate of university campus, and the flooding lasted from 17:20 to 18:00.

\subsubsection{Long duration rainfall events}

From $24^{\text {th }}$ to $25^{\text {th }}$ June 2011 , Typhoon Meari brought $143 \mathrm{~mm}$ rainfall during 14 hours to the study area and caused urban inundation. As shown in 
Please cite: Chang, T.J., Wang C.H., Chen, A.S., 2015, A novel approach to model dynamic flow interactions between storm sewer system and overland surface for different land covers in urban areas, Journal of Hydrology, doi: 10.1016/j.jhydrol.2015.03.014, in press.

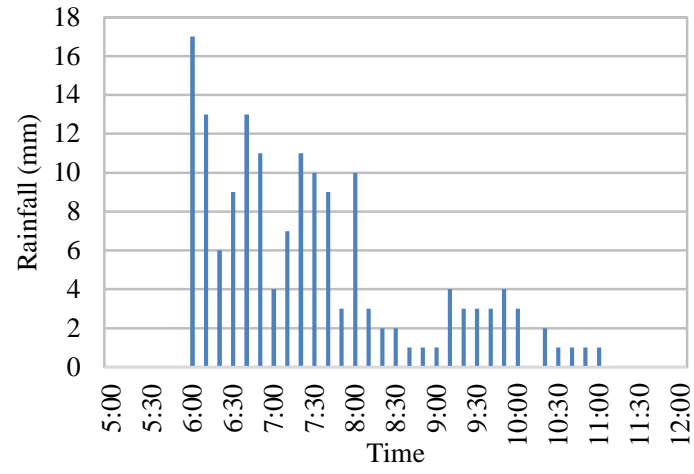

(a)

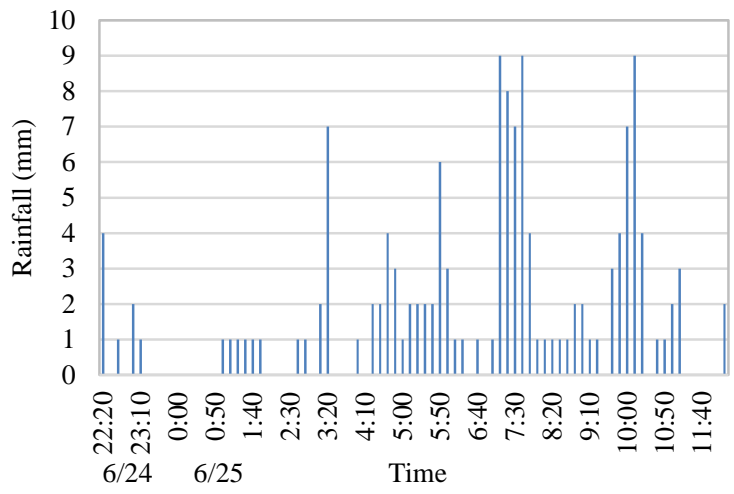

(c)

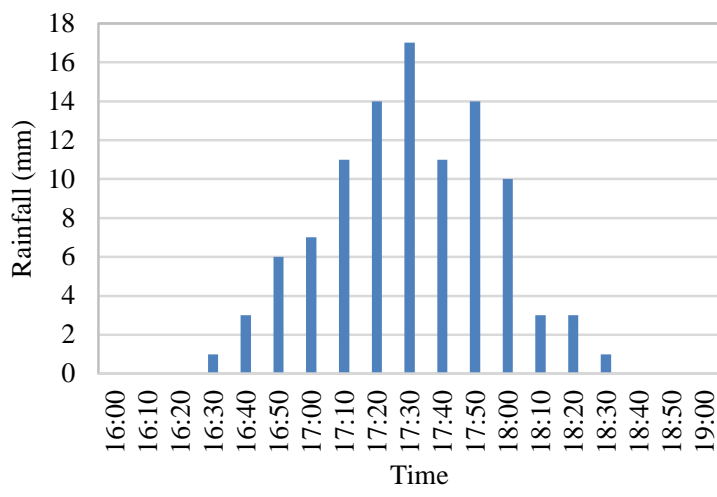

(b)

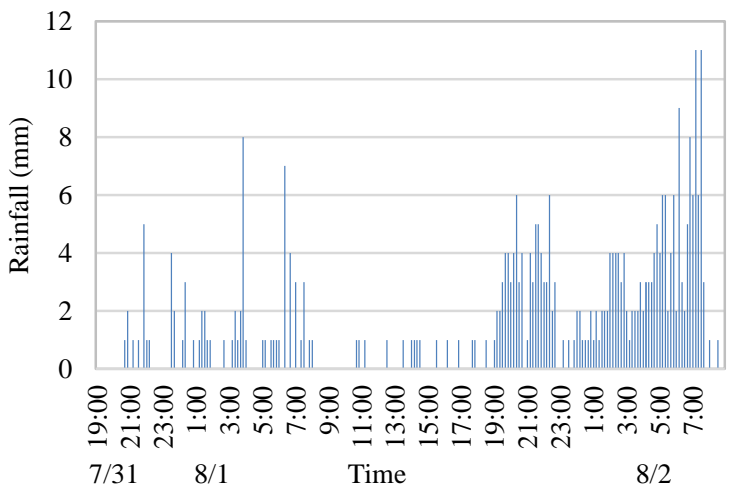

(d)

Figure $6 \mathrm{c}$, the peak rainfall $9 \mathrm{~mm}$ of the event occurred between 7:00 and 7:10, and the hourly rainfall between 7:00 and 8:00 was $38 \mathrm{~mm}$. 
Please cite: Chang, T.J., Wang C.H., Chen, A.S., 2015, A novel approach to model dynamic flow interactions between storm sewer system and overland surface for different land covers in urban areas, Journal of Hydrology, doi: 10.1016/j.jhydrol.2015.03.014, in press.

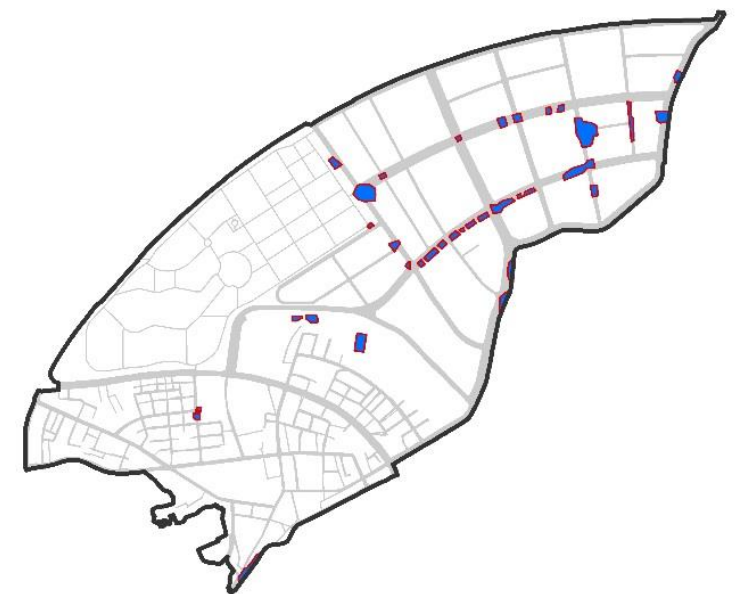

(a)

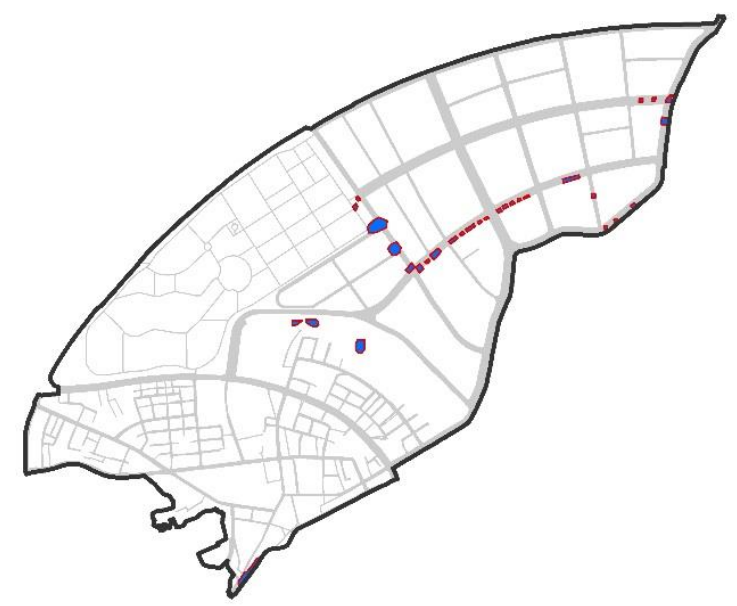

(c)

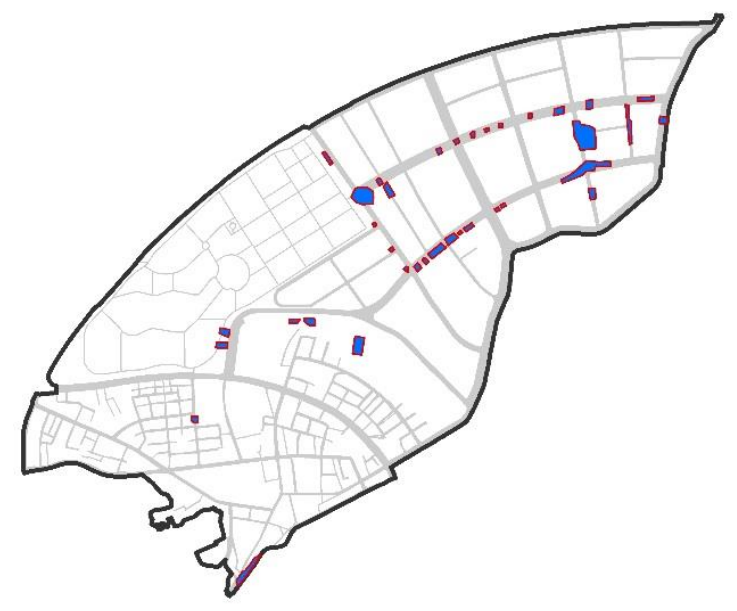

(b)

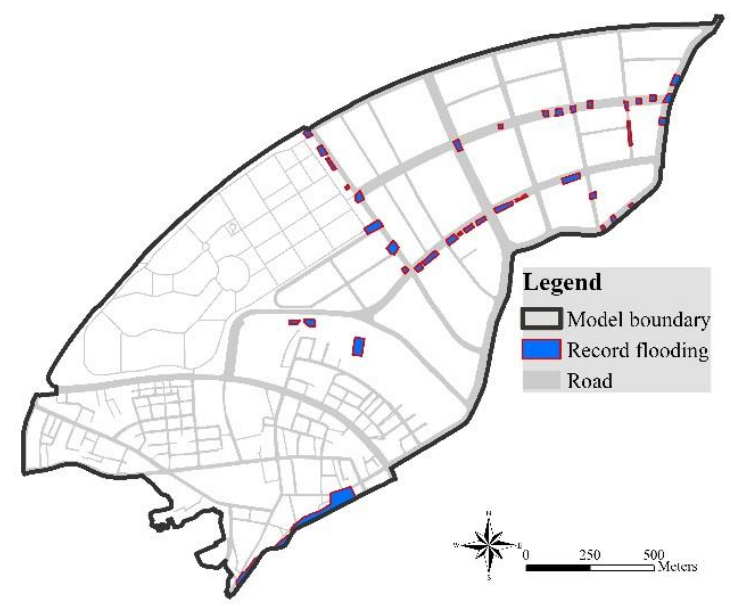

(d)

Figure 7 shows the recorded inundation areas were quite sporadic. The total flooded area was about 1.9 hectares with flood depths between 20 and $50 \mathrm{~cm}$.

From $31^{\text {st }}$ July to $2^{\text {nd }}$ August 2012, Typhoon Saola attacked Taiwan and caused severe inundation in the study area. 
Please cite: Chang, T.J., Wang C.H., Chen, A.S., 2015, A novel approach to model dynamic flow interactions between storm sewer system and overland surface for different land covers in urban areas, Journal of Hydrology, doi: 10.1016/j.jhydrol.2015.03.014, in press.

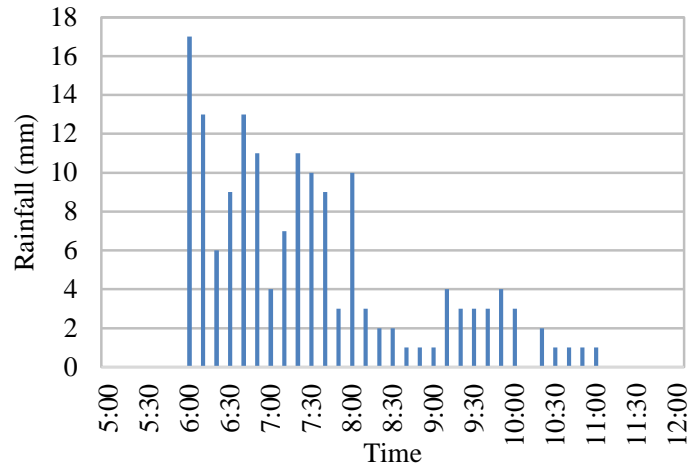

(a)

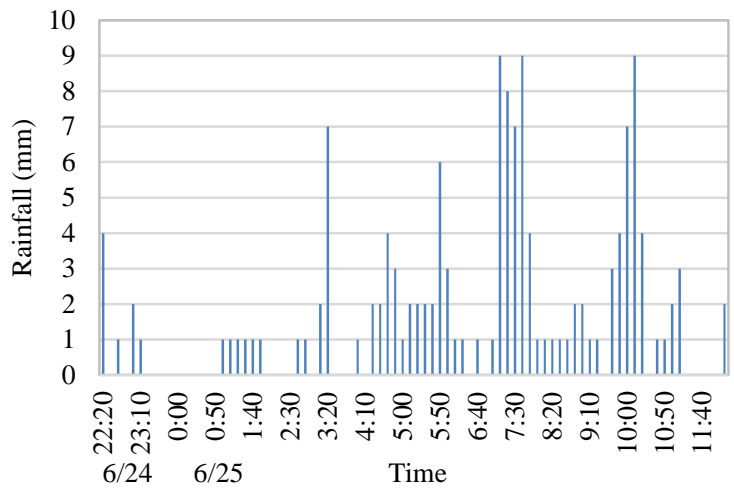

(c)

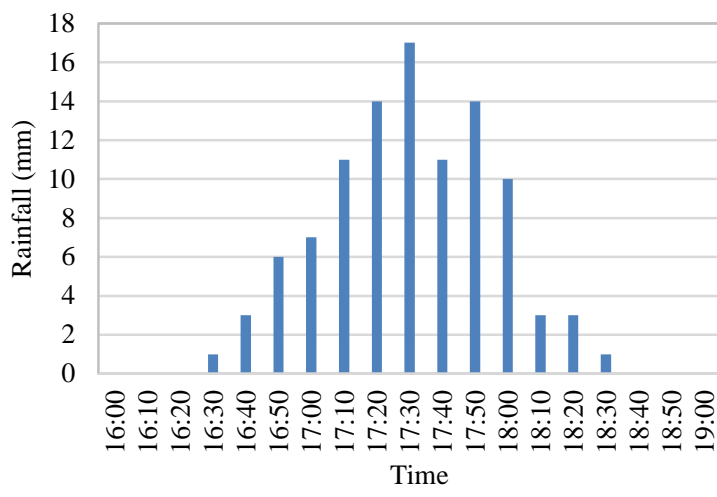

(b)

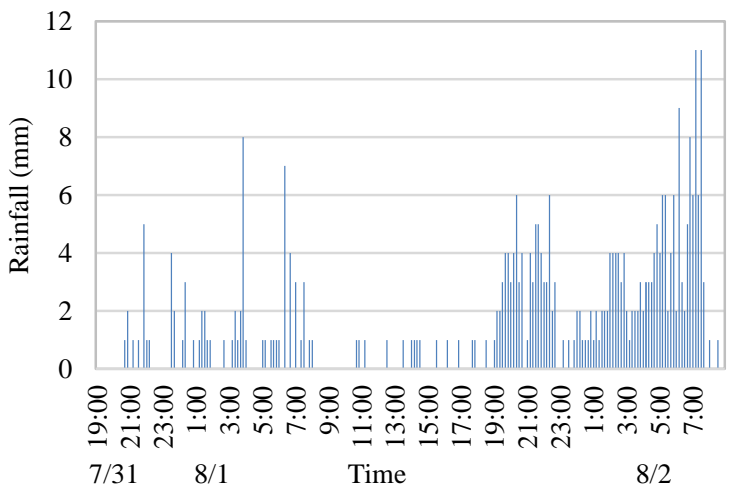

(d)

Figure $6 \mathrm{~d}$ shows the rainfall hyetograph of the event, which had total $335 \mathrm{~mm}$ in 36 hours with the peak intensity $47 \mathrm{~mm} / \mathrm{h}$ occurred between 06:30 and 07:30. 


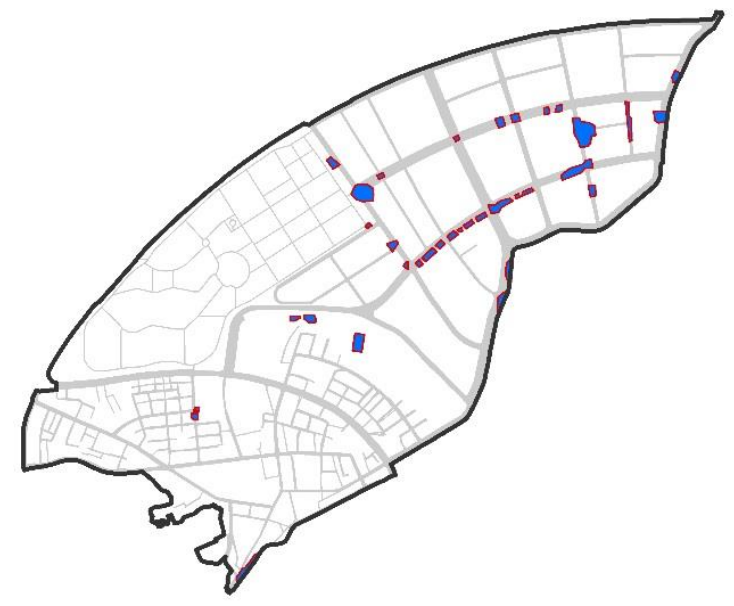

(a)

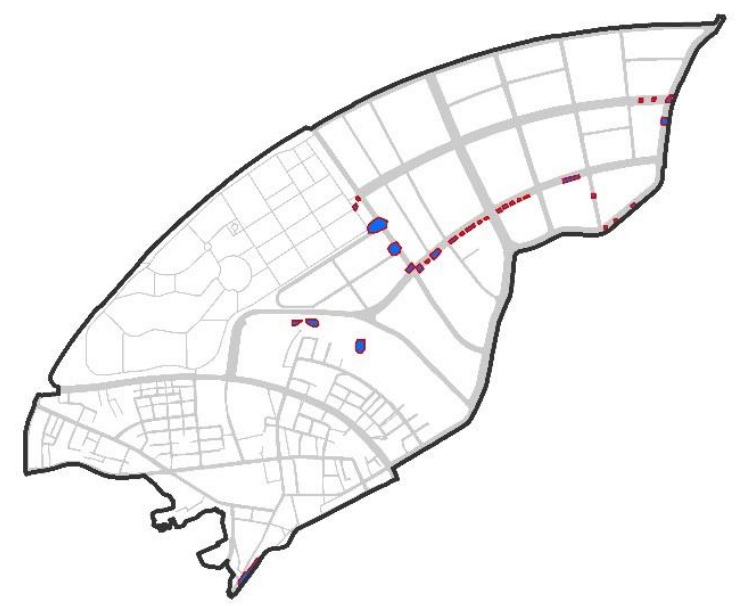

(c)

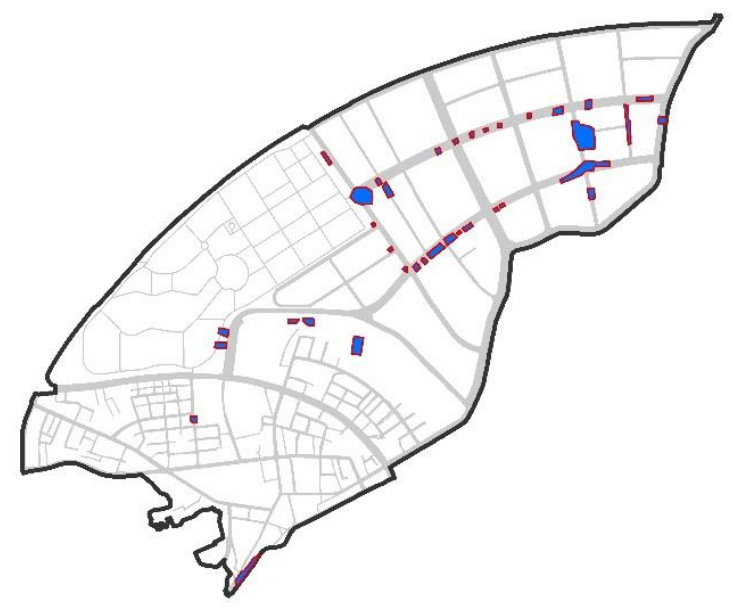

(b)

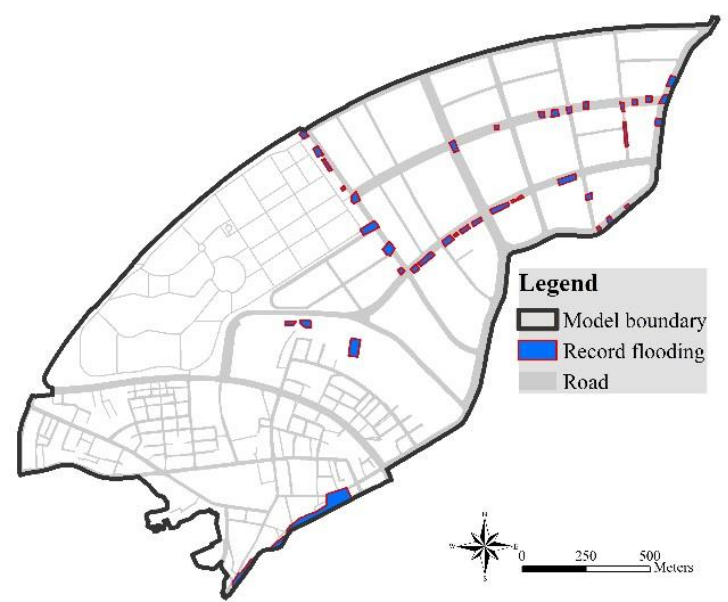

(d)

Figure $7 \mathrm{~d}$ gives the recorded inundation areas. The total flooded area was about 4.3 hectares, and the inundation depths ranged from 20 to $60 \mathrm{~cm}$.

\subsection{Numerical simulation details}

We simulated the flow in the sewer network with the SWMM and the overland flow with a 2D OFM using various model combining/coupling methodologies described in section 2.2 and 2.3. The sewer network includes 395 manholes and $23.1 \mathrm{~km}$ of 387 pipes with a diameter greater than $50 \mathrm{~cm}$. The Manning's roughness coefficient was 0.015 for all pipes. For the 2D OFM, a $5 \mathrm{~m}$ resolution digital elevation model (DEM) of bare terrain was used for the whole study area. We only considered the flat building roof with retaining walls, the main roof type in our case study, and adopted the coupled SFM/OFM for the built-up area. The Building Technical Regulations 
(Construction and Planning Agency, 2014) in Taiwan specify that the heights of retaining walls on the roof should be between $1.1 \mathrm{~m}$ and $1.5 \mathrm{~m}$ such that the ponding water caused by rainfall is unlikely to overspill to neighbouring ground surface.

Bare terrain was used for the 2D OFM such that the surface runoff may travel through buildings once the flooding exceeds the ground elevation of building sites. Some other 2D OFMs (Environment Agency, 2013; Gironás et al., 2009) increased elevation of buildings or lowered the street level to try and prevent flood water traversing buildings, which to an extent reflects real world conditions (presence of road curb, raised building base, blockage due to the presence of building walls). Nevertheless, for severe flood conditions, the water level may still reach the raised ground elevation and propagate through buildings. The bare DEM of the study area has shown the difference between street level and building site of elevation. To further reflect the influence of building walls and basement storage on flood dynamic, it will require extra effort to set the parameters correctly, which is beyond the scope of the paper. Therefore, we ignored these factors and used the bare DEM without further processing in the 2D OFM in the paper.

For the case study area, the inlets are densely distributed with spacing less than $5 \mathrm{~m}$ (the grid resolution of 2D modelling) along roads, therefore the inlets were uniformly set except for the central lanes of roads which were wider than $10 \mathrm{~m}$ (i.e., more than width of two cells), where the runoff will only be drained via the inlets along the roadsides. We did not consider the drains inside buildings, which are normally connected to the separate sewerage systems, so the surface runoff could only enter the sewer network from inlets outside buildings. Therefore, apart from the roof inlets included for the mixed SFM/OFM and OFM/SFM coupling approach, the inlet 
Please cite: Chang, T.J., Wang C.H., Chen, A.S., 2015, A novel approach to model dynamic flow interactions between storm sewer system and overland surface for different land covers in urban areas, Journal of Hydrology, doi: 10.1016/j.jhydrol.2015.03.014, in press.

settings were the same for all the coupling approaches (the coupled SFM/OFM, the coupled OFM/SFM, and the mixed SFM/OFM and OFM/SFM coupling).

The time steps for the SWMM and the 2D OFM were $1 \mathrm{~s}$ and $0.5 \mathrm{~s}$, respectively. The observations of the nearest rain gauge of various flood events, as shown in 
Please cite: Chang, T.J., Wang C.H., Chen, A.S., 2015, A novel approach to model dynamic flow interactions between storm sewer system and overland surface for different land covers in urban areas, Journal of Hydrology, doi: 10.1016/j.jhydrol.2015.03.014, in press.

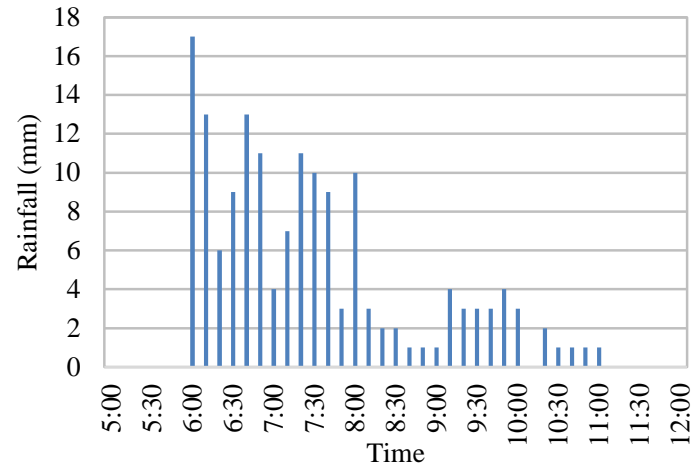

(a)

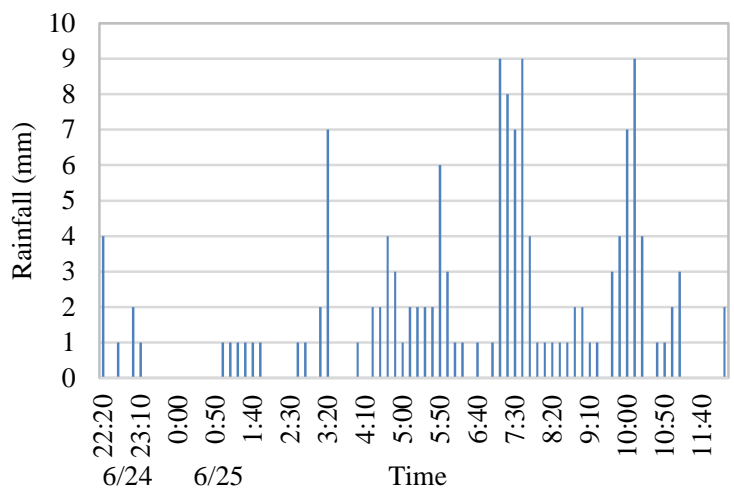

(c)

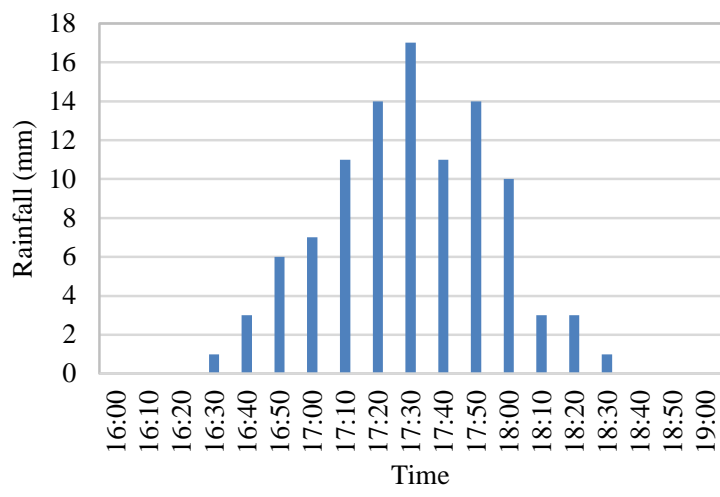

(b)

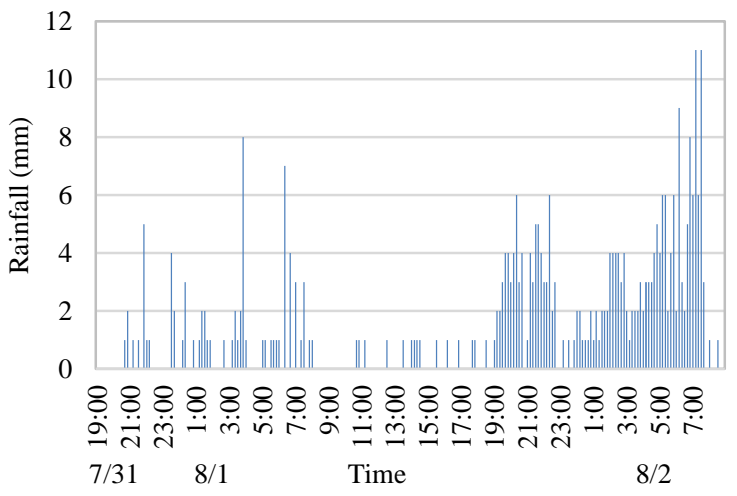

(d)

Figure 6, were considered to be uniformly distributed in the whole study area; however, the rainfall was applied to the SWMM or the 2D OFM depending on the land cover type as shown in 
Please cite: Chang, T.J., Wang C.H., Chen, A.S., 2015, A novel approach to model dynamic flow interactions between storm sewer system and overland surface for different land covers in urban areas, Journal of Hydrology, doi: 10.1016/j.jhydrol.2015.03.014, in press.

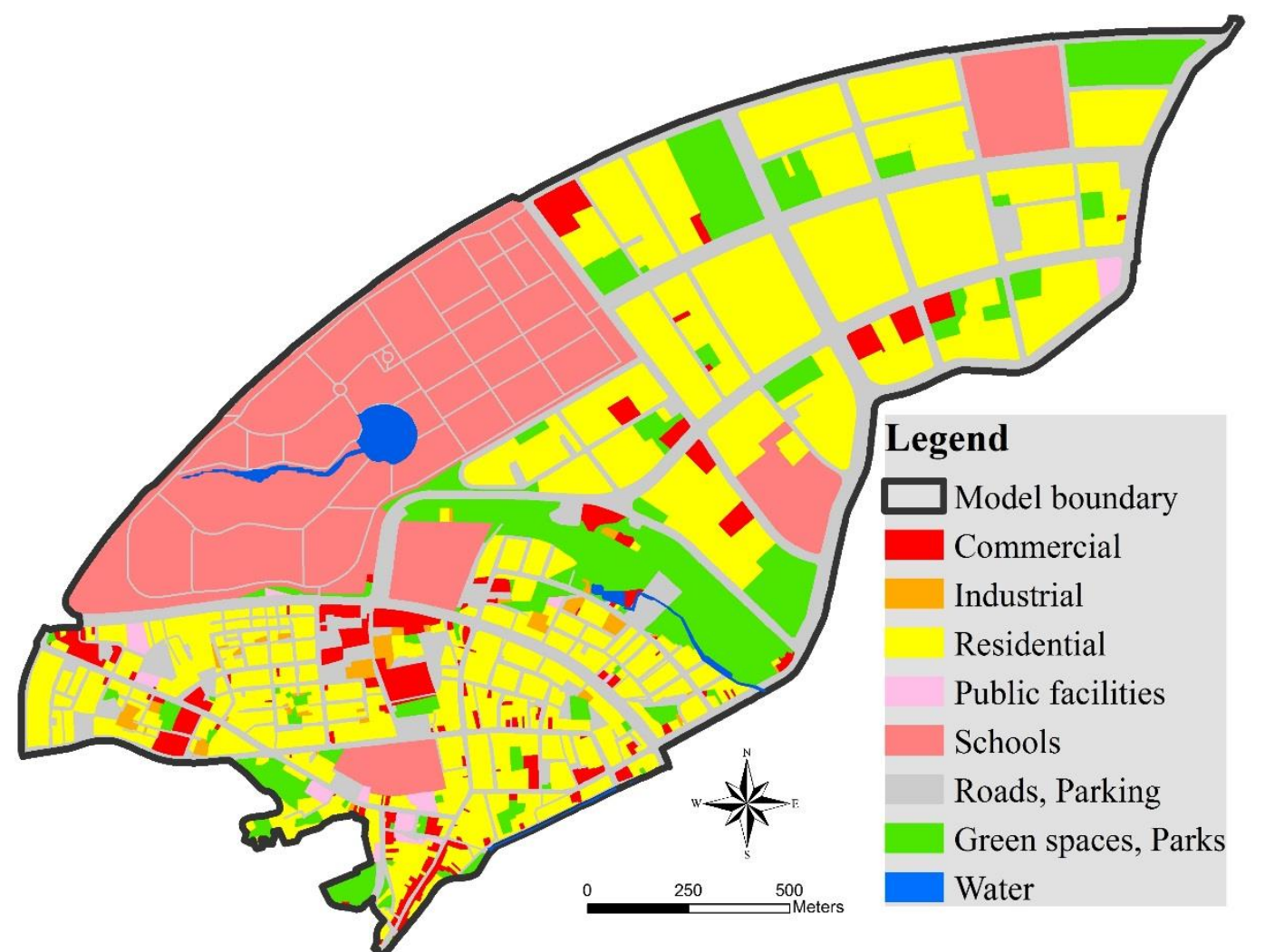

(a)

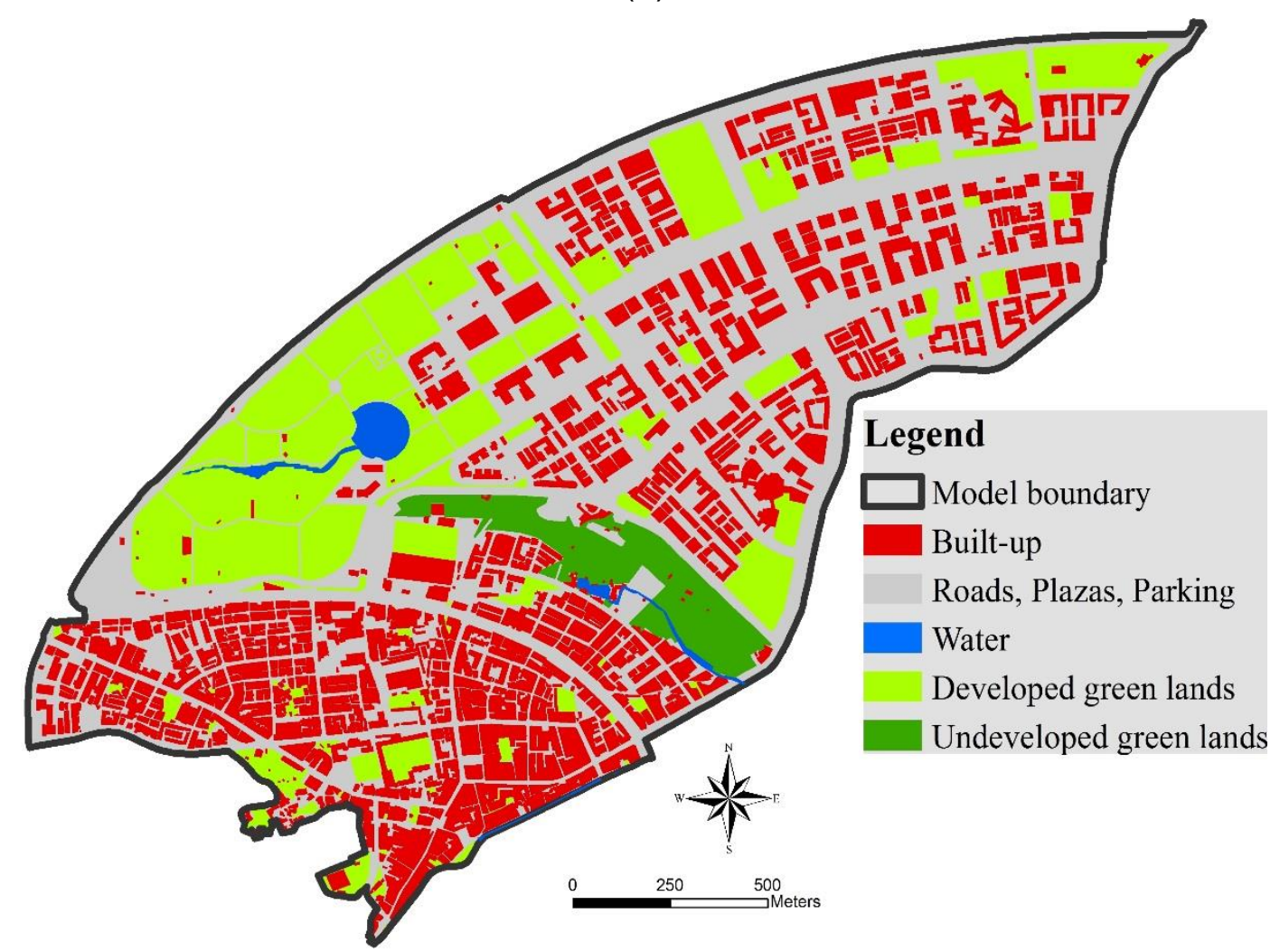

(b)

Figure 4b. Similarly, the Manning's roughness coefficients were also set based on three land cover types: (1) 0.02 for roads, plazas, pavements, etc.; (2) 0.08 for green 
Please cite: Chang, T.J., Wang C.H., Chen, A.S., 2015, A novel approach to model dynamic flow interactions between storm sewer system and overland surface for different land covers in urban areas, Journal of Hydrology, doi: 10.1016/j.jhydrol.2015.03.014, in press.

lands, parks, etc.; and (3) 0.05 for built-up areas.

\section{Results and discussion}

\subsection{Performance indicators}

In this paper, we adopted the confusion matrix (Aronoff, 1982; Congalton, 1991; Purnami et al., 2010) to calculate the indicators for evaluating the performance of the six modelling approaches. Table 1 shows the four categories of the possible agreement between the simulation results and the observations. True Positive (TP) represents the amount that the model correctly predicted, i.e. hit, the flooding as observed. False Positive (FP) means the number that the model wrongly predicted the flooding, i.e. false alarmed, which did not occur. False Negative (FN) denotes the number that the model failed to predict the flooding, i.e. missed, that was observed. True Negative (TN) indicates the number that the model rightly predicted no flooding, i.e. correct rejected, which neither occurred.

Three indicators, including Accuracy (ACC), Sensitivity (True Positive Rate; TPR) and Precision (Positive predictive value; PPV), as defined in Eqs. (9), (10) and (11), respectively, were then used to evaluate the goodness of modelling results.

$$
\begin{gathered}
A C C=\frac{T P+T N}{T P+T N+F P+F N} \\
T P R=\frac{T P}{T P+F N} \\
P P V=\frac{T P}{T P+F P}
\end{gathered}
$$

\begin{tabular}{|c|c|c|}
\hline \multirow{2}{*}{ Simulation } & \multicolumn{2}{|c|}{ Observation } \\
\hline & Positive & Negative \\
\hline
\end{tabular}

\subsection{Accuracy}


Please cite: Chang, T.J., Wang C.H., Chen, A.S., 2015, A novel approach to model dynamic flow interactions between storm sewer system and overland surface for different land covers in urban areas, Journal of Hydrology, doi: 10.1016/j.jhydrol.2015.03.014, in press.

\begin{tabular}{ccc}
\hline Positive & True positive (TP) & $\begin{array}{c}\text { False positive } \\
\text { (FP) }\end{array}$ \\
Negative & False negative (FN) & $\begin{array}{c}\text { True negative } \\
(\mathrm{TN})\end{array}$ \\
\hline \hline
\end{tabular}

Table 2 lists the indicators of all the simulated events for different modelling approaches. Each of 
Please cite: Chang, T.J., Wang C.H., Chen, A.S., 2015, A novel approach to model dynamic flow interactions between storm sewer system and overland surface for different land covers in urban areas, Journal of Hydrology, doi: 10.1016/j.jhydrol.2015.03.014, in press.

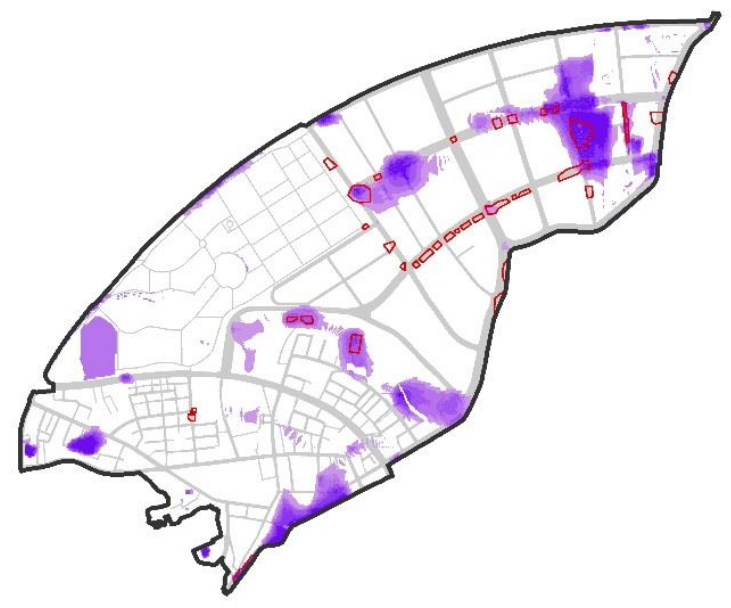

(a)

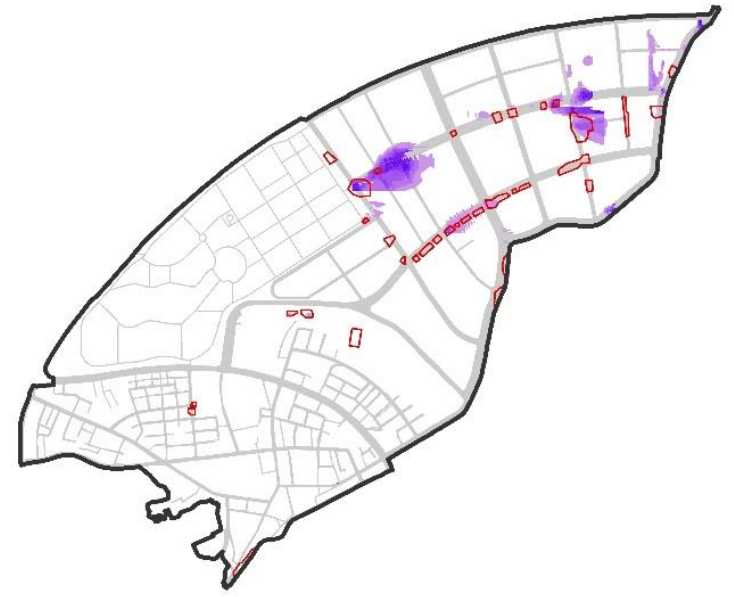

(c)

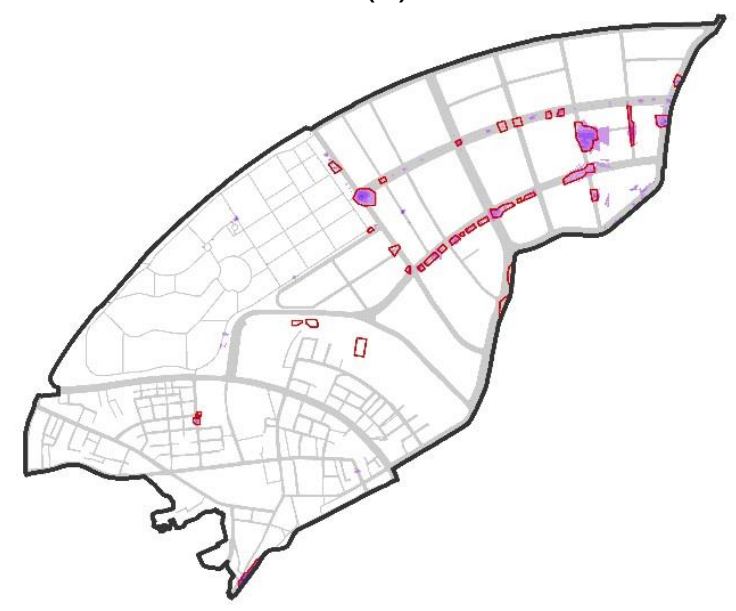

(e)

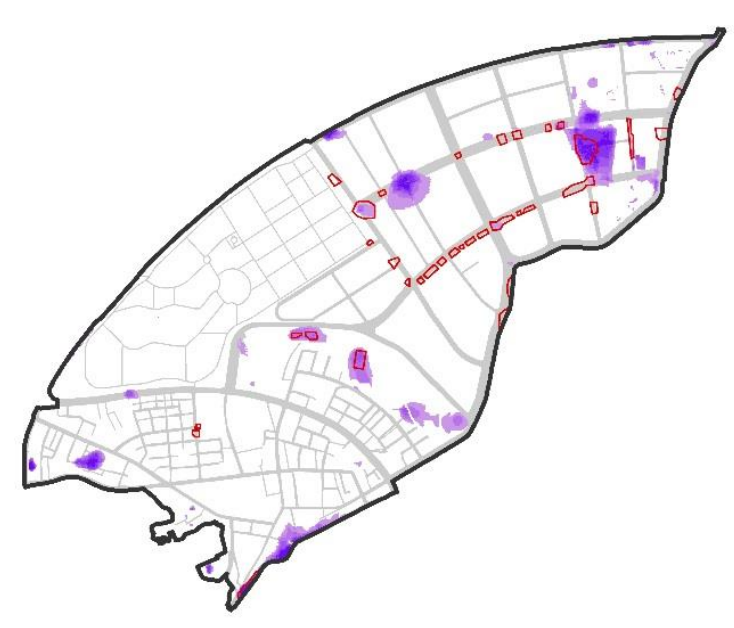

(b)

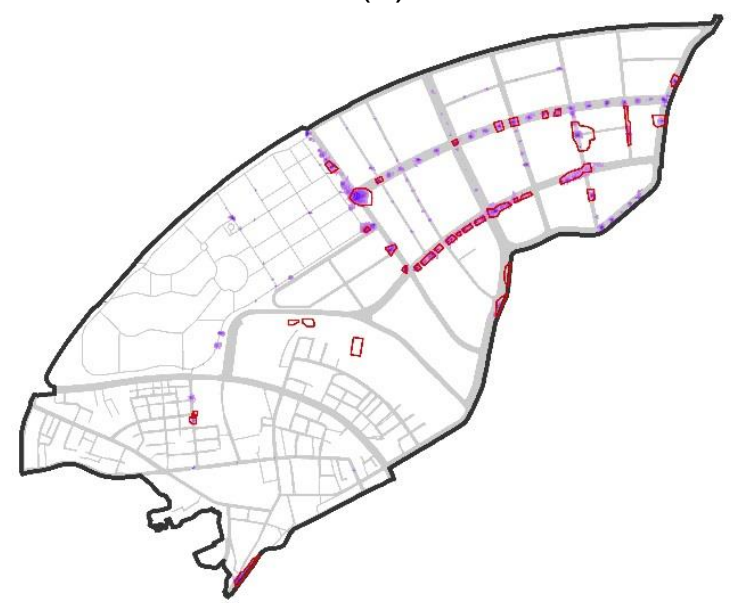

(d)

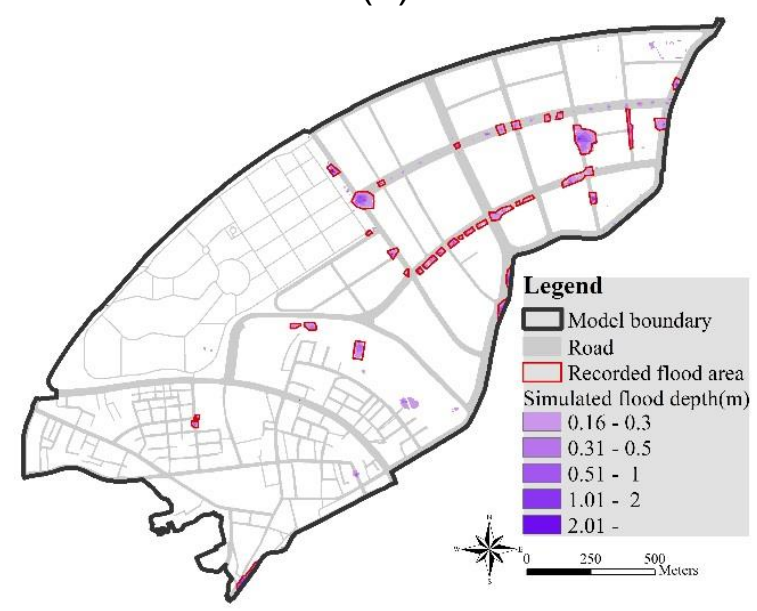

(f)

Figure 8 to 


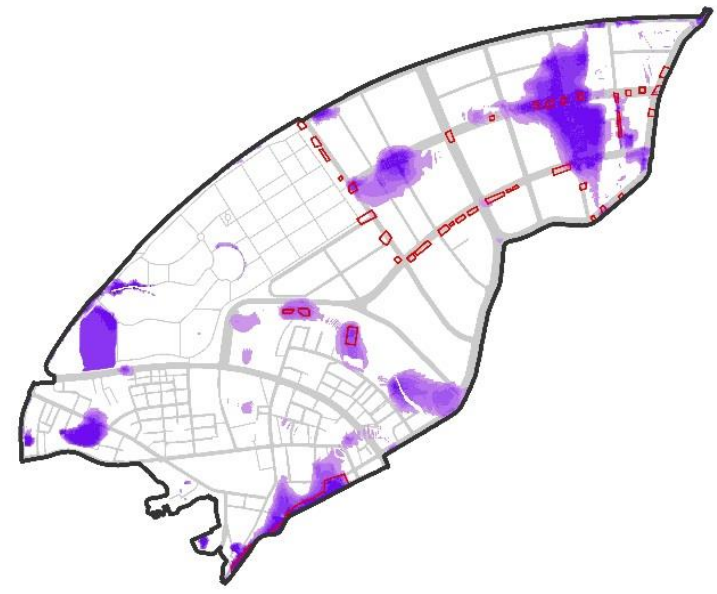

(a)

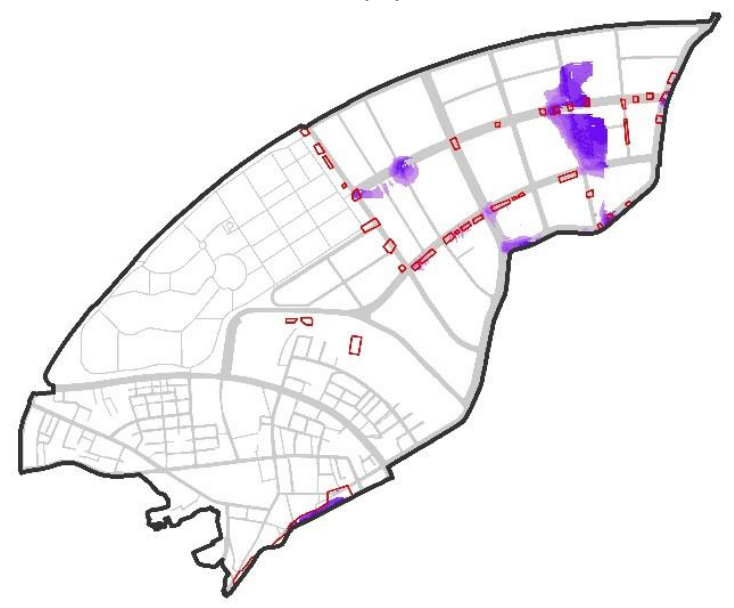

(c)

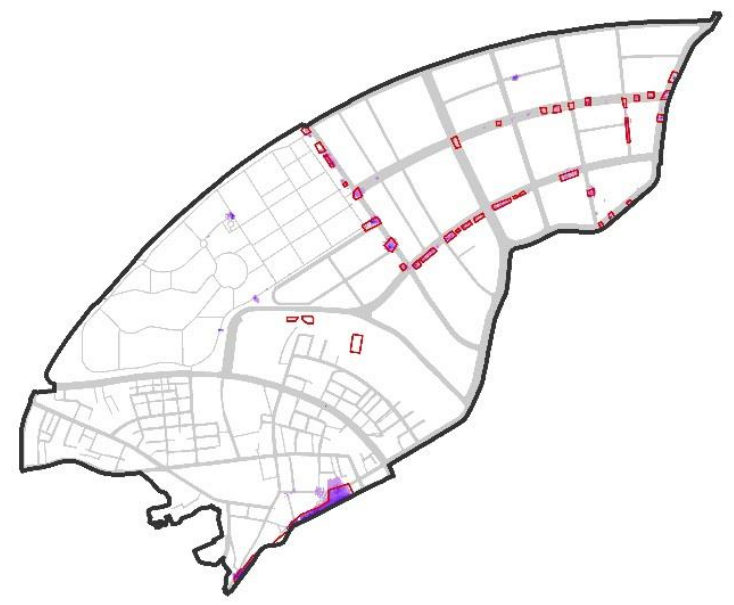

(e)

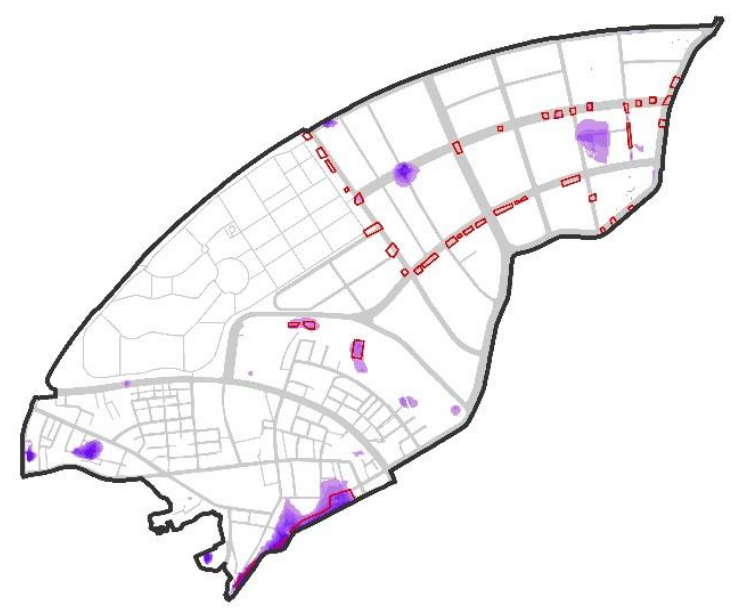

(b)

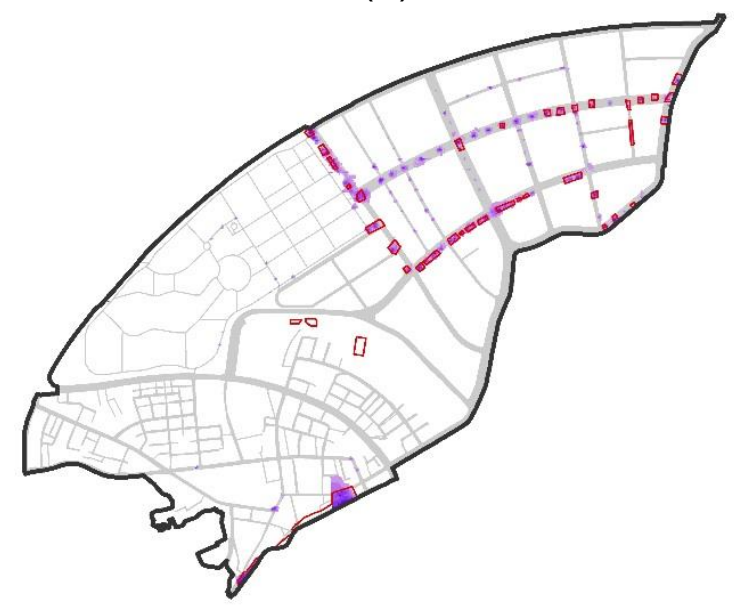

(d)

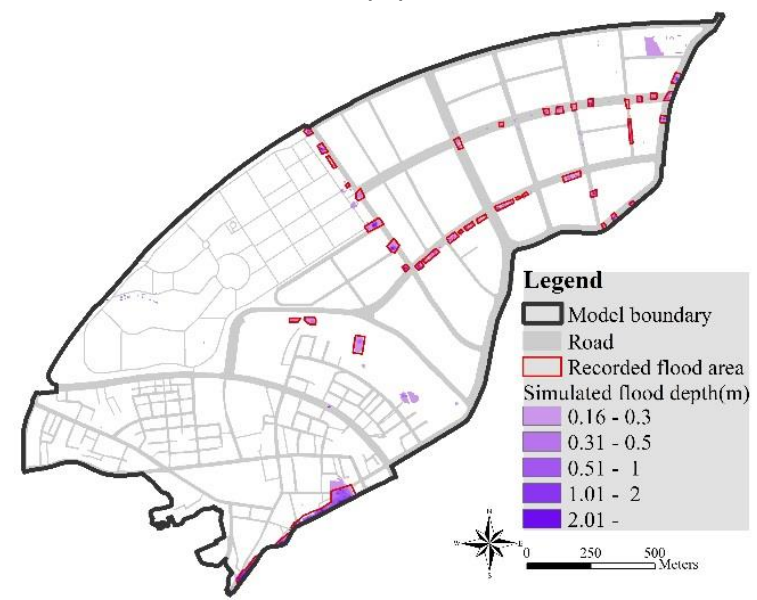

(f)

Figure 11 shows the modelled flood extents of the six approaches and the recorded flood areas (red boundary polygons) of a simulated event. Although the ACCs of the 2D OFM only approach for all the simulated events were around 0.85 , the results of other approaches were obviously better (above 0.94 ). The 2D OFM only approach 
ignored the sewer function and produced more runoff travelling along the surface. The water ponded in low-lying areas could not flow into the sewer network such that the results over-estimated the flood depths and extents.

The 2D OFM with rainfall reduction subtracts at a constant rate from the rainfall input to mimic the storm sewer drainage capacity without running a SFM. The approach to an extent reflected the function of storm sewer drainage such that the ACCs were better than the ones using the 2D OFM only approach. The combined SFM/OFM approach assumed that the runoffs were collected by the drainage system first, and the surcharge from the sewer network induced surface flooding. The consideration of the sewer function reduced the flooding on the surface and produced more accurate results than the 2D OFM only approach. The coupling approaches (the coupled SFM/OFM, the coupled OFM/SFM, and the mixed SFM/OFM and OFM/SFM coupling) described the bi-directional interactions between the surface and subsurface systems better than the non-coupling approaches (the 2D OFM only, the 2D OFM with rainfall reduction, and the combined SFM/OFM) such that the ACCs were further improved.

\subsection{Precision and sensitivity}

The improvement of ACCs in the 2D OFM with rainfall reduction and the combined SFM/OFM approaches were mainly on the predictions of TN, which occurred in most areas of the modelling domain and outweighed other factors. We further investigated the indicators for precision (PPV) and sensitivity (TPR), and found the two approaches performed worse than the coupling approaches.

The 2D OFM with rainfall reduction approach assumed that a part of the surface runoff was drained directly to the sewer network regardless of the flow condition in the pipes. The surcharge from the sewer was not taken into account in this 
Please cite: Chang, T.J., Wang C.H., Chen, A.S., 2015, A novel approach to model dynamic flow interactions between storm sewer system and overland surface for different land covers in urban areas, Journal of Hydrology, doi: 10.1016/j.jhydrol.2015.03.014, in press.

approach. Hence, the results had high FNs and low TPRs in the areas where flood was incurred by surcharges. In contrast, in cases where rainfall intensity exceeded the sewer capacity, the sewer system might not be able to digest the excess runoff immediately, such that the surface water would drain to the sewer later or from other downstream inlets. The 2D OFM with rainfall reduction was incapable of simulating the dynamic such as the excess runoff accumulated in the depressions, which was the same as the 2D OFM only approach. The results had wider flood areas outside the recorded extents, as shown in the sub-figures $b$ of 
Please cite: Chang, T.J., Wang C.H., Chen, A.S., 2015, A novel approach to model dynamic flow interactions between storm sewer system and overland surface for different land covers in urban areas, Journal of Hydrology, doi: 10.1016/j.jhydrol.2015.03.014, in press.

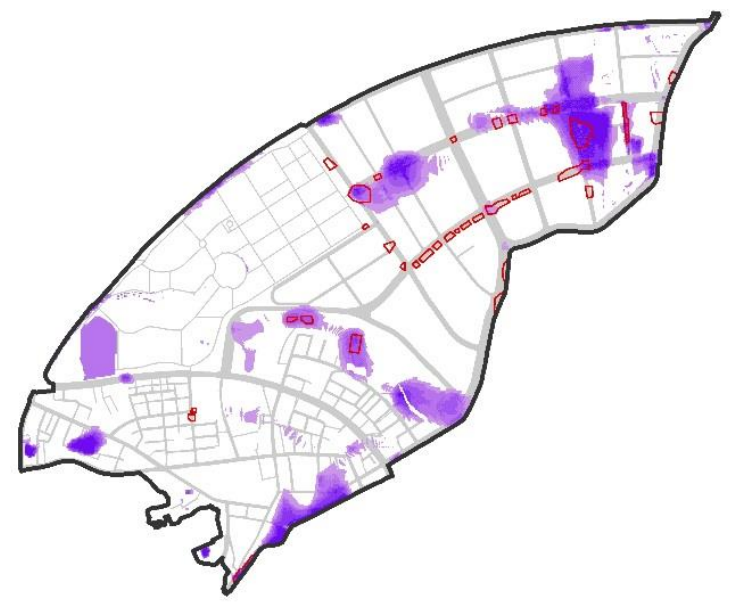

(a)

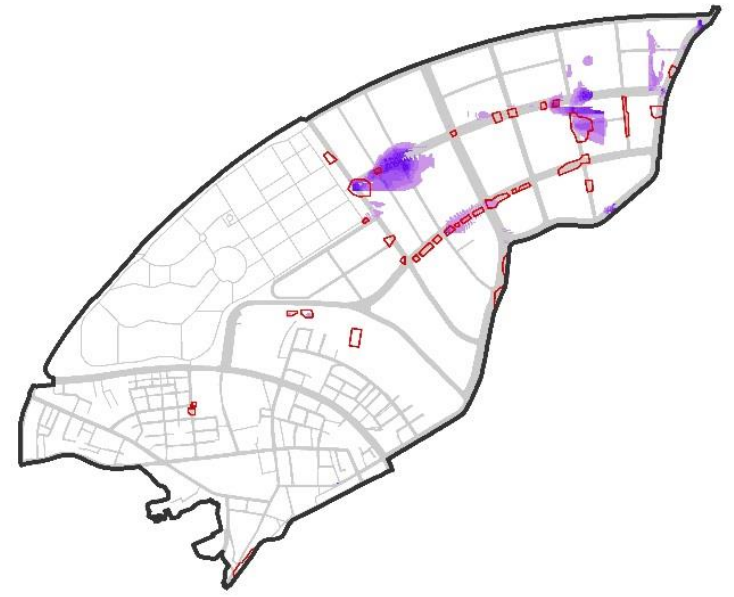

(c)

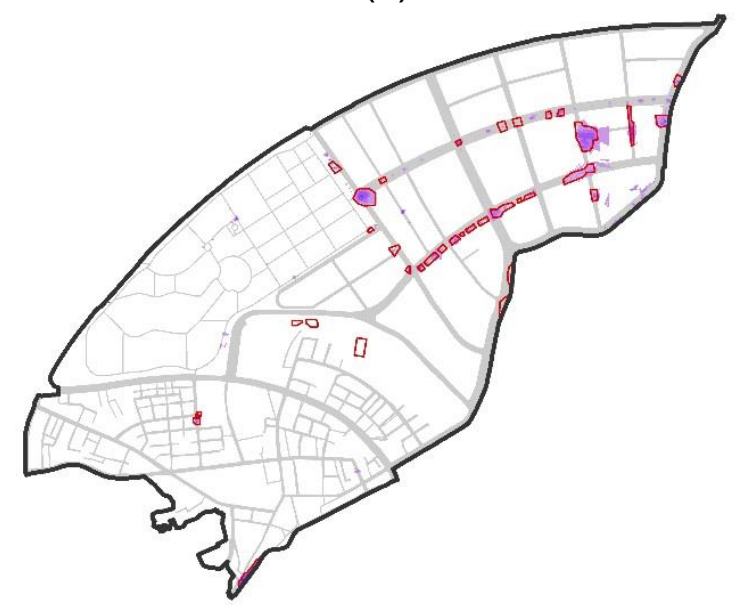

(e)

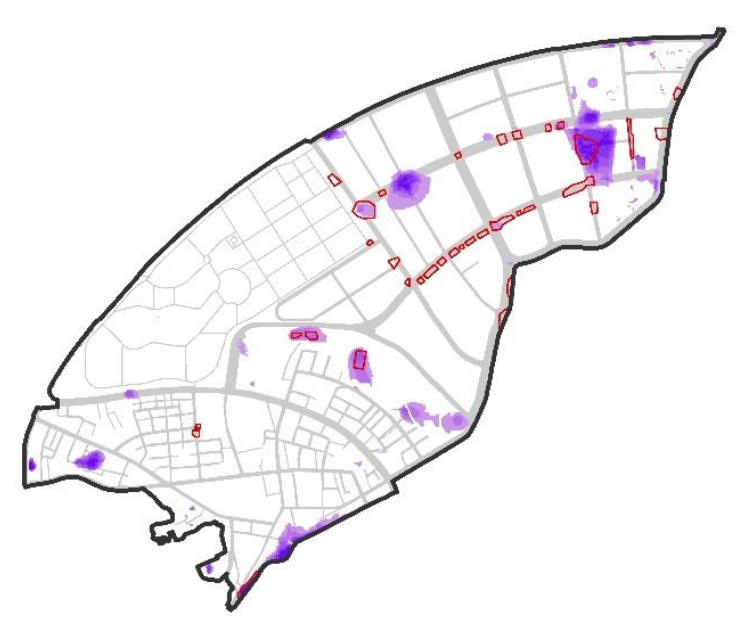

(b)

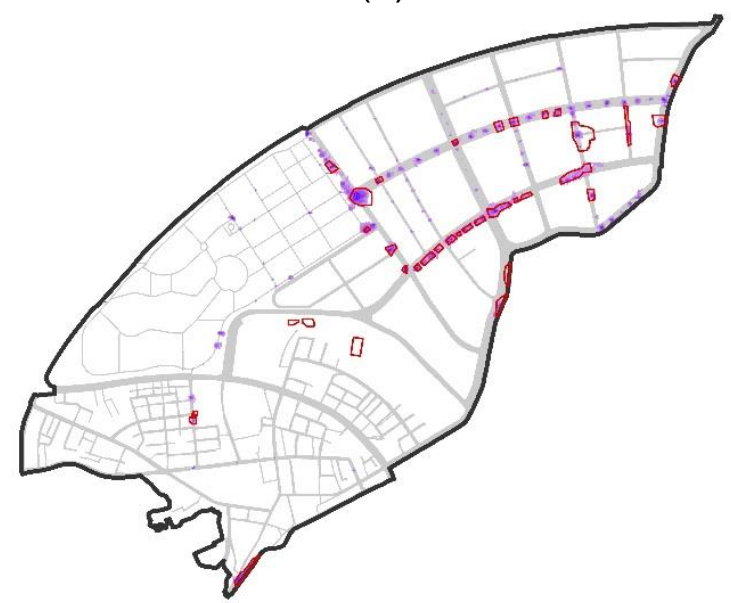

(d)

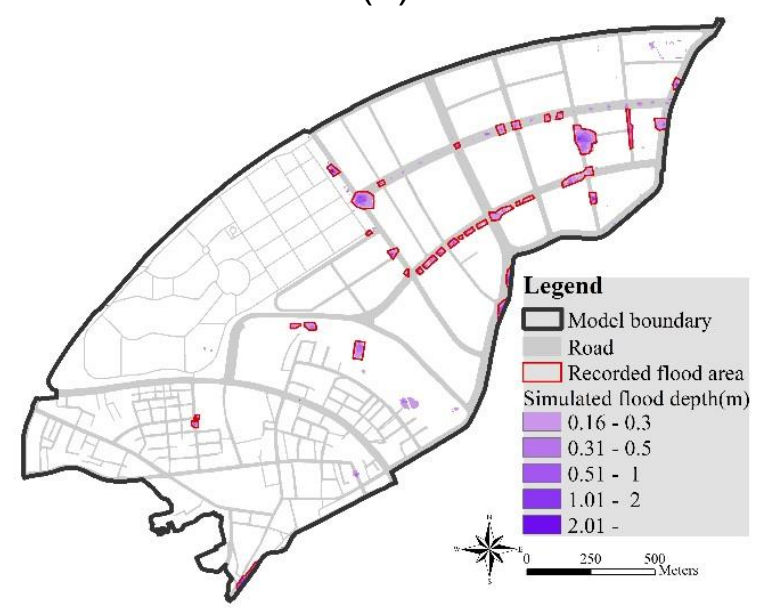

(f)

Figure 8 to 


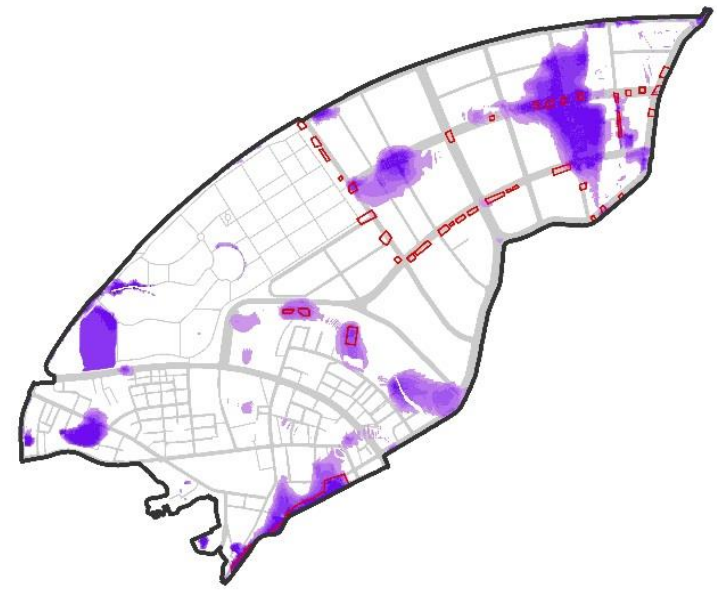

(a)

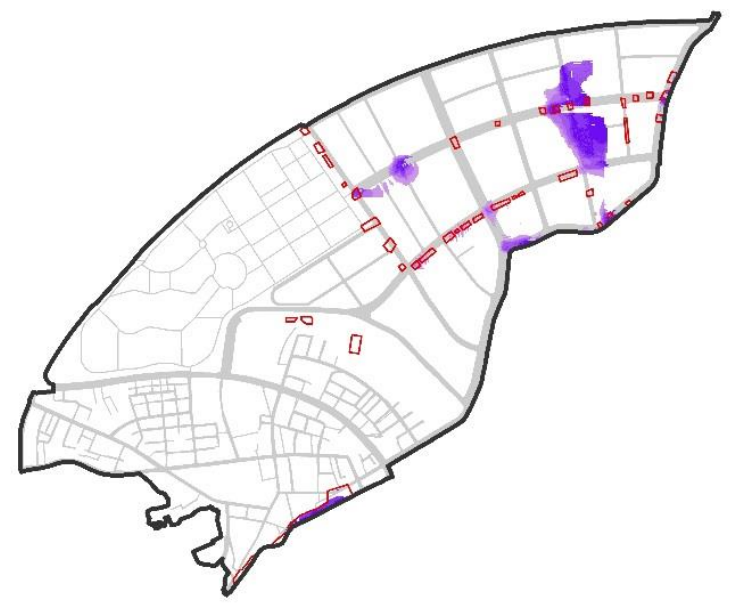

(c)

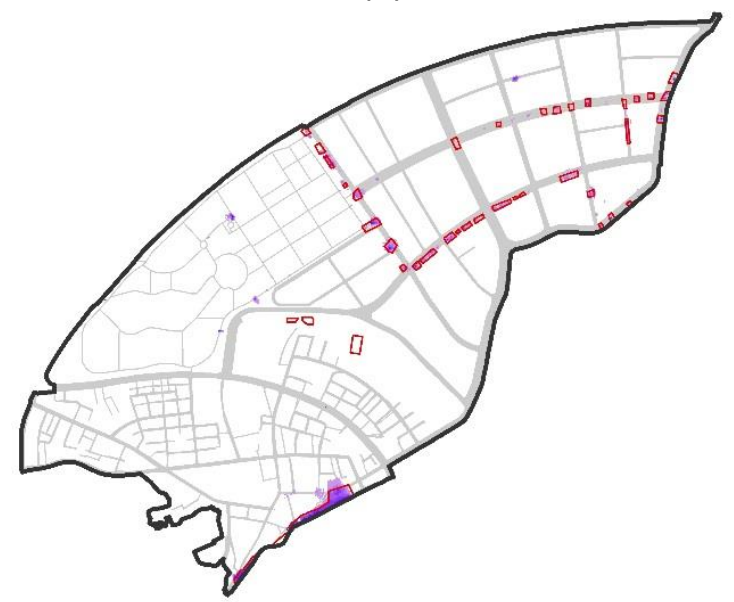

(e)

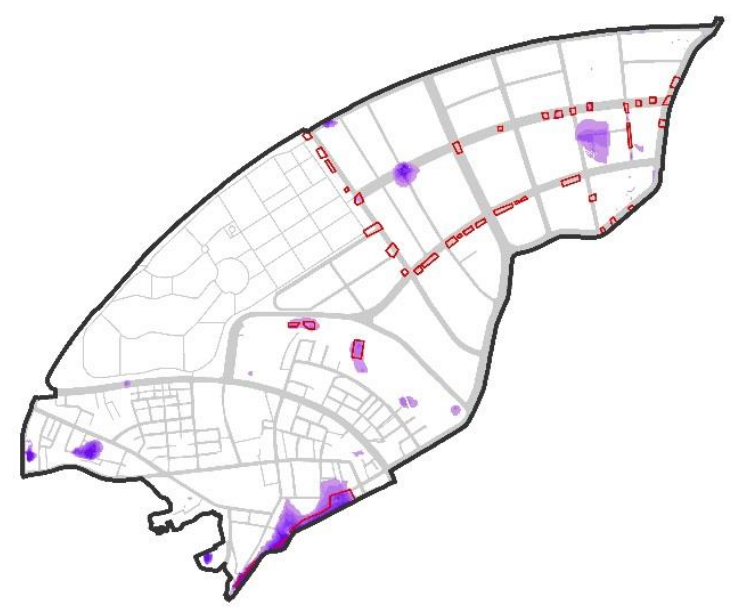

(b)

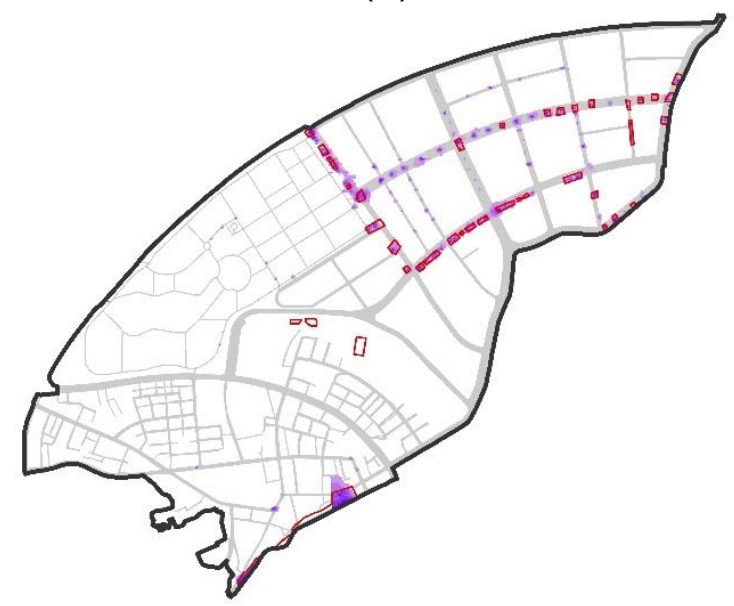

(d)

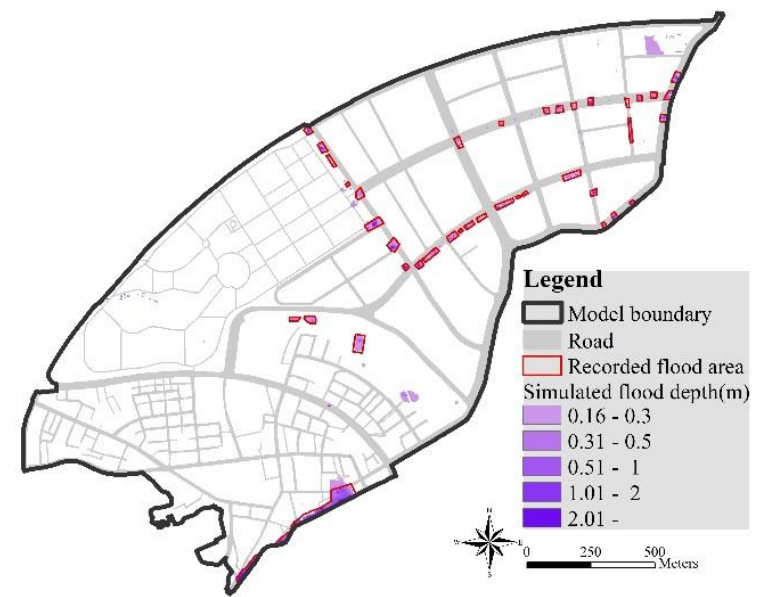

(f)

Figure 11, although the water could be drained to the sewer networks. Hence, the 2D OFM with rainfall reduction approach had high FPs that led to low PPVs.

For the combined SFM/OFM approach, the initial rainfall-runoff dynamic on the surface was not simulated by the 2D OFM such that the modelling results missed 
flood prediction in upstream sub-catchments. Hence, the FNs were high and the TPRs were low. For areas where the surcharges from the sewer network caused flooding, the model assumption only allowed one-way interaction between the subsurface and the surface systems and restricted the water movement vice versa. The modelled flooding extents and depths were over-estimated, which resulted in FPs and low PPVs.

The main difference between the 2D OFM with rainfall reduction and the combined SFM/OFM approaches was that the former had wider flood extents in the upstream sub-catchment of the sewer network. The runoff simply accumulated in the depressions on the ground surface although sewer systems existed in those areas because the 2D OFM with rainfall reduction approach did not allow the excess runoff to drain. The combined SFM/OFM approach had larger flood extents in downstream regions because the surcharged water could not flow back to the sewers.

For the coupling approaches, the mixed SFM/OFM and OFM/SFM coupling had the best results for all three indicators. The sub-figures $d$ of 
Please cite: Chang, T.J., Wang C.H., Chen, A.S., 2015, A novel approach to model dynamic flow interactions between storm sewer system and overland surface for different land covers in urban areas, Journal of Hydrology, doi: 10.1016/j.jhydrol.2015.03.014, in press.

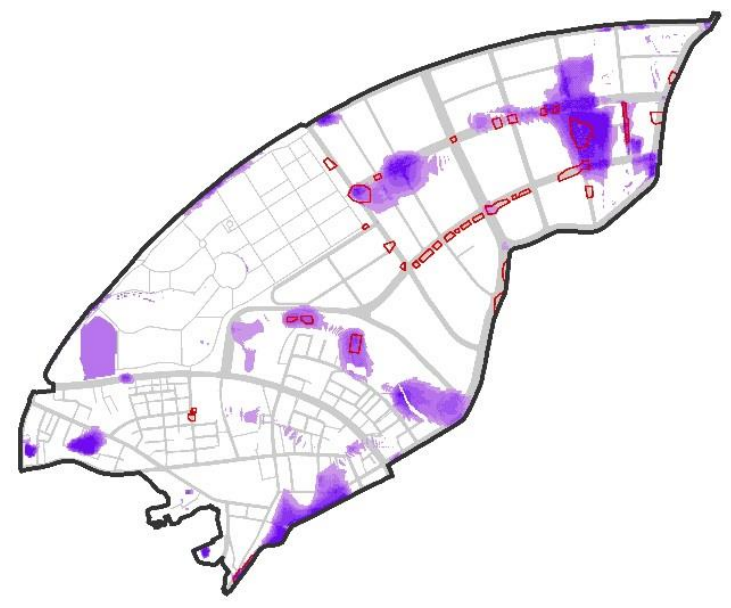

(a)

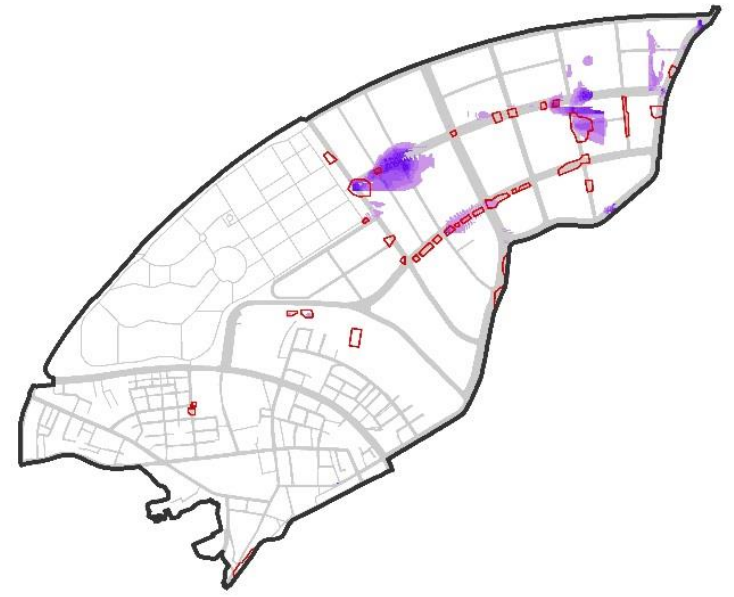

(c)

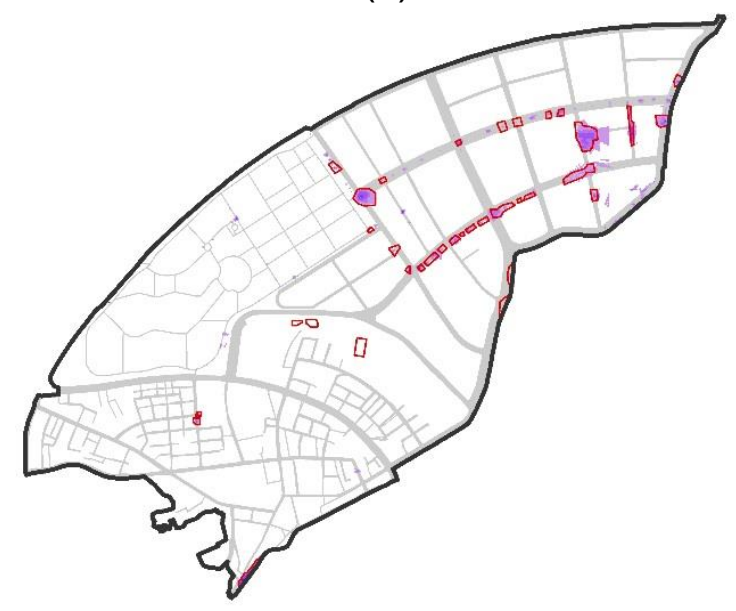

(e)

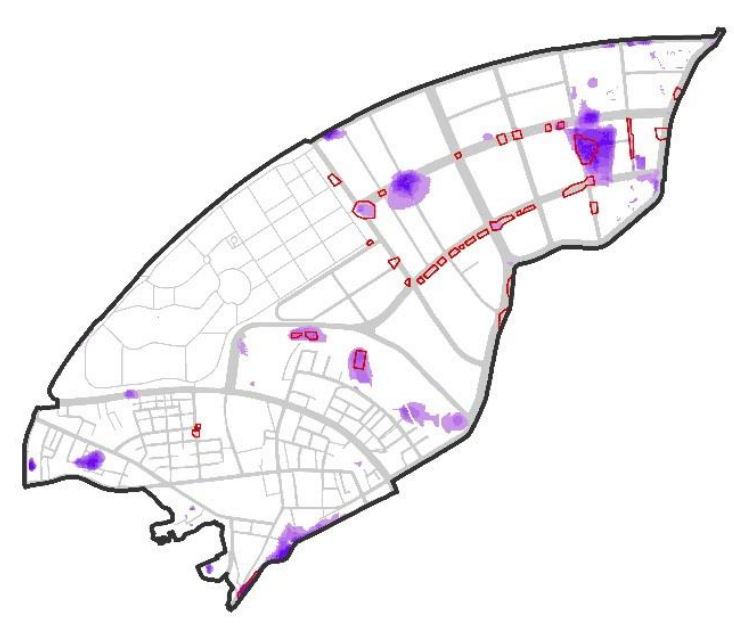

(b)

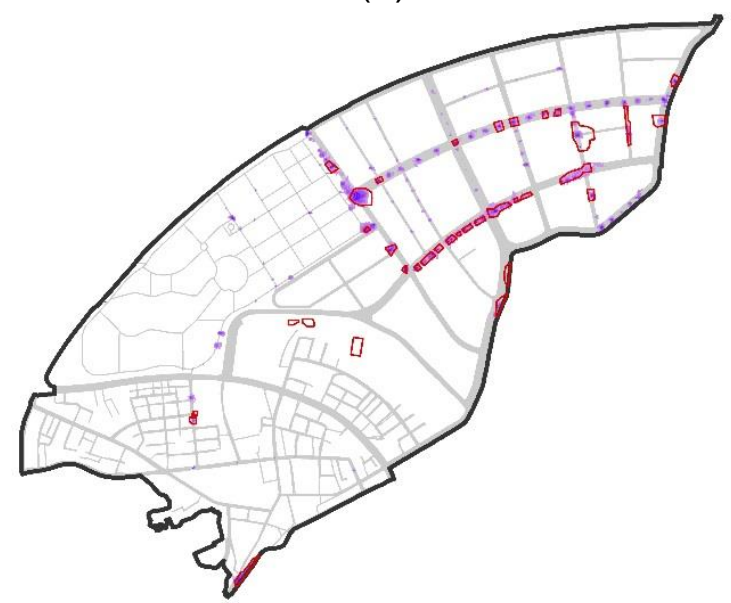

(d)

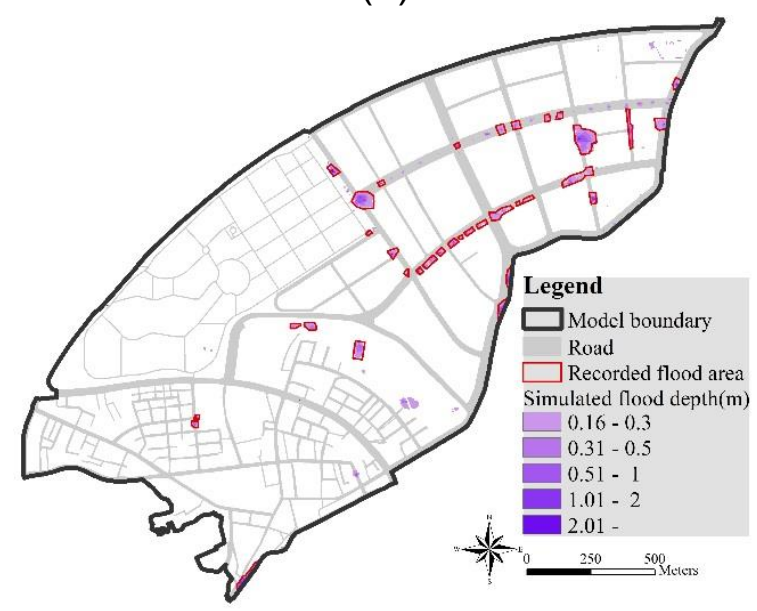

(f)

Figure 8 to 


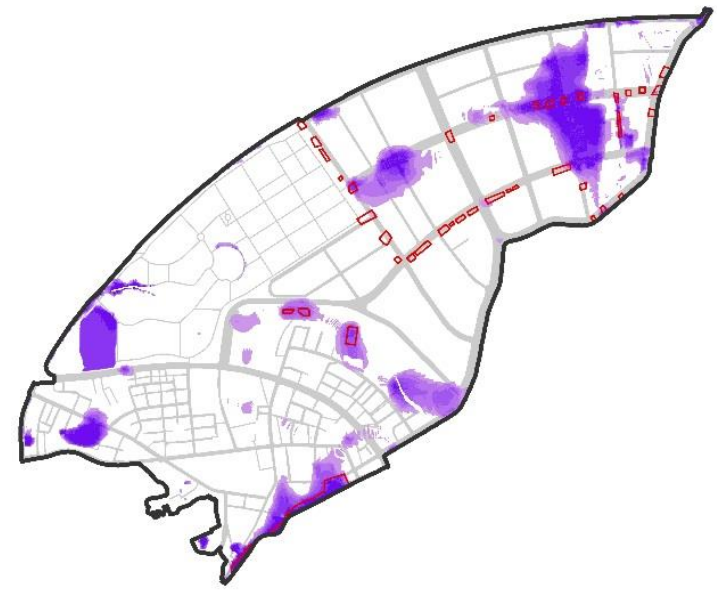

(a)

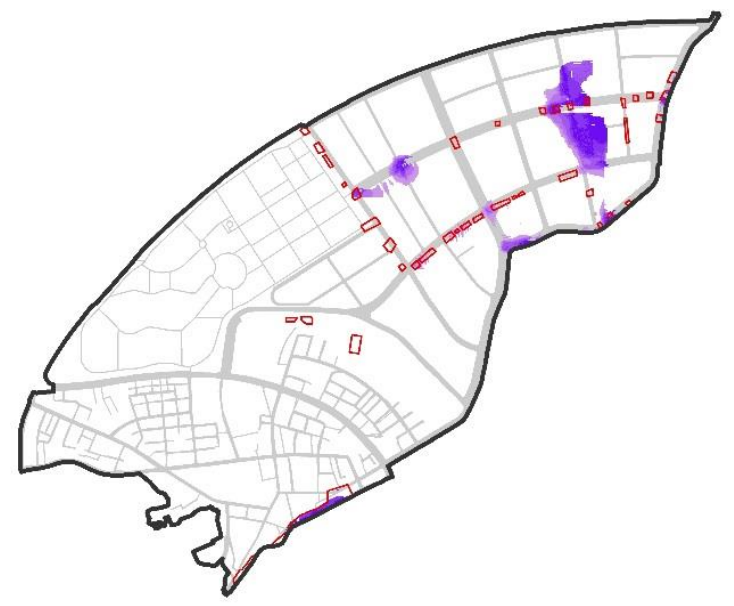

(c)

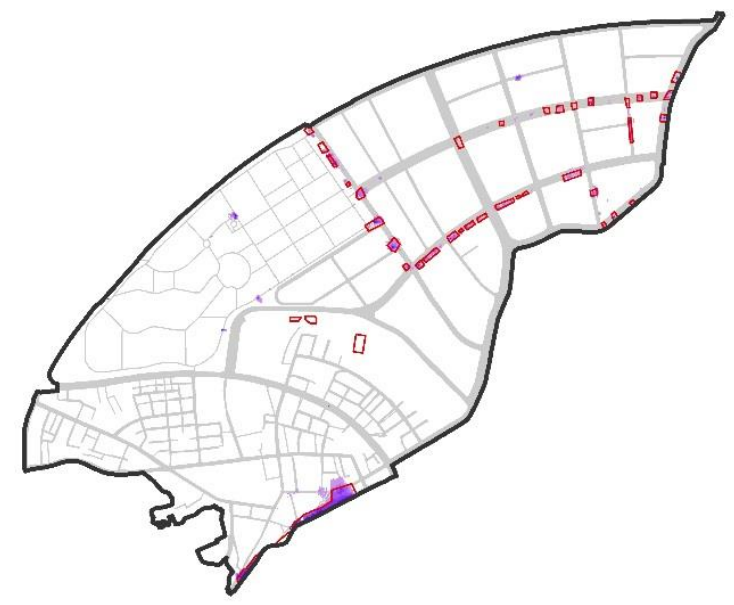

(e)

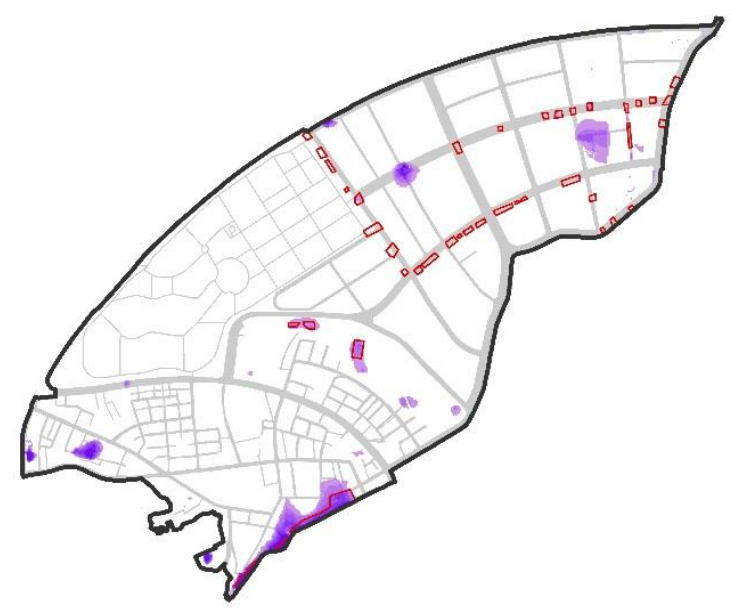

(b)

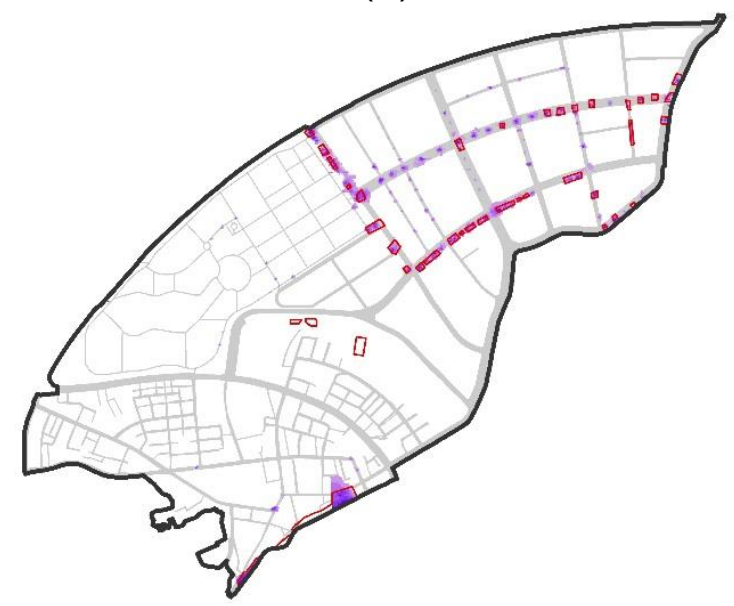

(d)

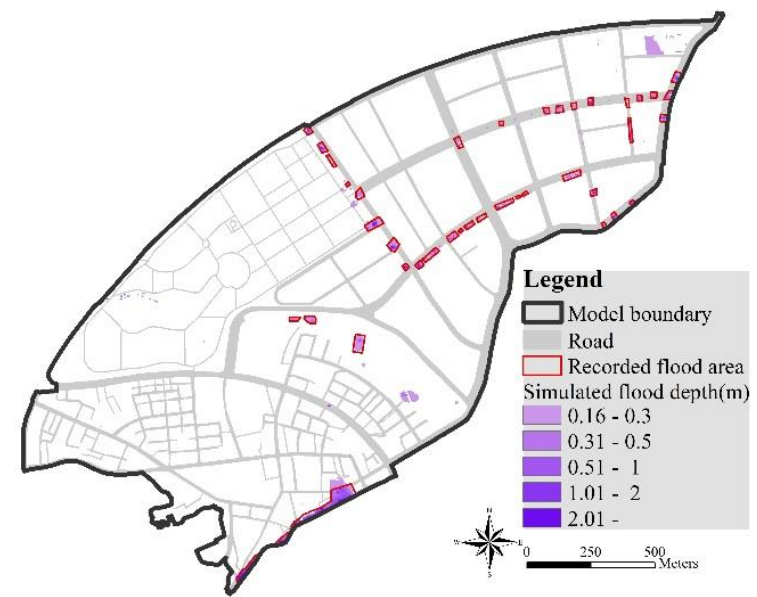

(f)

Figure 11 show that the coupled SFM/OFM approach had many flooding spots along the roads due to surcharges from manholes, where no flood extent was recorded. The coupled SFM/OFM collected the rainfall directly to the sewer system without considering the capacity of inlets, which allowed more runoff to enter the drainage 
Please cite: Chang, T.J., Wang C.H., Chen, A.S., 2015, A novel approach to model dynamic flow interactions between storm sewer system and overland surface for different land covers in urban areas, Journal of Hydrology, doi: 10.1016/j.jhydrol.2015.03.014, in press.

network and caused higher surcharge rate at downstream manholes where the flow concentrated to. Hence, this led to greater FPs and low precision (PPVs) than the ones obtained from the other two coupling approaches.

In contrast, the coupled OFM/SFM allowed the initial runoff to propagate along the surface before reaching an inlet. In Taiwan, the runoff on the roof is normally confined by the walls surrounding the roof and collected by the inlet. In this study, the bare terrain elevation was used and the walls surrounding the roof were excluded. In the coupled OFM/SFM approach, when the rainfall intensity exceeds the inlet capacity, the water will flow toward neighbour cells, instead of staying on the roof and being drained subsequently. Therefore, more runoff was produced and caused more flooding at the downstream of upstream sub-catchments where the inlets were unable to digest the surface flow. This resulted in lower discharge in the sewer pipes and less surcharge from downstream manholes. Therefore, the flooding was over-estimated at the downstream of upstream sub-catchments and underestimated in downstream areas. The over-estimations (FPs) were not as great/significant as the ones of the coupled SFM/OFM, so the PPVs were better. For the under-estimations, the continuous intense rainfall brought by typhoons generated more runoff than the discharge that the inlets were able to deal with. More water accumulated at the downstream of upstream sub-catchments such that the surcharges from downstream manholes reduced significantly in the coupled OFM/SFM approach that led to higher missed predictions (FNs). Therefore, the performances of sensitivity (TPRs) for typhoon events were worse than the ones using the coupled SFM/OFM approach.

The mixed SFM/OFM and OFM/SFM coupling approach distinguished the flow dynamics for the open spaces and the built-up areas. The inlet capacity in the 
OFM/SFM limited the surface runoff entering the sewer network, and the SFM/OFM for the roof sub-catchments prevents the runoff on the roof spilling to the open spaces. The model setting reflected the rainfall-runoff progress in urban areas closer to the physical phenomena such that it reduced both the over- and underestimations. The comparison of six modelling approaches has shown that the mixed SFM/OFM and OFM/SFM coupling approach a better method for urban flood modelling.

\subsection{Data requirements and model applicability}

The DEM and the land uses information are essential to set up topography and roughness, respectively, for all above approaches in urban flood modelling. The 2D OFM with rainfall reduction or infiltration rate approach requires expert knowledge to determine the parameters for reflecting the sewer capacity or the soil infiltration. Sewer network data are necessary for the approaches that include SFM. Due to the dense distribution of inlets in the case study area, which have been described in previous section, and $5 \mathrm{~m}$ resolution grid used for modelling, a simple procedure was implemented using road polygons in geographic information system (GIS) to set up inlets for grid cells along roadsides, but not for the cells in the central lanes of wide roads. In general, the combined SFM/OFM, the coupled SFM/OFM and the coupled OFM/SFM are using the same data, but applying different methods to connect the SFM and the OFM. We further utilised the land cover data to set up the infiltration rate of OFM in the mixed SFM/OFM and OFM/SFM coupling approach, which could be applied to the other three combined/coupled approaches as well.

The mixed SFM/OFM and OFM/SFM coupling requires additional information of building layouts to set up roof inlets linking to the sewer system. This is based on the condition that most buildings roofs in the case study area are flat with retaining walls, 
which act as temporary detention ponds during heavy rainfall events. For other roof conditions (e.g. slope roofs, or flat roofs without retaining walls) that the excess runoff on the roof may discharge directly to the neighbour cells of buildings, there are two possible ways to simulate the process. (1) If the bare terrain elevations are used in modelling, a pre-processing algorithm would be needed to assign the rainfall on the roof to the neighbour ground cells. Otherwise, the cells inside buildings may receive rainfall and be flooded, even for minor rainfall events, which would not reflect the physical phenomena properly. (2) If the roof heights are adopted in modelling, inlets without surface ponding area could be set along the edges of buildings to reflect the function of intercepting gullies. For the excess runoffs, the slope between roof and ground cells will automatically direct the water to the lower ground cells. However, the use of roof elevations implies that inside of buildings will be completely flood proof. When the street water levels exceed the ground elevation of building sites, the flood could enter the buildings via their entrances, if there is no further protection. In this case, the modelling with roof elevations could underestimate the flood depth inside buildings and overestimate the inundation on the streets. A further study would be carried out in the future to investigate the applicability of these possible solutions.

\section{Conclusions}

We developed a novel approach for urban flood modelling that reflects the rainfallrunoff processes for different land covers and flat building roofs with retaining walls, and the dynamic flow interactions between the storm sewer system and the ground surface in urban areas. The proposed approach was compared to five other urban flood modelling techniques with four rainfall events that have recorded flood areas. 
Based on the comparative results, the present research has led to the following conclusions:

1. Three indicators were adopted to evaluate the model performance and the results show that all approaches had good agreement with the recorded flood extents. The 2D OFM approach ignored the function of sewer networks and produced the least accurate results. However, the calculation of ACC includes the TN, which overweighed other factors such that the accuracies of the other five approaches were too close to conclude.

2. The comparison of the precision and sensitivity indicators, which have excluded TNs, helped to differentiate the performance of models. The 2D OFM with rainfall reduction and the combined SFM/OFM had much lower PPVs and TPRs than the coupling approaches because the latter considered the bi-directional interactions between the surface and the sewer systems so the results were closer to the reality. The mixed SFM/OFM and OFM/SFM coupling approach adopted different methods to simulate the rainfall-runoff in urban areas based on the characteristics of the land cover and successfully reduced the over-predictions of flooding at the downstream of upstream sub-catchments, and also decreased the underpredictions of flooding caused by manhole surcharges in downstream areas.

3. The 2D OFM with rainfall reduction, which uses a discount factor to replace storm sewer drainage capacity, the ACC indicator is greater than 0.94 for all simulated events. Regardless of the discrepancy between the modelled and actual flood locations, the approach is still a useful alternative solution for modelling where there is an absence of sewer information. The combined SFM /OFM approach can be used to estimate the potential flood areas, with ACC greater than 0.96 , for the planning of regional flood relief measures when a high level of accuracy of exact 
flood locations is not required.

4. The coupled SFM/OFM and the coupled OFM/SFM can produce more accurate results, with better TPRs and PPVs, because of the improved methodology to describe the flow dynamics between the surface and the sewer systems but both models are subject to their assumptions such that larger errors will occur for the applications of extreme rainfall events.

5. The mixed SFM/OFM and OFM/SFM coupling approach required limited additional information and pre-processing to set up the roof inlets for modelling. Yet, the approach can surpass the limit of dealing extreme rainfall events and consequently provide best ACCs, TRPs and PPVs, which describe the flood dynamics in urban areas with flat roof buildings better than other approaches compared in the paper.

\section{Acknowledgment}

The study was part of the International Exchanges Scheme funded by the Royal Society, UK (Ref IE131653) and the Ministry of Science and Technology, Taiwan (grant no. NSC 103-2911-I-002-536). The authors would like to thank Miss Louisa King for her proofreading.

\section{References}

Abbott, M.B., Minns, A.W., 1998. Computational Hydraulics, 2nd ed. Ashgate Publishing Limited, The Netherlands.

Allitt, R., Blanksby, J., Djordjević, S., Maksimović, C., Stewart, D., 2009. Investigations into 1D-1D and 1D-2D Urban Flood Modelling - UKWIR project. Presented at the WaPUG Autumn Conference 2009, Blackpool, UK.

Aronoff, S., 1982. Classification accuracy: a user approach. Photogramm. Eng. Remote Sens. 48, 1299-1307.

Bates, P.D., Horritt, M.S., Fewtrell, T.J., 2010. A simple inertial formulation of the shallow water equations for efficient two-dimensional flood inundation modelling. J. Hydrol. 387, 33-45. doi:10.1016/j.jhydrol.2010.03.027 
British Standards Institution, 1998. Drain and sewer systems outside buildings - Part 4: Hydraulic design and environmental considerations. British Standards Institution.

Burton, A., Glenis, V., Bovolo, C.I., Blenkinsop, S., Fowler, H.J., Chen, A.S., Djordjević, S., Kilsby, C.G., 2010. Stochastic rainfall modelling for the assessment of urban flood hazard in a changing climate. Presented at the BHS Third International Symposium, Managing Consequences of a Changing Global Environment, Newcastle upon Tyne, UK.

Chang, T.-J., Kao, H.-M., Chang, K.-H., Hsu, M.-H., 2011. Numerical simulation of shallow-water dam break flows in open channels using smoothed particle hydrodynamics. J. Hydrol. 408, 78-90. doi:10.1016/j.jhydrol.2011.07.023

Chen, A.S., Djordjević, S., Fowler, H.J., Burton, A., Walsh, C., Harvey, H., Hall, J., Dawson, R., Wood, G., 2009. Pluvial flood modelling of the South East London Resilience Zone in the Community Resilience to Extreme Weather (CREW) Project. Presented at the Flood and Coastal Risk Management Conference, Telford, UK.

Chen, A.S., Djordjević, S., Leandro, J., Savic, D., 2007. The urban inundation model with bidirectional flow interaction between 2D overland surface and 1D sewer networks. Presented at the NOVATECH 2007, Lyon, France, pp. 465-472.

Chen, A.S., Evans, B., Djordjević, S., Savić, D.A., 2012. A coarse-grid approach to representing building blockage effects in 2D urban flood modelling. J. Hydrol. 426-427, 1-16. doi:10.1016/j.jhydrol.2012.01.007

Congalton, R.G., 1991. A review of assessing the accuracy of classifications of remotely sensed data. Remote Sens. Environ. 37, 35-46. doi:10.1016/00344257(91)90048-B

Construction and Planning Agency, 2014. Building Technical Regulations.

Crossley, A., Lamb, R., Waller, S., 2010a. Fast solution of the shallow water equations using GPU technology, in: Managing Consequences of a Changing Global Environment. Presented at the BHS Third International Symposium, London: British Hydrological Society, Newcastle, UK.

Crossley, A., Lamb, R., Waller, S., Dunning, P., 2010b. Fast 2D flood modelling using GPU technology - recent applications and new developments. Presented at the European Geosciences Union General Assembly 2010, Vienna, Austria.

Deltares systems, 2014. SOBEK Suite [WWW Document]. Deltares Syst. URL http://www.deltaressystems.com/hydro/product/108282/sobek-suite (accessed 5.29.14).

DHI Software, 2012. MIKE 21 FLOW MODEL Hydrodynamic Module Scientific Documentation. DHI Software, Hørsholm, Denmark.

DHI Software, 2014. MIKE URBAN - Collection System. Hørsholm, Denmark.

Djordjević, S., Prodanović, D., Maksimović, C., 1999. An approach to stimulation of dual drainage. Wat Sci Tech 39, 95-103.

Environment Agency, 2013. What is the updated Flood Map for Surface Water? (No. Report version 1.0). Bristol, UK. 
Gironás, J., Niemann, J., Roesner, L., Rodriguez, F., Andrieu, H., 2009. Evaluation of Methods for Representing Urban Terrain in Storm-Water Modeling. J. Hydrol. Eng. 15, 1-14. doi:10.1061/(ASCE)HE.1943-5584.0000142

Halcrow, 2012. ISIS 2D ISIS 2D User Manual.

Halcrow, 2013. Integrated river and pipe modelling - Combining open-channel,closed pipe and overland flow.

Hsu, M.H., Chen, S.H., Chang, T.J., 2000. Inundation simulation for urban drainage basin with storm sewer system. J. Hydrol. 234, 21-37. doi:10.1016/S00221694(00)00237-7

Hsu, M.H., Chen, S.H., Chang, T.J., 2002. Dynamic inundation simulation of storm water interaction between sewer system and overland flows. J. Chin. Inst. Eng. 25, 171-177.

Hunter, N.M., Bates, P.D., Horritt, M.S., De Roo, P.J., Werner, M.G.F., 2005. Utility of different data types for calibrating flood inundation models within a GLUE framework. Hydrol. Earth Syst. Sci. 9, 412-430.

Hunter, N.M., Bates, P.D., Neelz, S., Pender, G., Villanueva, I., Wright, N.G., Liang, D., Falconer, R.A., Lin, B., Waller, S., Crossley, A.J., Mason, D.C., 2008. Benchmarking 2D hydraulic models for urban flooding. Proc. Inst. Civ. Eng.Water Manag. 161, 13-30.

Innovyze, 2012. InfoWorks ICM Help v2.5.

Innovyze, 2014. InfoWorks ICM Help v5.0.

Kao, H.-M., Chang, T.-J., 2012. Numerical modeling of dambreak-induced flood and inundation using smoothed particle hydrodynamics. J. Hydrol. 448-449, 232244. doi:10.1016/j.jhydrol.2012.05.004

Lamb, R., Crossley, M., Waller, S., 2009. A fast two-dimensional floodplain inundation model. Proc. Inst. Civ. Eng.-Water Manag. 162, 363-370.

Landon, J.R., 1984. Booker Tropical Soil Manual: A Handbook for Soil Survey and Agricultural Land Evaluation in the Tropics and Subtropics. Longman Scientific \& Technical Group, New York, USA.

Leandro, J., Chen, A.S., Djordjević, S., Savic, D.A., 2009. Comparison of 1D/1D and 1D/2D Coupled (Sewer/Surface) Hydraulic Models for Urban Flood Simulation. J. Hydraul. Eng. 135, 495-504. doi:10.1061/(ASCE)HY.19437900.0000037

Maksimović, C., Prodanović, D., Boonya-Aroonnet, S., Leitao, J.P., Djordjević, S., Allitt, R., 2009. Overland flow and pathway analysis for modelling of urban pluvial flooding. J. Hydraul. Res. 47, 512-523. doi:10.3826/jhr.2009.3361

Mays, L.W., 2011. Water resources engineering. John Wiley, Hoboken, NJ.

Néelz, S., Pender, G., 2013. Benchmarking the latest generation of 2D hydraulic modelling packages. Environment Agency, Horison House, Deanery Road, Bristol, BS1 9AH.

Oraei Zare, S., Saghafian, B., Shamsai, A., 2012. Multi-objective optimization for combined quality-quantity urban runoff control. Hydrol Earth Syst Sci 16, 4531-4542. doi:10.5194/hess-16-4531-2012 
Phillips, B.C., Yu, S., Thompson, G.R., De Silva, N., 2005. 1D and 2D Modelling of Urban Drainage Systems using XP-SWMM and TUFLOW, in: 10th International Conference on Urban Drainage, Copenhagen/Denmark. pp. 2126.

Purnami, S., Zain, J., Embong, A., 2010. A New Expert System for Diabetes Disease Diagnosis Using Modified Spline Smooth Support Vector Machine, in: Taniar, D., Gervasi, O., Murgante, B., Pardede, E., Apduhan, B. (Eds.), Computational Science and Its Applications - ICCSA 2010, Lecture Notes in Computer Science. Springer Berlin Heidelberg, pp. 83-92.

Ranger, N., Hallegatte, S., Bhattacharya, S., Bachu, M., Priya, S., Dhore, K., Rafique, F., Mathur, P., Naville, N., Henriet, F., Herweijer, C., Pohit, S., Corfee-Morlot, J., 2011. An assessment of the potential impact of climate change on flood risk in Mumbai. Clim. Change 104, 139-167. doi:10.1007/s10584-010-9979-2

Roserner, L.A., Aldrich, J.A., Dickinson, R.E., 1988. Storm Water Management Model. User's Manual Ver. IV: EXTRAN Addendum. U. S. Environmental Protection Agency., Athens Georgia, U.S.A.

Rossman, L.A., 2010. Storm water management model: User's manual Version 5.0.

Seyoum, S.D., Vojinovic, Z., Price, R.K., Weesakul, S., 2012. Coupled 1D and Noninertia 2D Flood Inundation Model for Simulation of Urban Flooding. J. Hydraul. Eng.-Asce 138, 23-34. doi:10.1061/(Asce)Hy.1943-7900.0000485

Syme, W.J., 2001. TUFLOW - Two \& one-dimensional Unsteady FLOW Software for rivers, estuaries and coastal waters, in: IEAust Water. Panel Seminar and Workshop on 2d Flood Modelling. Sydney.

XP Solutions, 2013. XP-SWMM Stormwater and wastewater management model: Getting started manual. 
Please cite: Chang, T.J., Wang C.H., Chen, A.S., 2015, A novel approach to model dynamic flow interactions between storm sewer system and overland surface for different land covers in urban areas, Journal of Hydrology, doi: 10.1016/j.jhydrol.2015.03.014, in press.

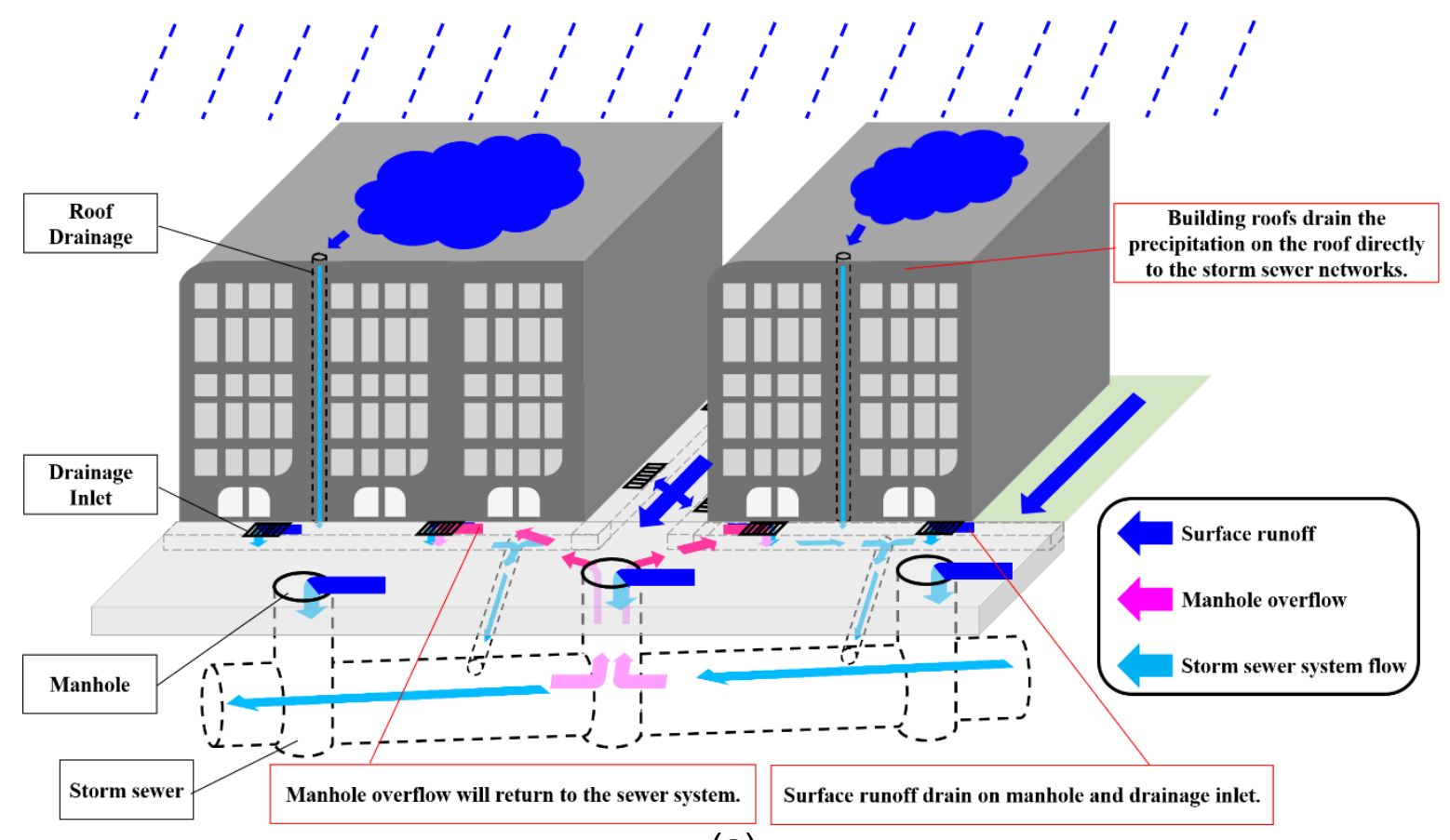

(a)

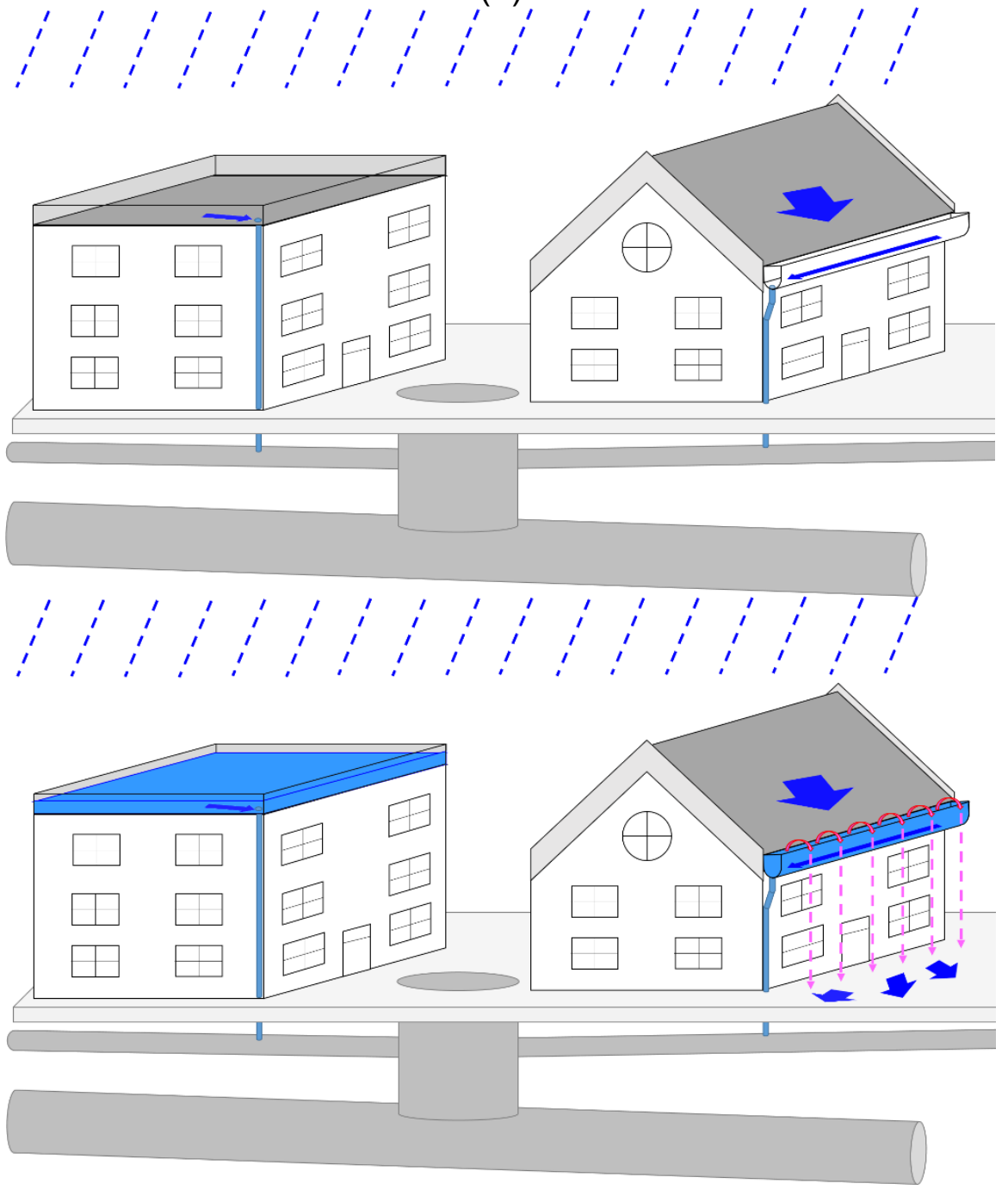

(b)

Figure 1 Schematics of urban drainage physics. 
Please cite: Chang, T.J., Wang C.H., Chen, A.S., 2015, A novel approach to model dynamic flow interactions between storm sewer system and overland surface for different land covers in urban areas, Journal of Hydrology, doi: 10.1016/j.jhydrol.2015.03.014, in press.

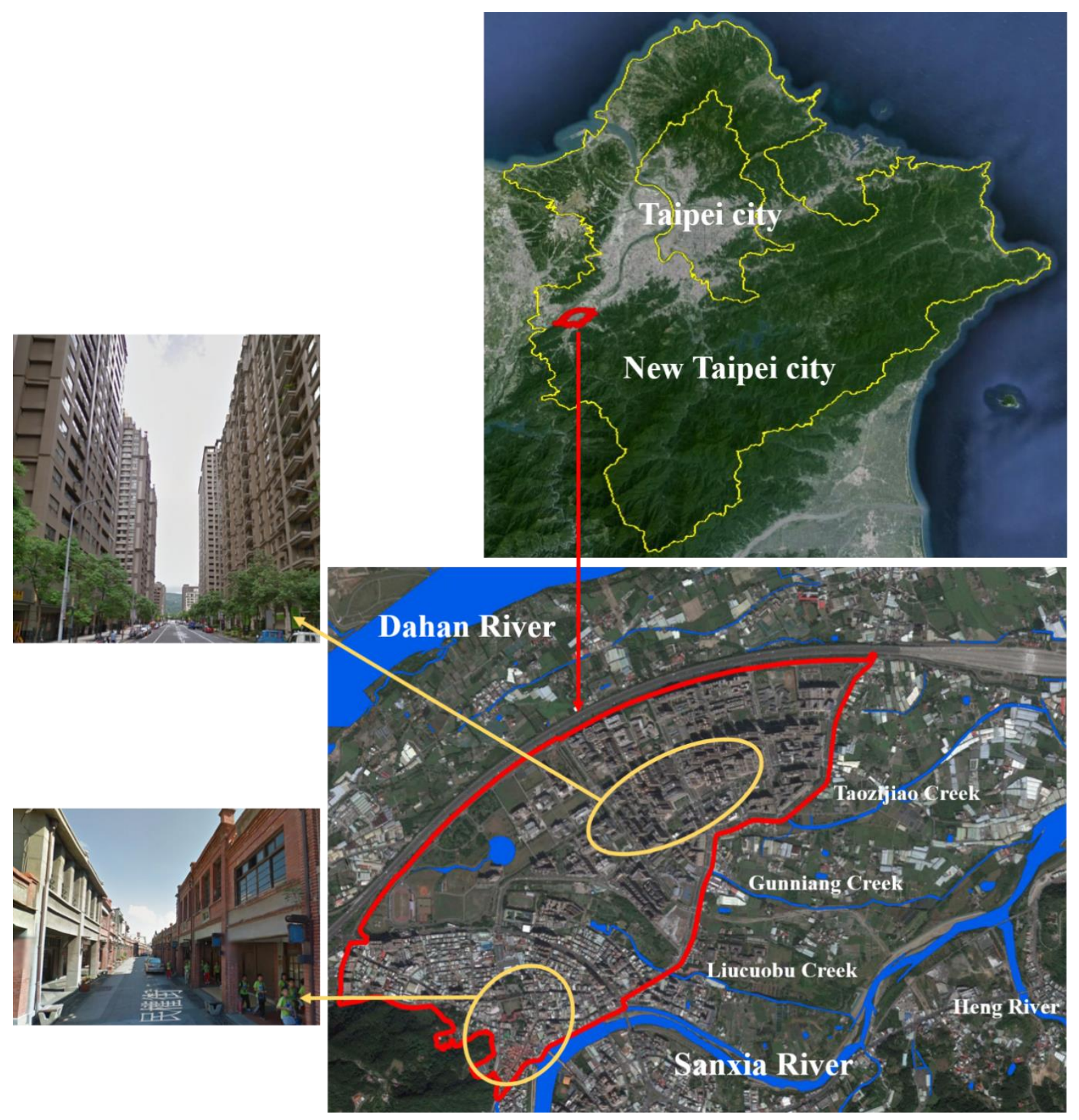

Figure 2 Location of the study area. 
Please cite: Chang, T.J., Wang C.H., Chen, A.S., 2015, A novel approach to model dynamic flow interactions between storm sewer system and overland surface for different land covers in urban areas, Journal of Hydrology, doi: 10.1016/j.jhydrol.2015.03.014, in press.

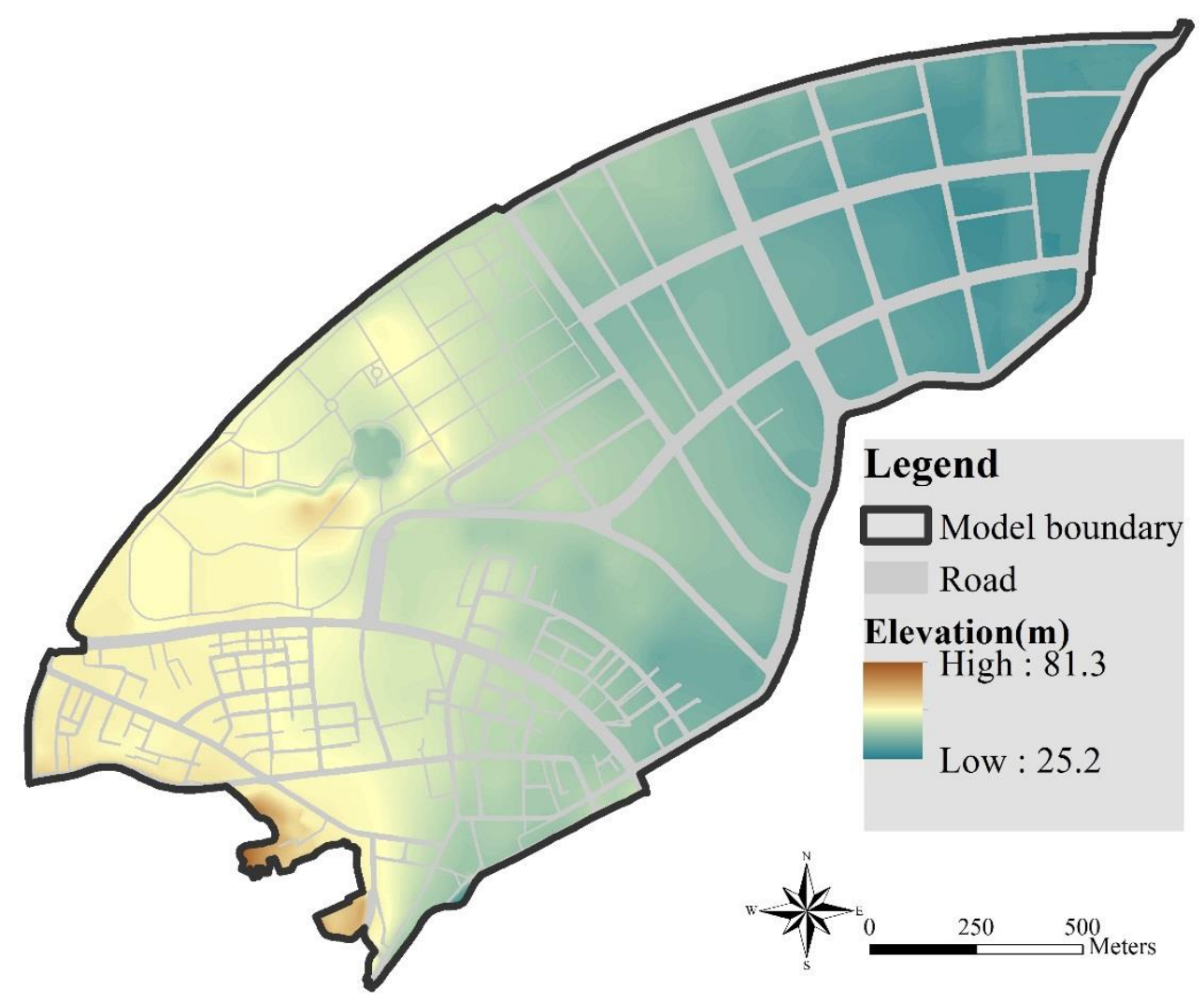

Figure 3 The digital elevation map of the study area. 
Please cite: Chang, T.J., Wang C.H., Chen, A.S., 2015, A novel approach to model dynamic flow interactions between storm sewer system and overland surface for different land covers in urban areas, Journal of Hydrology, doi: 10.1016/j.jhydrol.2015.03.014, in press.

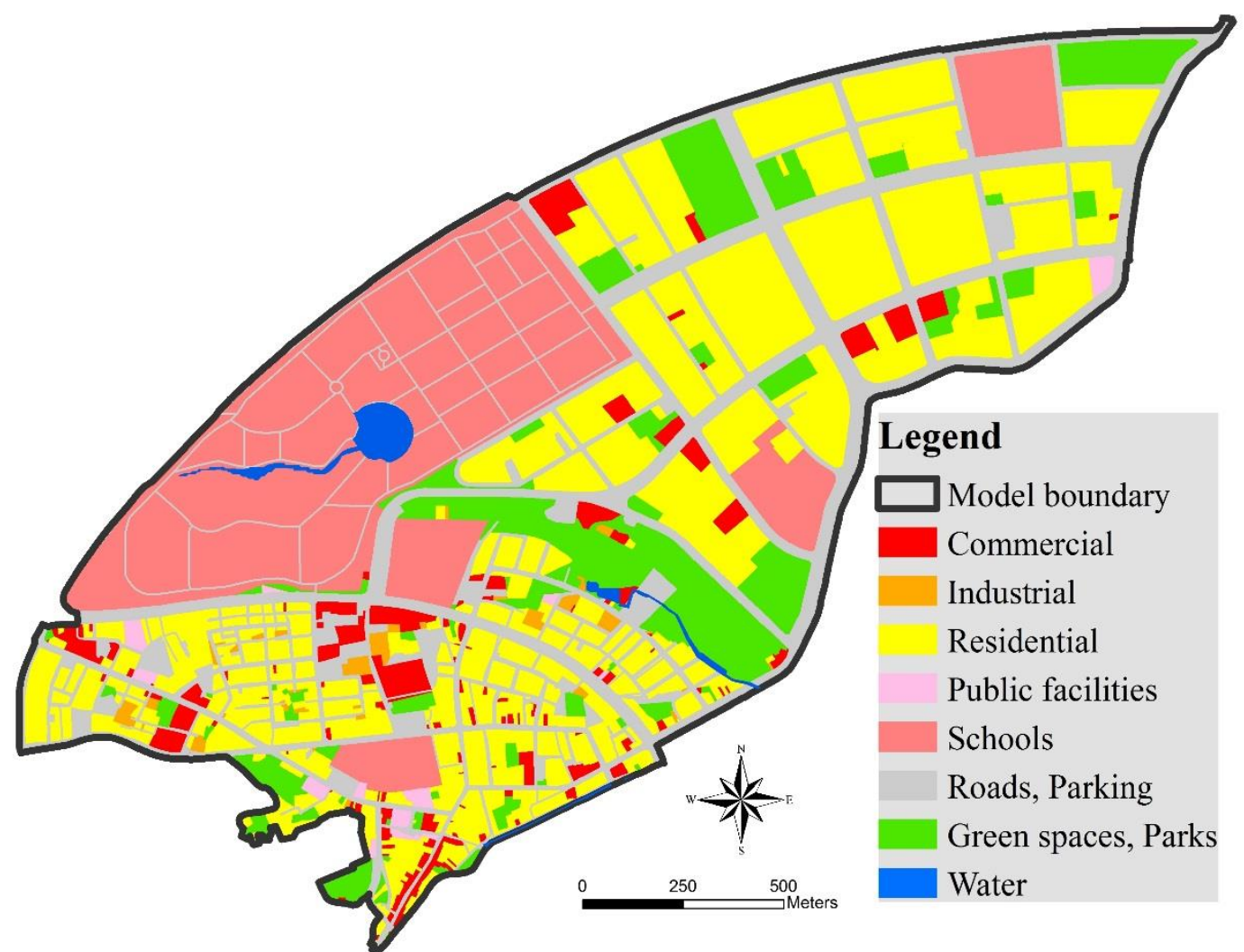

(a)

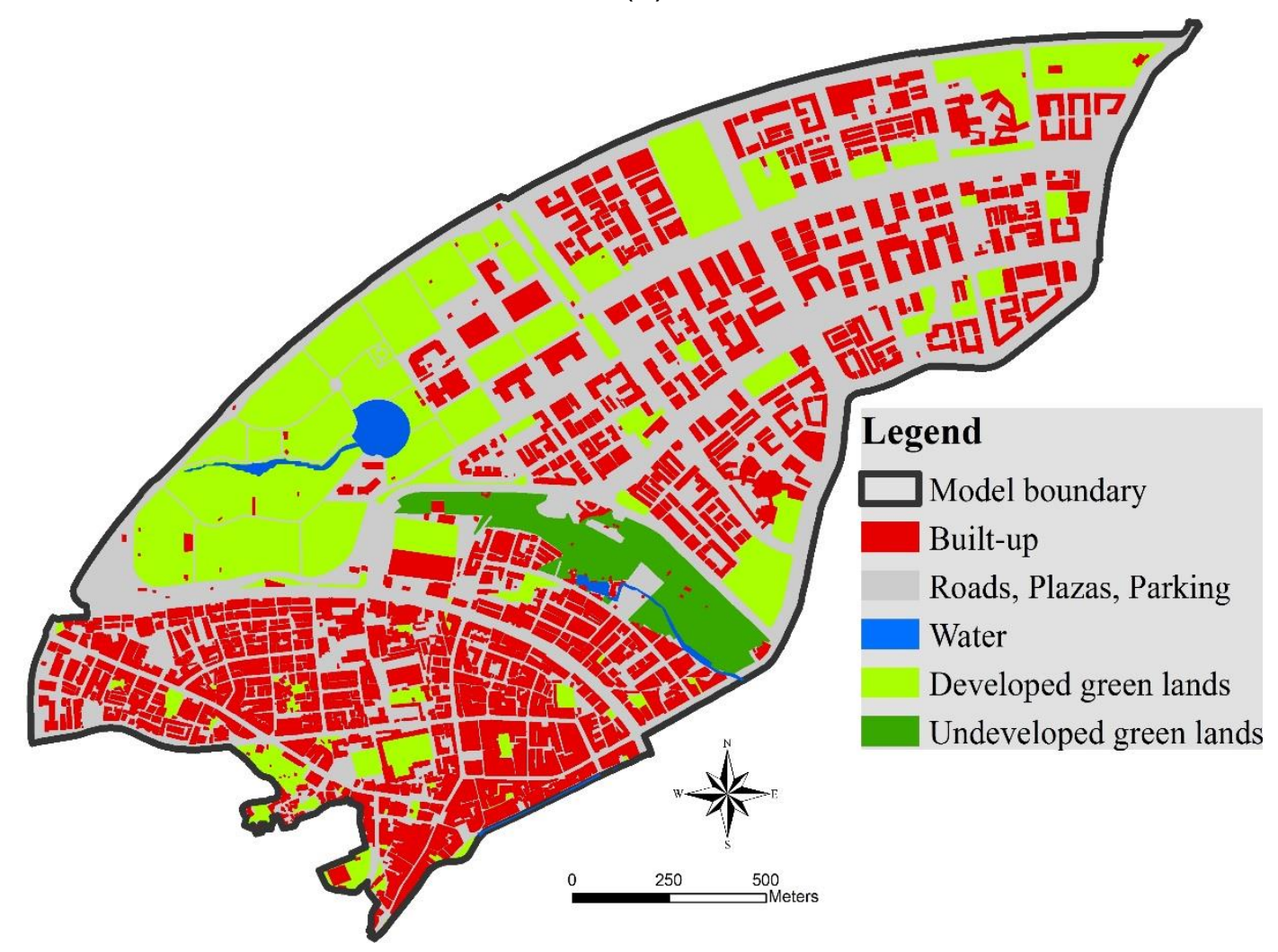

(b)

Figure 4 (a) The land-use and (b) the land-cover maps of the study area. 
Please cite: Chang, T.J., Wang C.H., Chen, A.S., 2015, A novel approach to model dynamic flow interactions between storm sewer system and overland surface for different land covers in urban areas, Journal of Hydrology, doi: 10.1016/j.jhydrol.2015.03.014, in press.

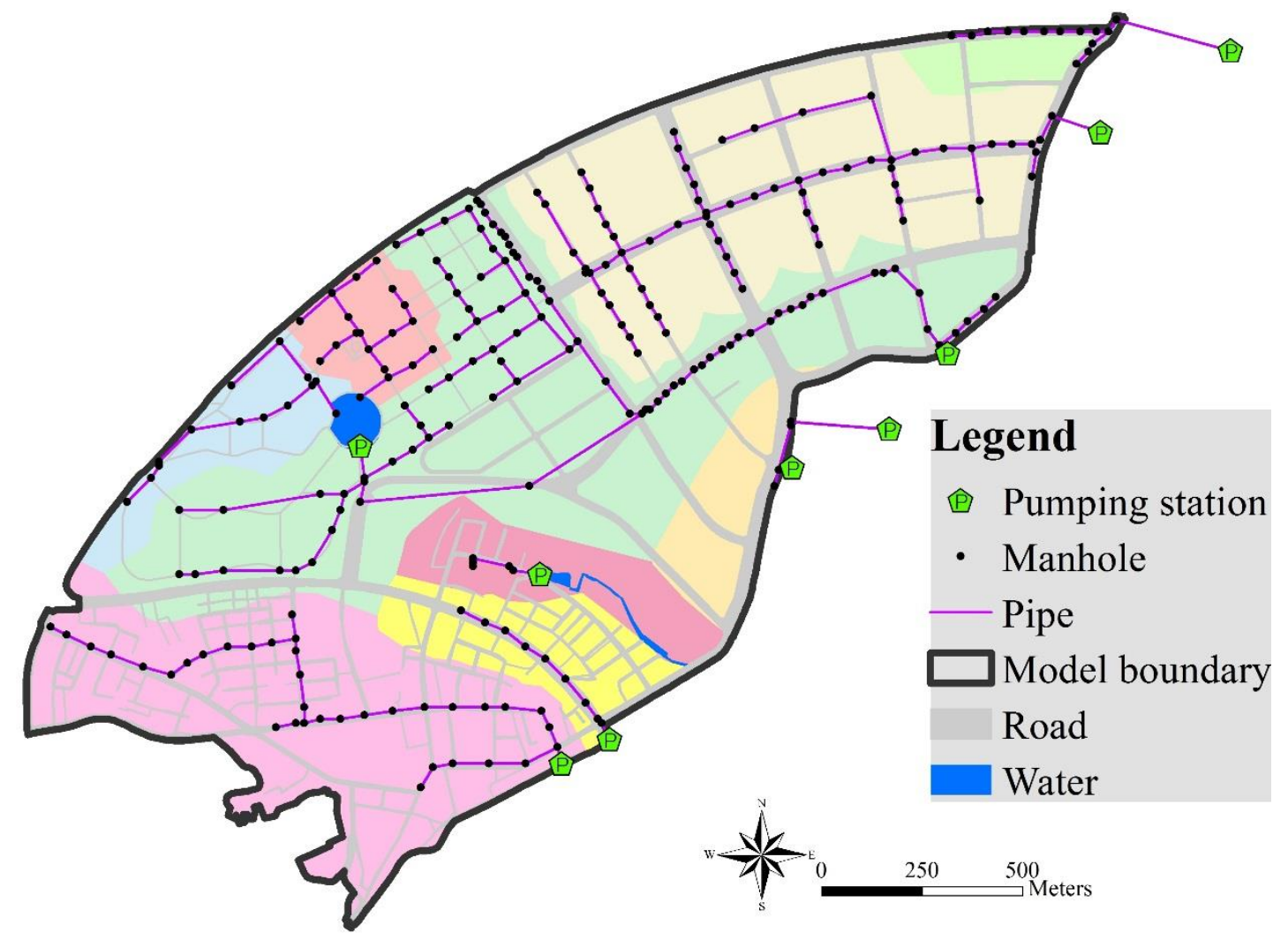

Figure 5 The storm drainage system in the study area. 
Please cite: Chang, T.J., Wang C.H., Chen, A.S., 2015, A novel approach to model dynamic flow interactions between storm sewer system and overland surface for different land covers in urban areas, Journal of Hydrology, doi: 10.1016/j.jhydrol.2015.03.014, in press.

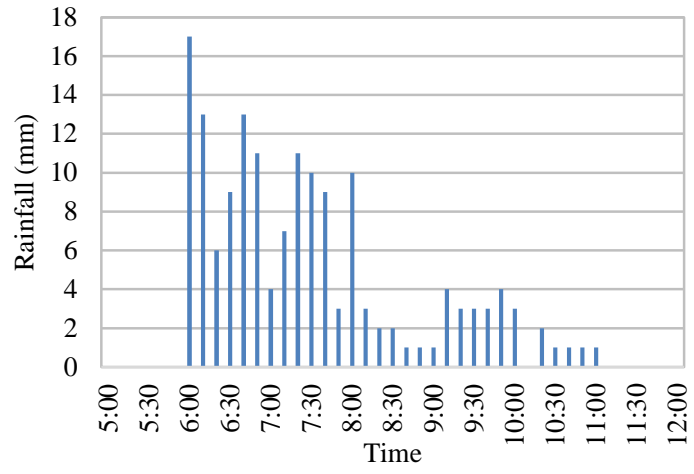

(a)

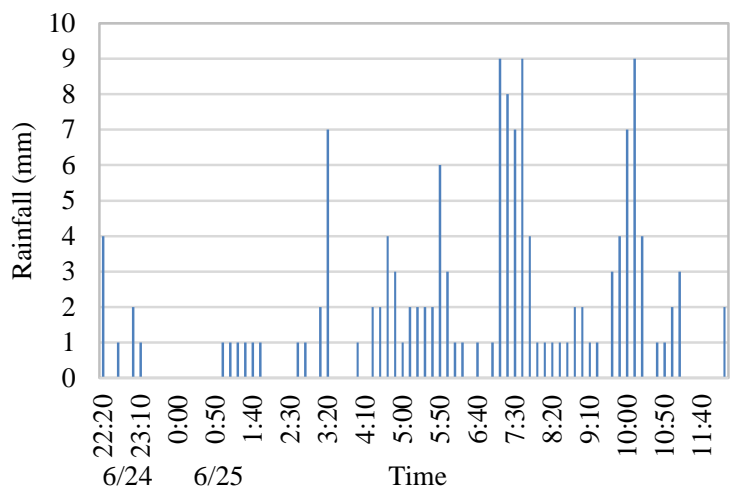

(c)

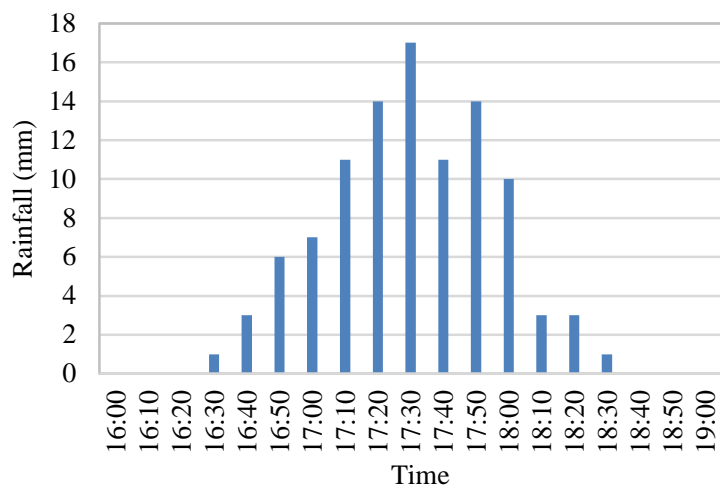

(b)

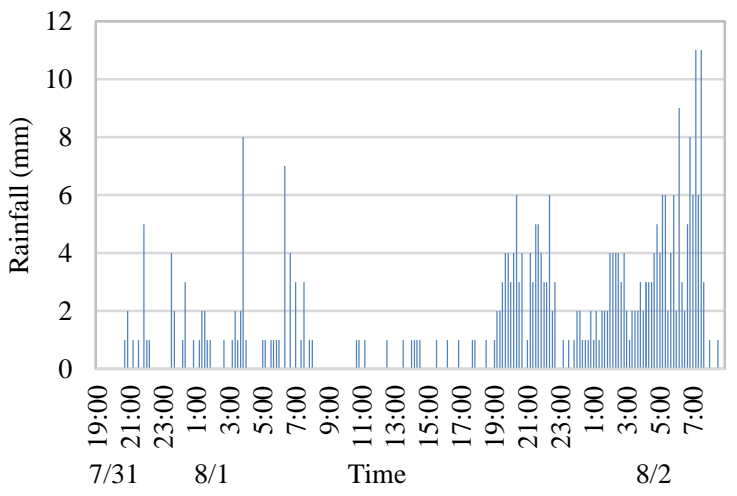

(d)

Figure 6 The rainfall hyetographs of the events, (a) 12 June 2012, (b) 15 June 2012, (c) Typhoon Meari (2011), and (d) Typhoon Saola (2012). 
Please cite: Chang, T.J., Wang C.H., Chen, A.S., 2015, A novel approach to model dynamic flow interactions between storm sewer system and overland surface for different land covers in urban areas, Journal of Hydrology, doi: 10.1016/j.jhydrol.2015.03.014, in press.

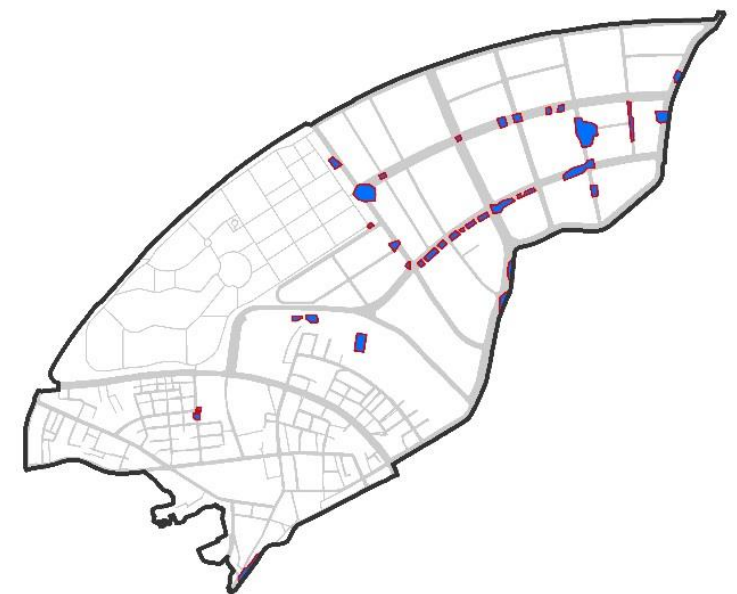

(a)

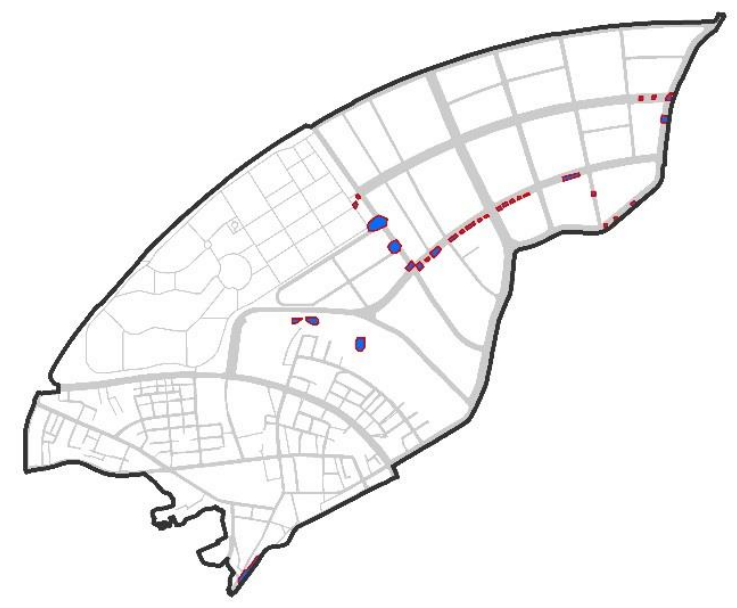

(c)

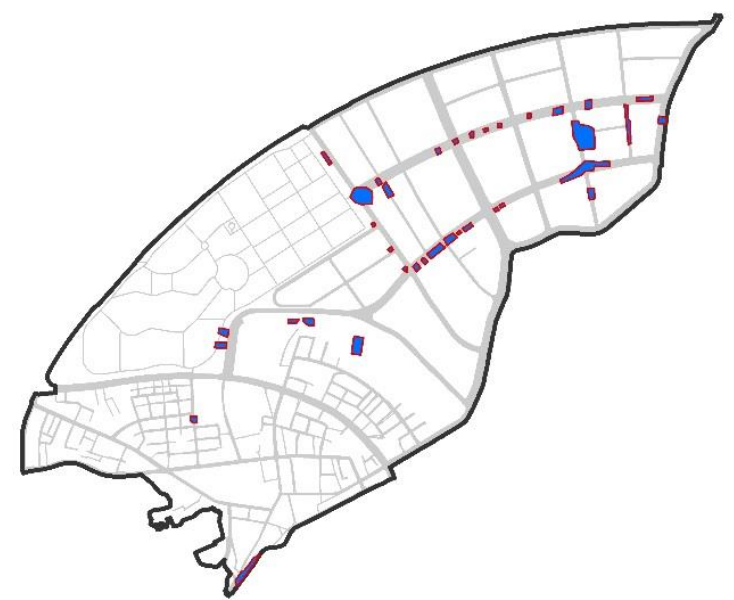

(b)

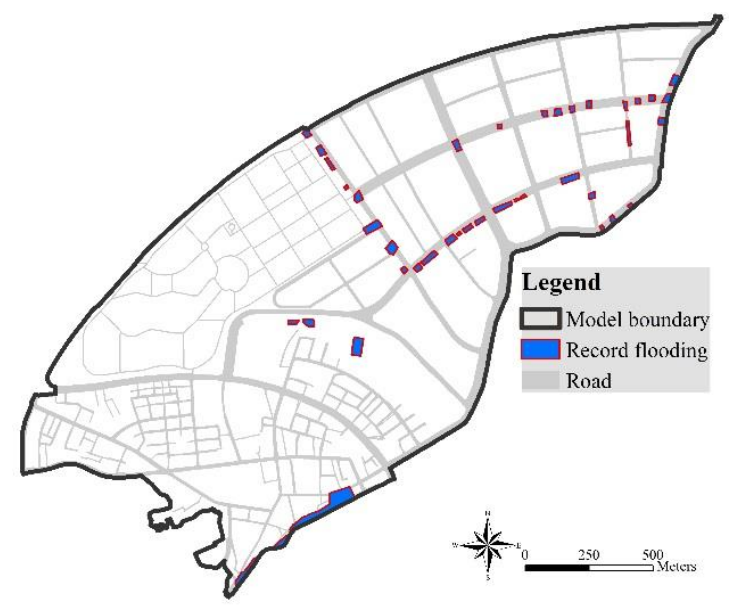

(d)

Figure 7 The recorded inundation areas of the events, (a) 12 June 2012, (b) 15 June 2012, (c) Typhoon Meari (2011), and (d) Typhoon Saola (2012). 


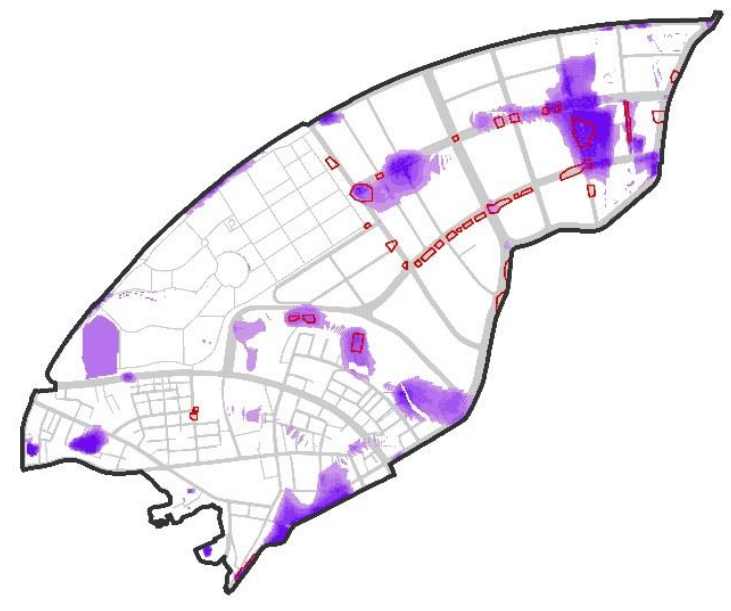

(a)

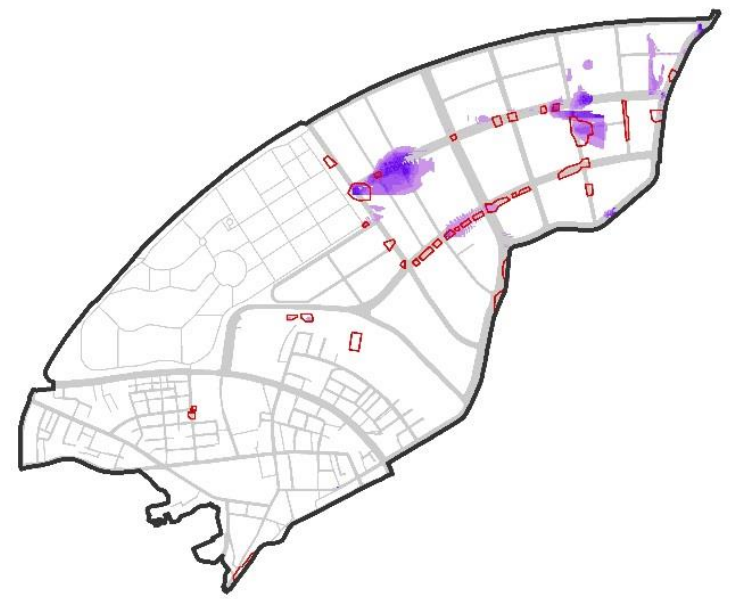

(c)

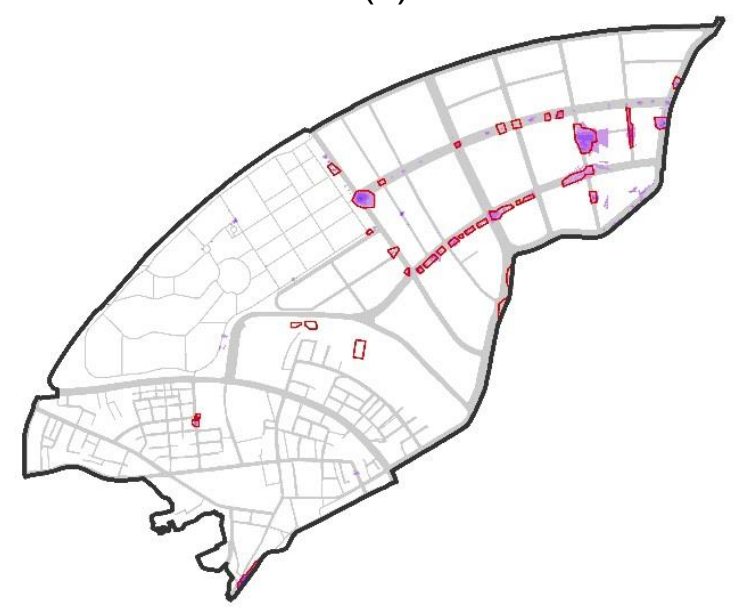

(e)

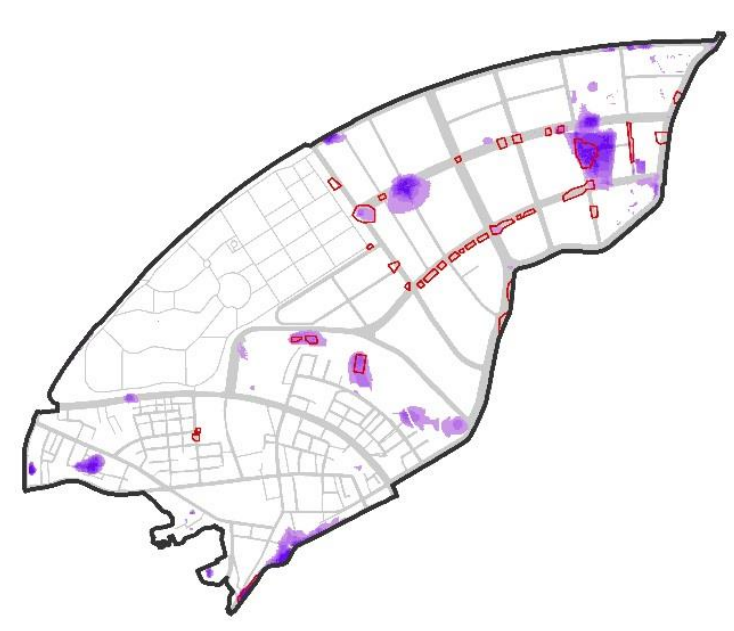

(b)

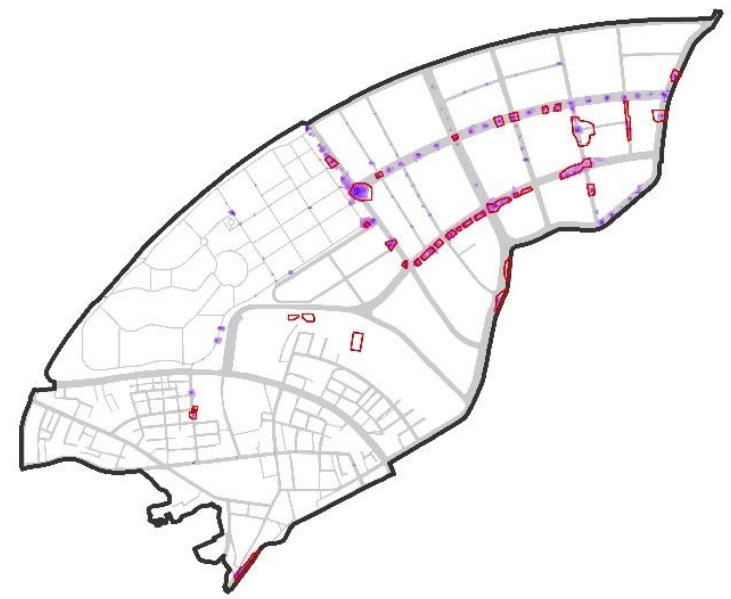

(d)

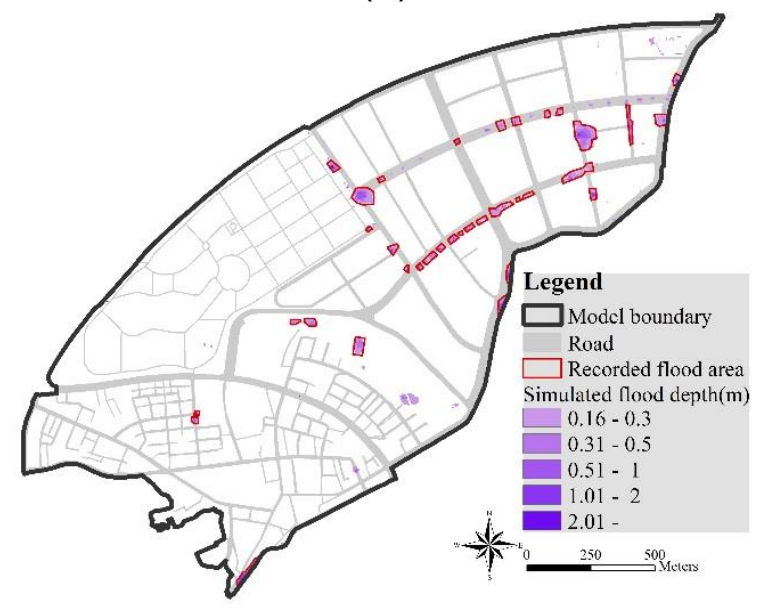

(f)

Figure 8 The modelled flood extents of the six approaches and the recorded flood areas (red boundary polygons) for the 12 June 2012 event, (a) the 2D OFM only, (b) the 2D OFM with rainfall reduction, (c) the combined SFM/OFM approach, (d) the coupled SFM/OFM approach, (e) the coupled OFM/SFM approach, and (f) the mixed SFM/OFM and OFM/SFM approach. 


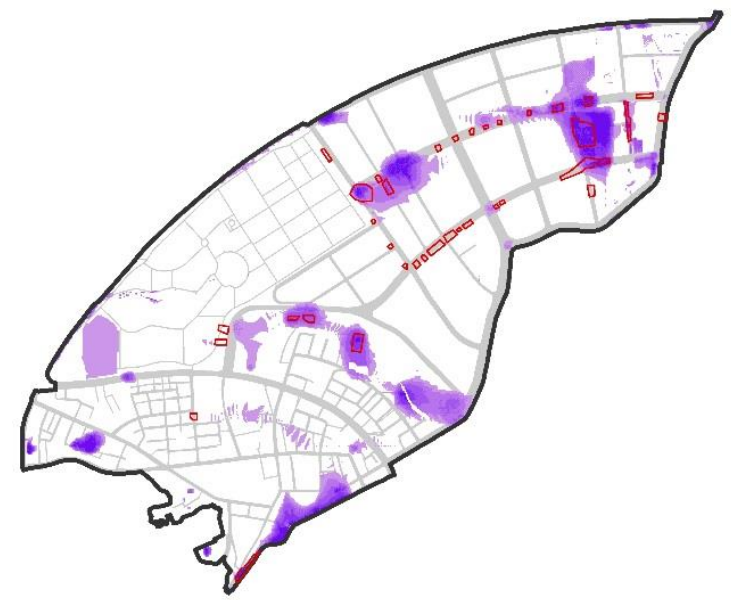

(a)

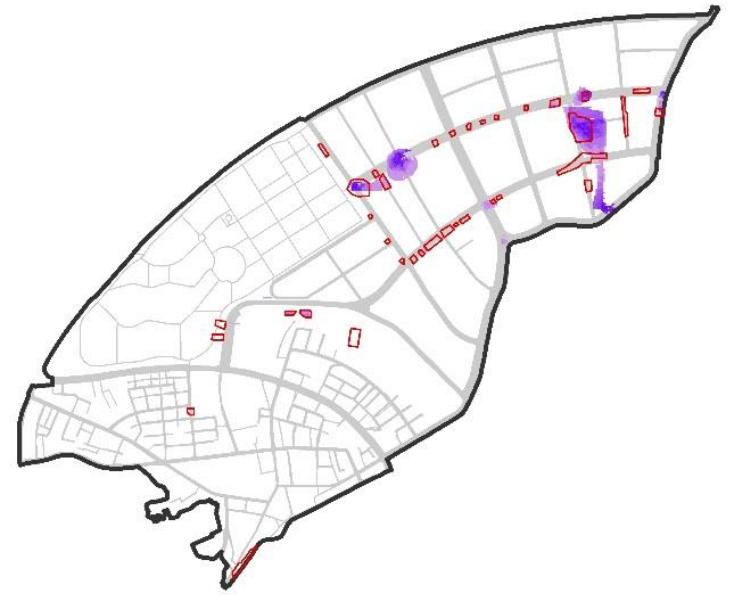

(c)

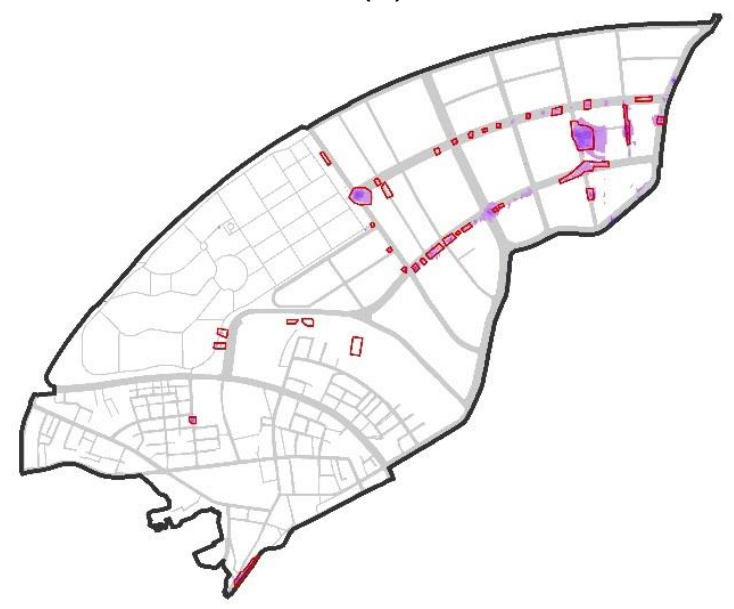

(e)

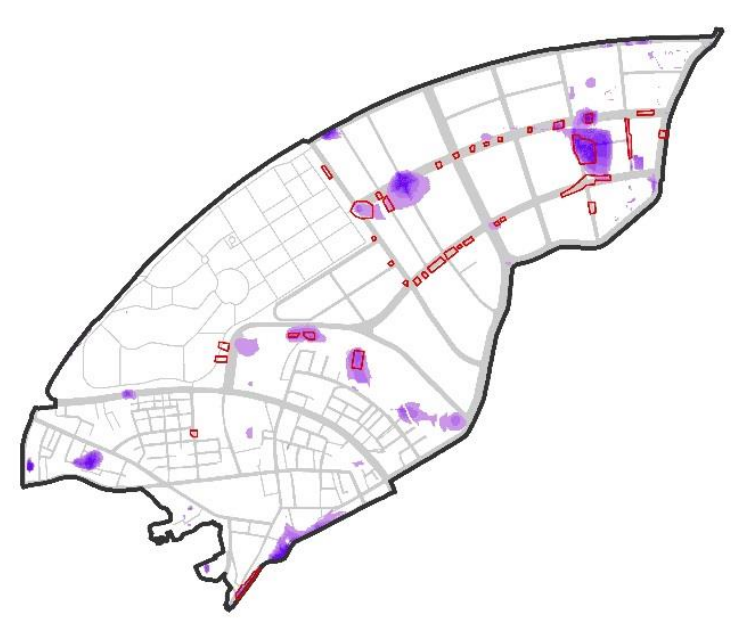

(b)

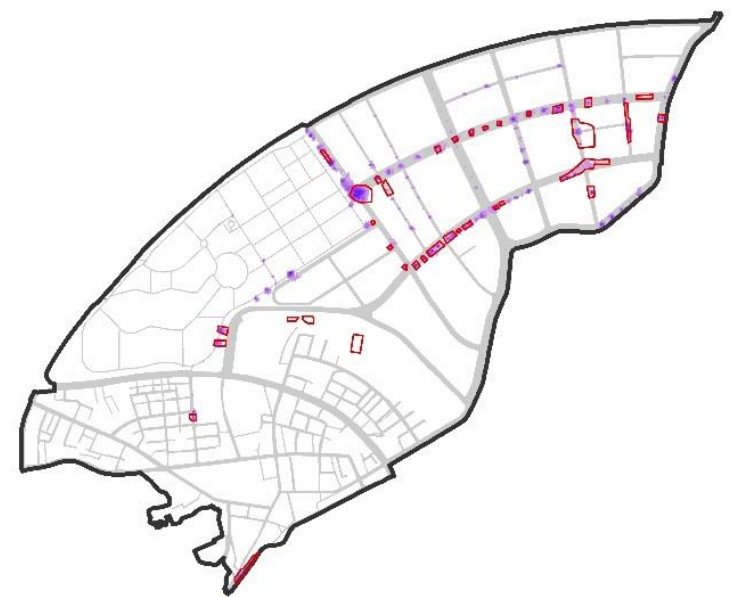

(d)

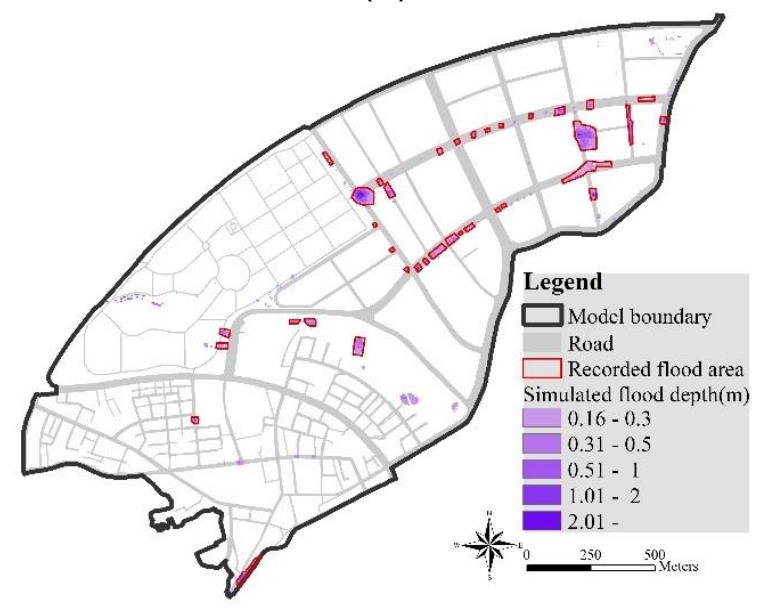

(f)

Figure 9 The modelled flood extents of the six approaches and the recorded flood areas (red boundary polygons) for the 15 June 2012 event, (a) the 2D OFM only, (b) the 2D OFM with rainfall reduction, (c) the combined SFM/OFM, (d) the coupled SFM/OFM, (e) the coupled OFM/SFM, and (f) the mixed SFM/OFM and OFM/SFM coupling. 


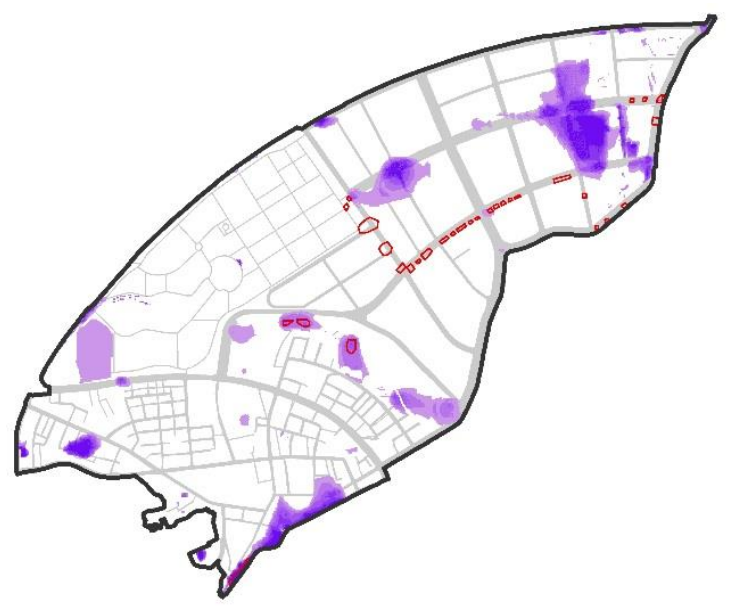

(a)

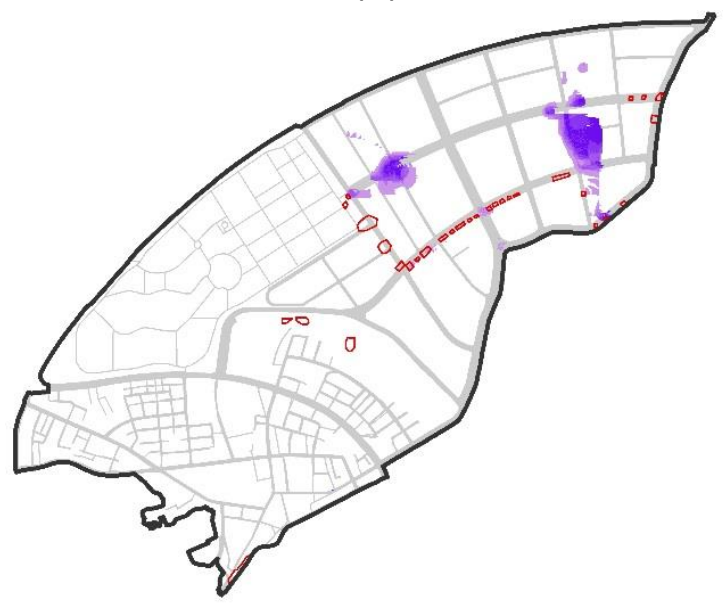

(c)

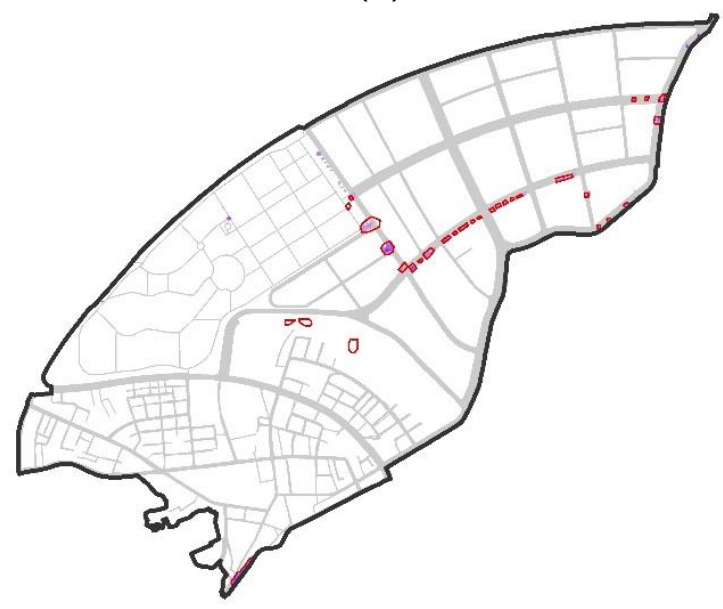

(e)

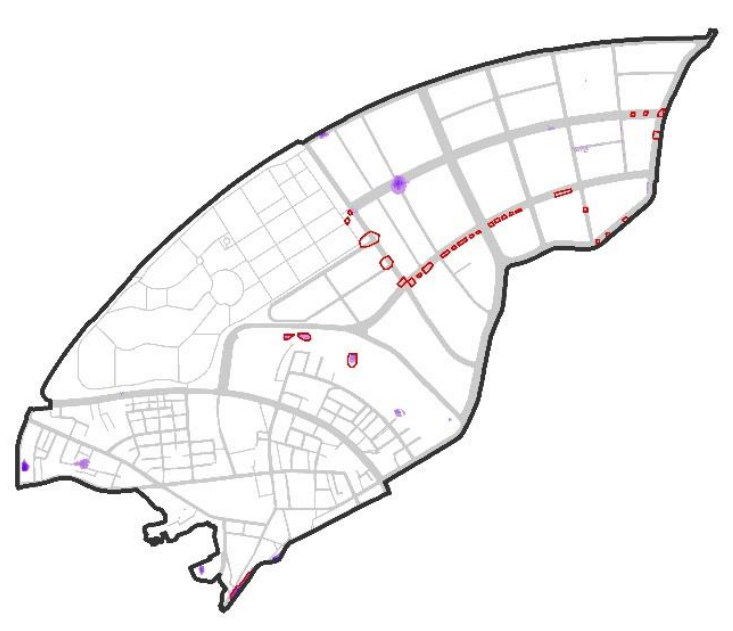

(b)

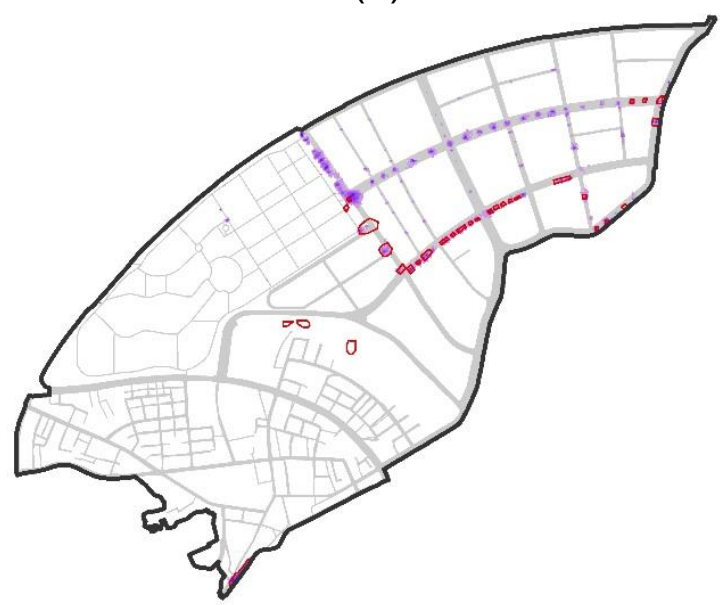

(d)

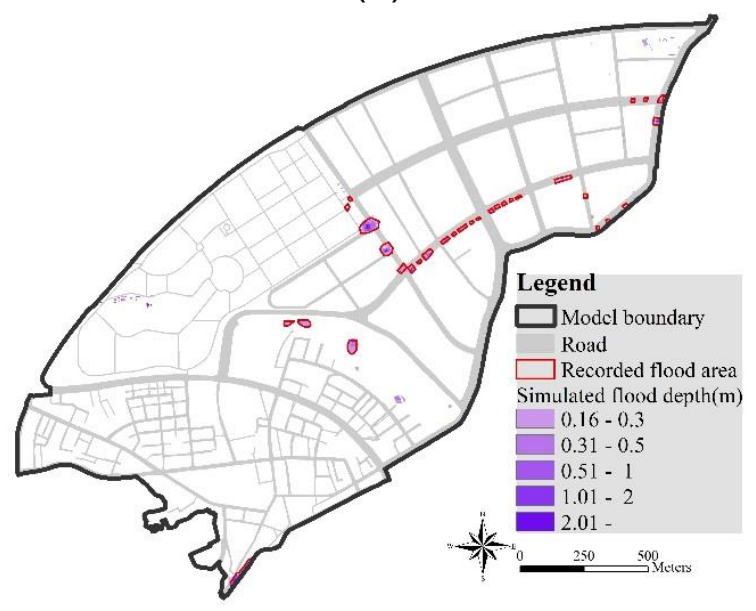

(f)

Figure 10 The modelled flood extents of the six approaches and the recorded flood areas (red boundary polygons) for Typhoon Meari (2011), (a) the 2D OFM only, (b) the 2D OFM with rainfall reduction, (c) the combined SFM/OFM, (d) the coupled SFM/OFM, (e) the coupled OFM/SFM, and (f) the mixed SFM/OFM and OFM/SFM coupling. 


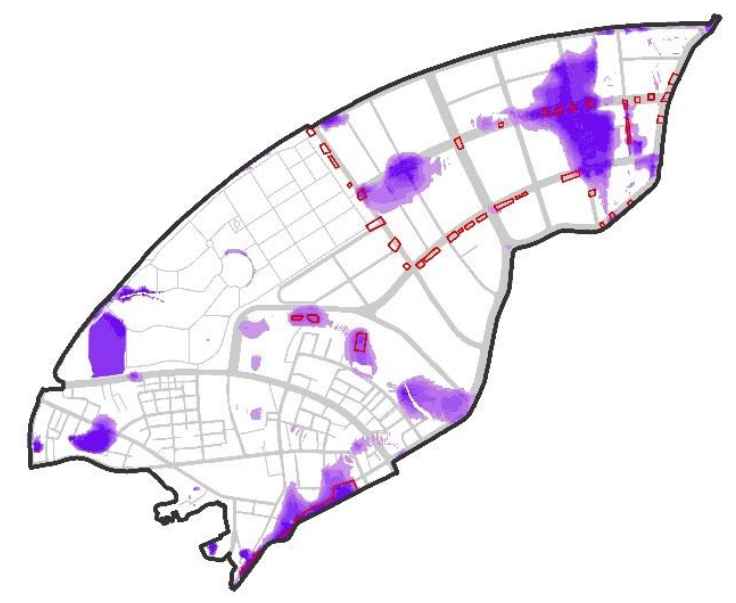

(a)

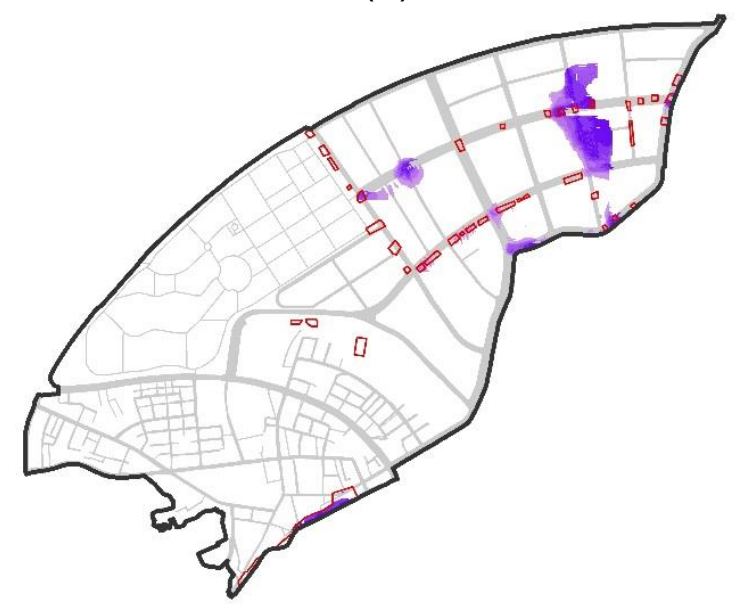

(c)

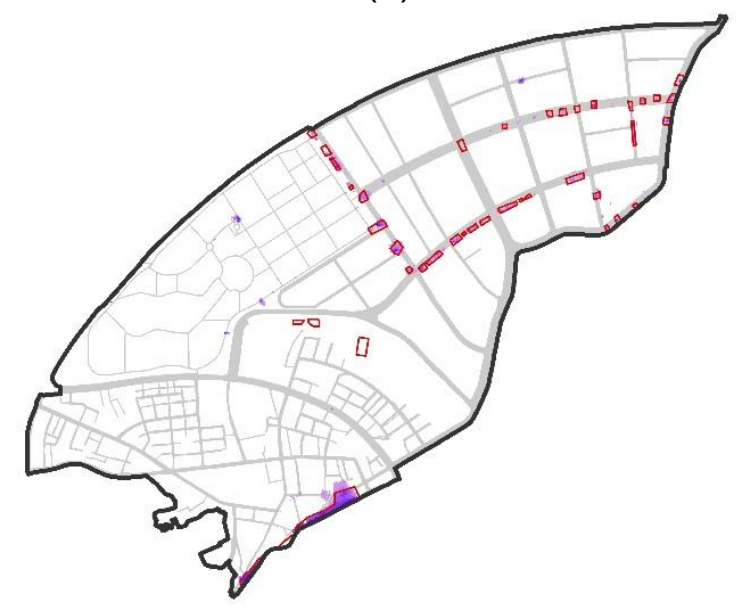

(e)

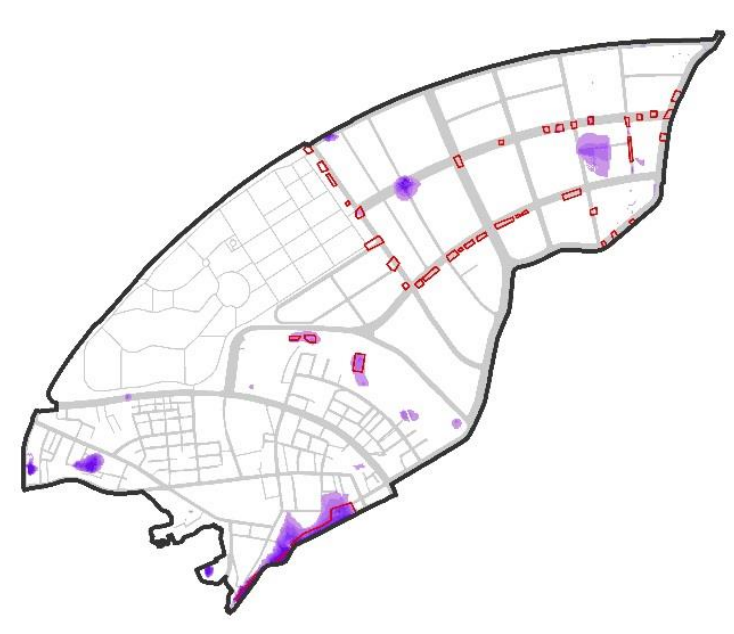

(b)

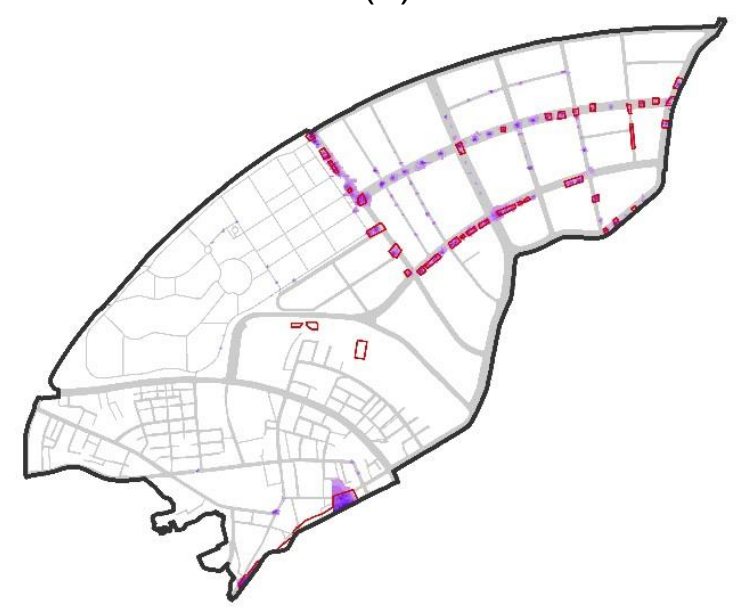

(d)

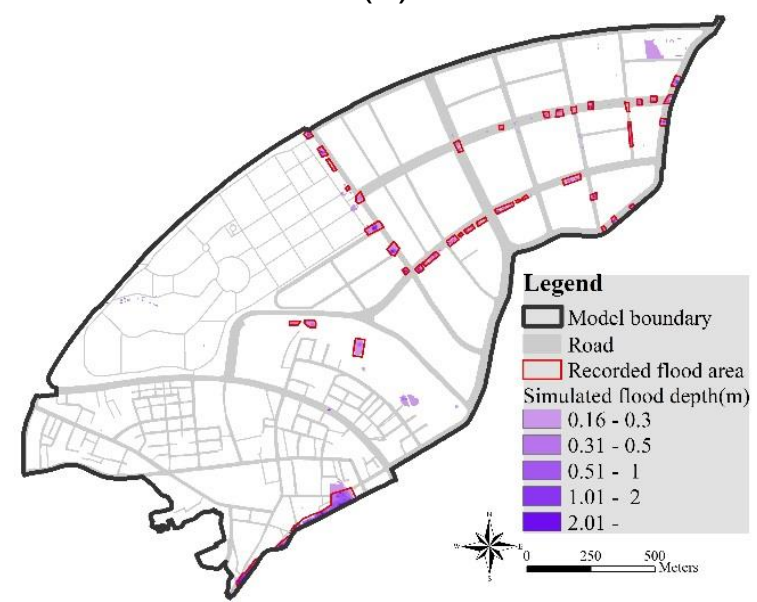

(f)

Figure 11 The modelled flood extents of the six approaches and the recorded flood areas (red boundary polygons) for Typhoon Saola (2012), (a) the 2D OFM only, (b) the 2D OFM with rainfall reduction, (c) the combined SFM/OFM, (d) the coupled SFM/OFM, (e) the coupled OFM/SFM, and (f) the mixed SFM/OFM and OFM/SFM coupling. 
Please cite: Chang, T.J., Wang C.H., Chen, A.S., 2015, A novel approach to model dynamic flow interactions between storm sewer system and overland surface for different land covers in urban areas, Journal of Hydrology, doi: 10.1016/j.jhydrol.2015.03.014, in press.

Table 1 Confusion matrix

\begin{tabular}{ccc}
\hline \hline \multirow{2}{*}{ Simulation } & \multicolumn{2}{c}{ Observation } \\
\cline { 2 - 3 } Positive & Prue positive & Negative \\
\hline Negative & False negative (FN) & $\begin{array}{c}\text { False positive } \\
\text { (FP) }\end{array}$ \\
\hline \hline
\end{tabular}

Table 2 The indicators of all the simulated events for different modelling approaches.

\begin{tabular}{cccccccc}
\hline \hline Event & Indicator & $\begin{array}{c}\text { 2D OFM } \\
\text { only }\end{array}$ & $\begin{array}{c}\text { 2D OFM/ } \\
\text { rainfall } \\
\text { reduction }\end{array}$ & $\begin{array}{c}\text { Combined } \\
\text { SFM/OFM }\end{array}$ & $\begin{array}{c}\text { Coupled } \\
\text { SFM/OFM }\end{array}$ & $\begin{array}{c}\text { Coupled } \\
\text { OFM/SFM }\end{array}$ & $\begin{array}{c}\text { Mixed } \\
\text { SFM/OFM \& } \\
\text { OFM/SFM }\end{array}$ \\
\hline \multirow{2}{*}{ 12 June } & ACC & 0.87 & 0.94 & 0.96 & 0.98 & 0.99 & 0.99 \\
2012 & TPR & 0.54 & 0.39 & 0.27 & 0.61 & 0.59 & 0.76 \\
& PPV & 0.07 & 0.13 & 0.15 & 0.39 & 0.59 & 0.79 \\
\hline \multirow{2}{*}{ 15 June } & ACC & 0.88 & 0.95 & 0.98 & 0.98 & 0.99 & 0.99 \\
\multirow{2}{*}{2012} & TPR & 0.65 & 0.50 & 0.34 & 0.53 & 0.60 & 0.76 \\
& PPV & 0.08 & 0.15 & 0.26 & 0.38 & 0.55 & 0.72 \\
\hline \multirow{2}{*}{ Typhoon } & ACC & 0.89 & 0.99 & 0.97 & 0.98 & 0.99 & 0.99 \\
& TPR & 0.32 & 0.26 & 0.05 & 0.61 & 0.50 & 0.79 \\
\multirow{2}{*}{ Typhoon } & PPV & 0.02 & 0.29 & 0.01 & 0.21 & 0.70 & 0.72 \\
Saola & TPR & 0.85 & 0.96 & 0.96 & 0.98 & 0.99 & 0.99 \\
\hline \hline
\end{tabular}

